\title{
Sealing Large-Diameter Cast-Iron Pipe Joints Under Live Conditions
}

\author{
Final Report \\ March 25, 2002 - September 24, 2005
}

By:

Kiran M. Kothari

(Gas Technology Institute)

and

Gerard T. Pittard

(Maurer Technology Inc.)

December 2005

DE-FC22-02NT41316

GAS TECHNOLOGY INSTITUTE

1700 South Mount Prospect Road

Des Plaines, Illinois 60018-1804

MAURER TECHNOLOGY INC.

13135 South Dairy Ashford, Suite 800

Sugar Land, Texas 77478-3686 


\section{Disclaimer}

This report was prepared as an account of work sponsored by an agency of the United States Government. Neither the United States Government nor any agency thereof, nor any of their employees, makes any warranty, express or implied, or assumes any legal liability or responsibility for the accuracy, completeness, or usefulness of any information, apparatus, product, or process disclosed, or represents that its use would not infringe privately owned rights. Reference herein to any specific commercial product, process, or service by trade name, trademark, manufacturer, or otherwise does not necessarily constitute or imply its endorsement, recommendation, or favoring by the United States Government or any agency thereof. The views and opinions of authors expressed herein do not necessarily state or reflect those of the United States Government or any agency thereof. 


\section{Abstract}

Utilities in the U.S. operate over $75,000 \mathrm{~km}(47,000$ miles) of old cast-iron pipes for gas distribution. Bell-and-spigot joints that connect these pipe sections together tend to leak as the pipes age. Current repair techniques are costly and highly disruptive. The objective of this program is to design, test and commercialize a robotic system capable of sealing multiple castiron bell-and-spigot joints from a single pipe entry point. The proposed system will perform repairs while the pipe remains in service by traveling through the pipe, cleaning each joint surface, and installing a stainless-steel sleeve lined with an epoxy-impregnated felt across the joint. This system will save considerable time and labor, minimize excavation, avoid traffic disruption, and eliminate any requirement to interrupt gas delivery to customers (which would result in enormous expense to utilities).

Several technical challenges must be overcome including: (1) an innovative bolt-on entry fitting is required to conduct safe repair operations on live mains; (2) the assembly must travel long distances through pipes containing debris; (3) the pipe wall must be effectively cleaned in the immediate area of the joint to assure good bonding of the sleeve; and (4) repair sleeves must compensate for diametric variation and eccentricity of old cast-iron pipes.

This development effort for a system to be deployed in large cast-iron pipes was organized as eleven tasks. Progress under each is described in the report. Repair patch sleeves and other system hardware and components have been significantly improved based on laboratory testing in preparation for field trials.

This phase of development is now complete. Recent accomplishments include:

1. Shop testing of the pipe inspection/wall-cleaning module under increasingly more difficult and realistic conditions. These tests were conducted in the laboratory with larger in-pipe travel distances and full exercise of control electronics and software.

2. Testing of the patch-setting module with the latest generation of 12-inch repair sleeves. Test results were used to optimize design of the patch assembly and the patch-setting robot train. Patches were set across several 12-inch bell-and-spigot joints. To confirm patch success, the ends of these joints were then capped and the line pressurized. Leak-off test results showed the patches to be tight and $100 \%$ successful.

3. Full-scale laboratory testing of 12 -inch version of the cast-iron bolt-on entry fitting to allow entry into a live gas main without interrupting service to customers. The fittings were leak free and a special template was developed to assure the fitting is properly located on the main prior to bolt make-up.

4. Testing the hole saw used to cut an angled access hole into pressurized cast-iron pipes. The hole saw was shown to be capable of cutting access holes into ductile iron pipes in approximately 40-45 minutes with $100 \%$ retention of the coupon. 
Access holes in older cast-iron pipes are expected to be cut in approximately 30 minutes due to better machinability of cast iron.

5. Conducting full-up tests of the system in the shop, including cutting multiple access holes through the bolt-on fitting and setting several patches across joints in the test main.

6. Implementing software controls and system displays into the LabVIEW userinterface/robotics-control environment. The LabVIEW environment is used to control all aspects of the robot operation including camera pan, zoom, tilt, lighting, cleaning motor operation, patch setting, etc.

7. Collecting additional information and data to conduct a benefit analysis. A practical cost/benefit analysis will be completed under the future field tests to be conducted with a large gas distribution company located in the Northeast United States. This company has agreed to perform a direct cost comparison of external joint encapsulation, internal spraying with an anaerobic sealant and the robotically set Link-Pipe patches.

8. Planning a field test demonstration of the large-diameter robotic system currently scheduled for second quarter 2006 (after the end of the current heating season). Several discussions between GTI, MTI, Public Service Electric \& Gas Company, and other utilities have been conducted for scheduling field tests. A Master Service Agreement has already been signed to allow this work to be conducted.

9. Preparing a Final Report that documents all project activities during this phase of the development. 


\section{Table of Contents}

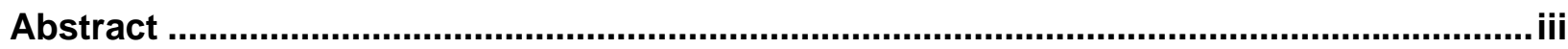

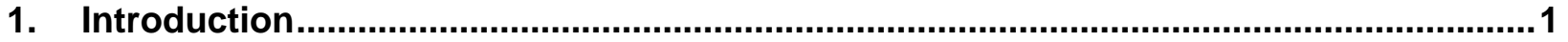

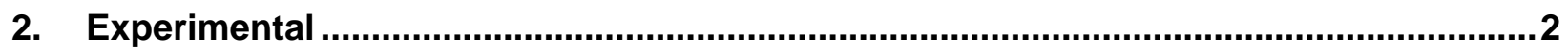

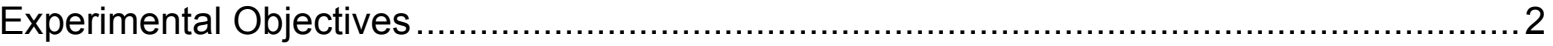

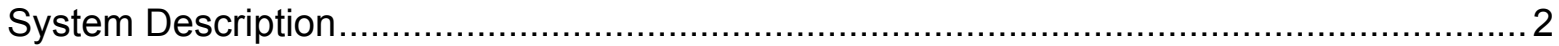

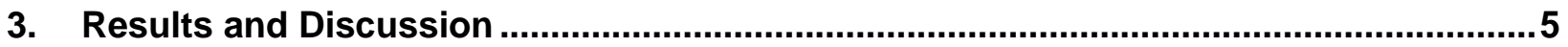

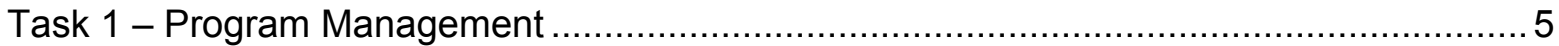

Task 2 - Establishment of Detailed Design Specifications ........................................... 5

Task 3 - Design/Fabricate Ratcheting Stainless-Steel Repair Sleeves ............................. 7

Task 4 - Design, Fabricate and Test Patch-Setting Robotic Train ................................... 10

Task 5 - Design and Fabricate Pipe Wall Cleaning Robot Train with PZT Camera............ 17

Task 6 - Design and Build Surface Control and Monitoring System ...............................2.

Task 7 - Design and Fabricate Large-Diameter Live Access System............................... 26

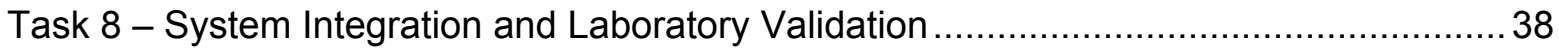

Task 9 - Field Testing and System Refinement ...................................................... 42

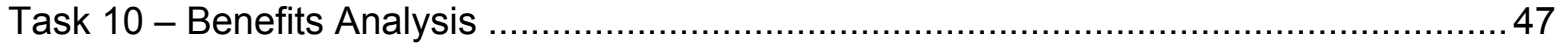

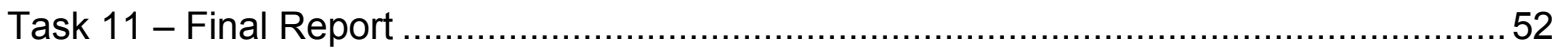

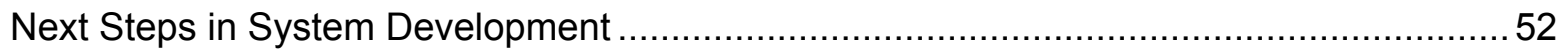

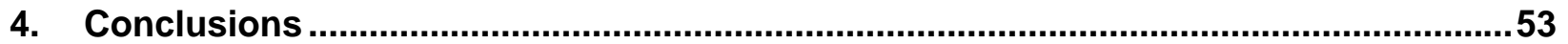

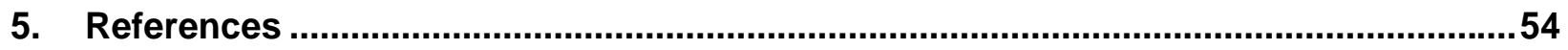

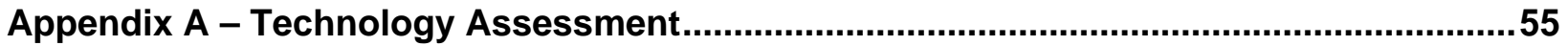

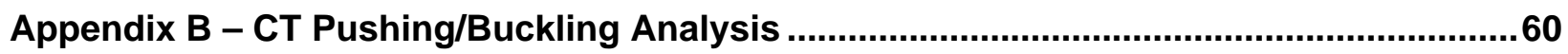




\section{List of Tables}

Table 1. Comparison of Cast-Iron Pipe Joint Repair Methods.............................................. 5

Table 2. Surface Power Supply for Camera ....................................................................... 19

Table 3. Comparison of Cast-Iron Pipe Joint Repair Methods ............................................50

Table 4. Costs of Cast-Iron Pipe Joint Repair Methods ..................................................... 51

\section{List of Figures}

Figure 1. Pipe Wall Inspection/Preparation Robot Train .................................................... 2

Figure 2. Camera's View of Bell-and-Spigot Joint Seam .................................................. 3

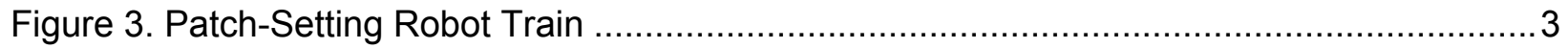

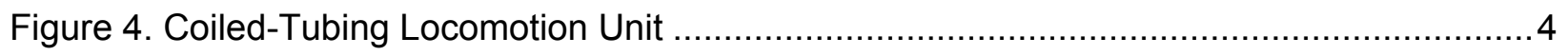

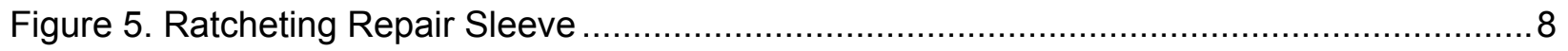

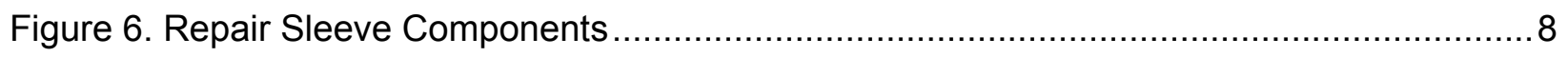

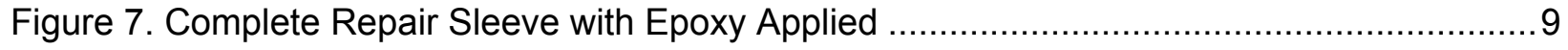

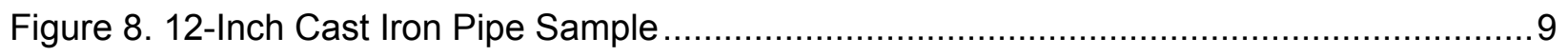

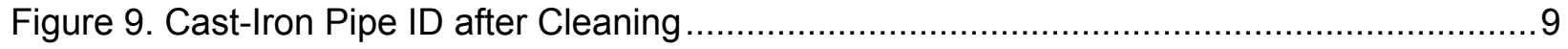

Figure 10. Successfully Installed Repair Sleeve ..................................................... 10

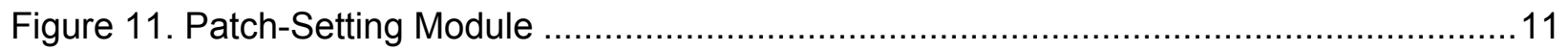

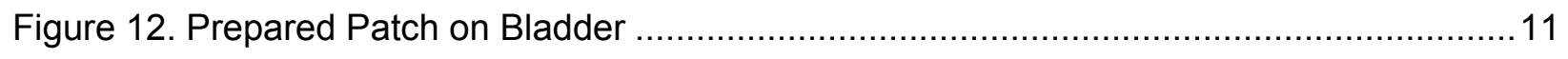

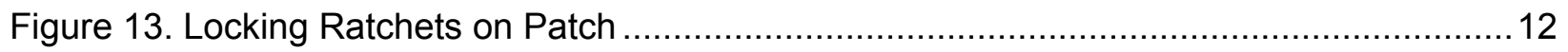

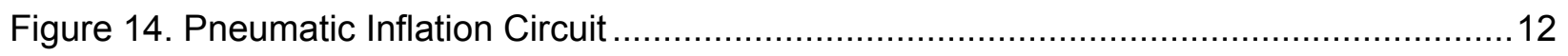

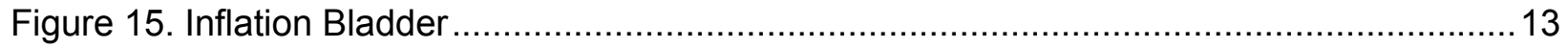

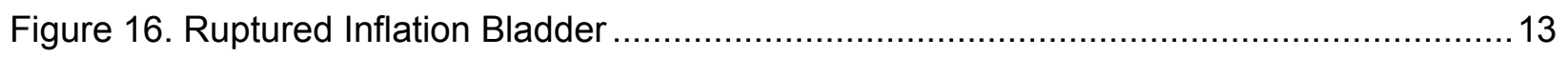

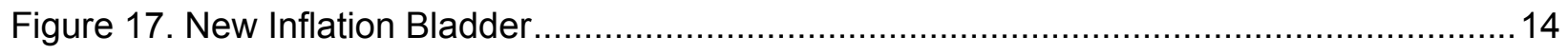

Figure 18. Cast-Iron Joint Tested for Leaks ............................................................ 14

Figure 19. Bladder/Patch Assembly Hung in Joint...................................................... 15

Figure 20. Partial Ratchet Engagement After Patch Setting ........................................... 15

Figure 21. Sample Cast-Iron Joint for Full-Function Tests of Patching Module ........................16

Figure 22. Final Patch Design Set in Test Joint ....................................................... 17

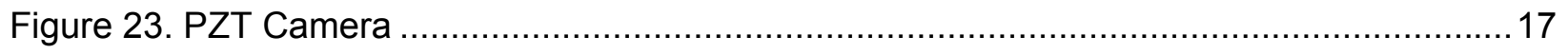

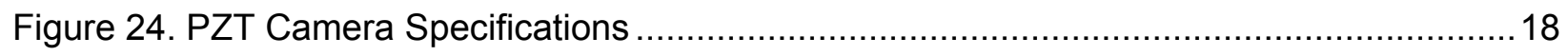

Figure 25. Downhole Camera Control Circuit Board ......................................................20

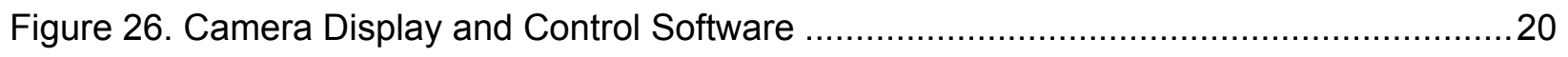

Figure 27. Pipe Wall Cleaning Assembly ................................................................... 21

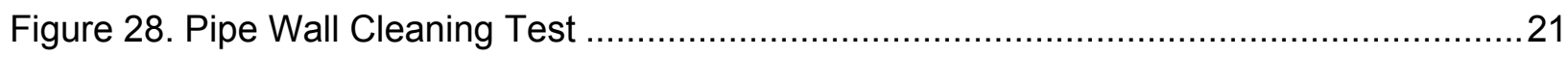

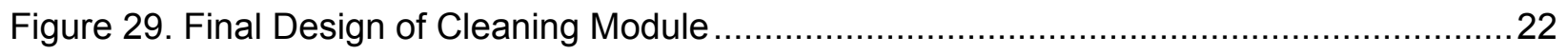

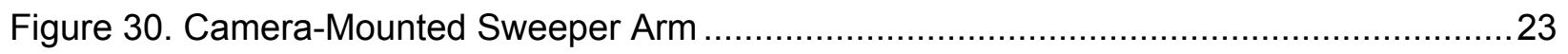

Figure 31. Cleaning Module Motor Heat Tests ............................................................. 24

Figure 32. Schematic of Surface Control Module ..................................................... 24 


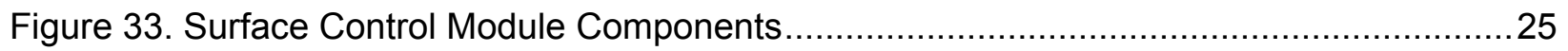

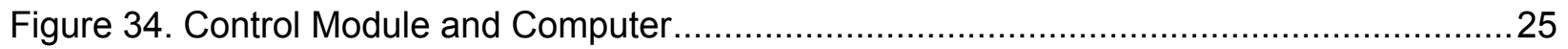

Figure 35. Cast-Iron Entry Fitting (4-inch Prototype) ........................................................ 26

Figure 36. Bolt-On Fitting for Live Access into 12-in. Cast-Iron Mains ...................................28

Figure 37. Initial Assembly of Large-Diameter Bolt-On Fitting ...........................................29

Figure 38. Bolt-On Fitting Lowered into Position ............................................................... 29

Figure 39. Large-Diameter Bolt-On Fitting Installed ......................................................... 30

Figure 40. Drilling Assembly for Cutting Access Hole in 12-in. Cast-Iron Mains........................31

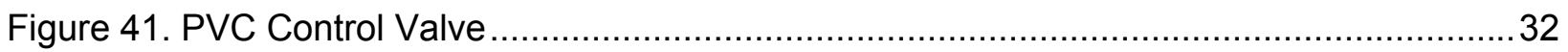

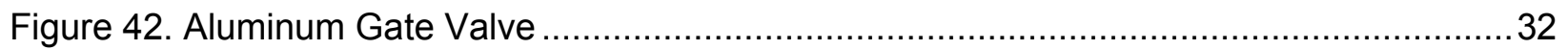

Figure 43. Hole Saw for Cutting Access Hole in Gas Main.................................................. 33

Figure 44. Drilling Assembly for Large-Diameter Pipe ...................................................... 33

Figure 45. Drilling Assembly with Hole Saw .................................................................... 34

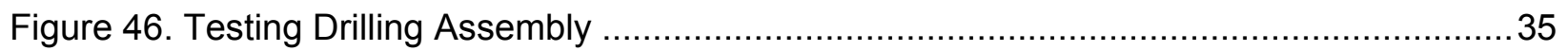

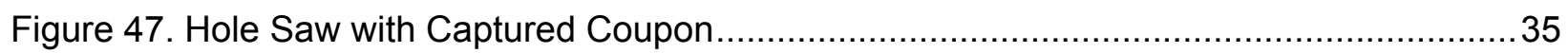

Figure 48. Pipe Coupon after Retrieval ....................................................................... 36

Figure 49. Plug-Setting Assembly for Resealing 12-in. Cast-Iron Mains .................................... 37

Figure 50. Shop Tests - Entry Fitting, CT Unit and Pipeline ................................................. 38

Figure 51. Shop Tests - Test Pipeline with Cast-Iron Joint ................................................ 39

Figure 52. Assembling Drilling Components ................................................................... 39

Figure 53. Launch Spoon (viewed from inside pipeline) ................................................... 40

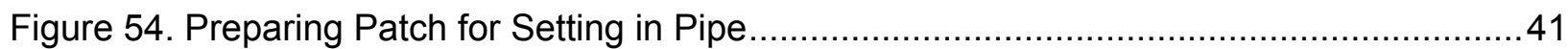

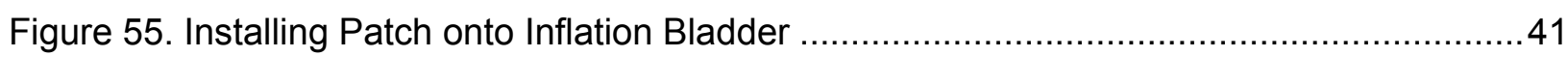

Figure 56. Successfully Patched Joint ........................................................................... 42

Figure 57. Patched Cl Joint Tested for Leaks................................................................. 42

Figure 58. Field Test Site for Small-Diameter System ......................................................... 43

Figure 59. Attaching 4-in. Entry Fitting to Pipe Prior to Welding ..............................................44

Figure 60. Magnet Assembly for Removing Filings ........................................................ 44

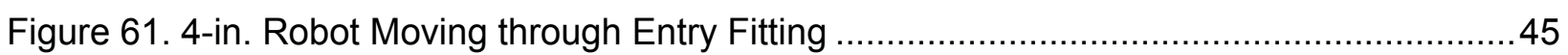

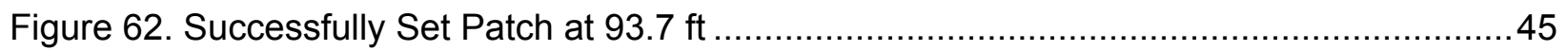

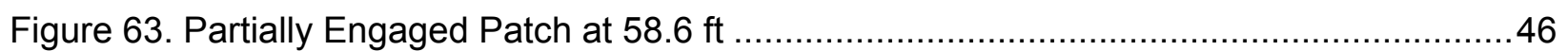

Figure 64. 4-in. Entry Fitting Ready for Burial .................................................................46

Figure 65. Break-Even Cost for Robotic Joint Repair ..............................................51 


\section{Introduction}

Utilities in the U.S. operate over $75,000 \mathrm{~km}(47,000$ miles) of old cast-iron pipes for distribution of natural gas. Most of this pipe is in highly urbanized areas and its replacement is prohibitively expensive. While the cast-iron pipe itself generally retains acceptable mechanical competency, the joints (of bell-and-spigot design) tend to leak as the pipe ages. Current repair practices are to: (1) excavate and expose each joint and encapsulate it externally; or (2) take the line out of service and apply repair sleeves or cured-in-place liners. Both methods are costly and highly disruptive.

The objective of this program is to design, test and commercialize a robotic system capable of sealing multiple cast-iron bell-and-spigot joints from a single pipe entry. The proposed system will perform repairs while the pipe remains in service by traveling through the pipe, cleaning each joint surface, and installing a stainless-steel sleeve lined with an epoxyimpregnated felt across the joint. This approach will save considerable time and labor, avoid traffic disruption, and eliminate the requirement to interrupt service (which results in enormous expense to utilities and considerable inconvenience to customers).

This development effort represents an aggressive expansion of existing technologies. Applying this technique inside large-diameter cast-iron pipes poses a number of technical challenges, among them: (1) an innovative bolt-on entry fitting is required to conduct repair operations on live mains; (2) the assembly must travel long distances through pipes having significant levels of debris; (3) the pipe wall must be effectively cleaned in the immediate area of the joint to assure good bonding of the sleeve; (4) repair sleeves must compensate for diametric variation and eccentricity of cast-iron pipes; and (5) coiled-tubing equipment must be designed to optimize push distance from a single pipe entry point. 


\section{Experimental}

\section{Experimental Objectives}

The objective of this development program is to design, test and commercialize a robotic system capable of sealing multiple large-diameter cast-iron bell-and-spigot joints from a single pipe entry point. The proposed system will perform repairs while the pipe remains in service by traveling through the pipe, cleaning each joint surface, and attaching a stainless-steel sleeve lined with an epoxy-impregnated felt across the joint. This approach will save considerable time and labor, avoid traffic disruption from excavation operations, and eliminate any requirement to interrupt service to customers (which would result in enormous expense to utilities).

\section{System Description}

The robotic joint-sealing system will be comprised of four main subsystems. These are: (1) two sequentially run, multiple-module robot trains; (2) pipe-access hardware for safely admitting into and removing the robot trains from the live gas-main environment; (3) a coiledtubing (CT) delivery system (see Appendix B) for providing primary locomotion, power and data communication from/to the in-pipe robot and (4) surface control and display electronics.

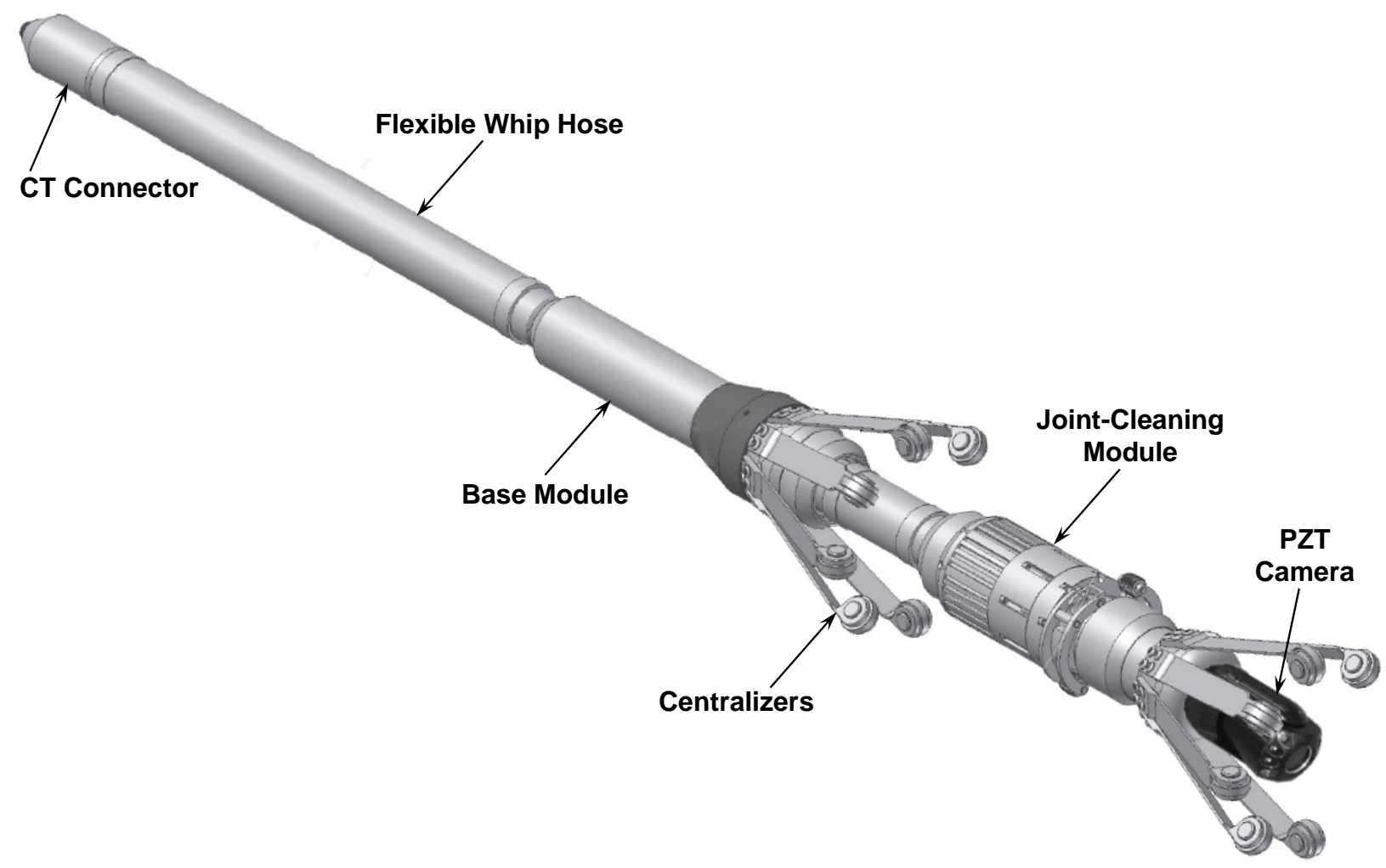

Figure 1. Pipe Wall Inspection/Preparation Robot Train 
Two in-pipe robot trains are required. The first train (Figure 1) has a front-mounted PZT (pan/zoom/tilt) camera that is used to visually locate each bell-and-spigot joint (Figure 2). Directly behind this camera is a rotating brushing module whose function is to remove debris from the pipe wall immediately next to the cast-iron bell-and-spigot joint. The third module is a base module that houses all power and microprocessor control of the other modules. The base module is common to both trains.

In operation, the inspection/cleaning robot train will be pushed by the CT to the farthest castiron joint to be repaired from a given launch

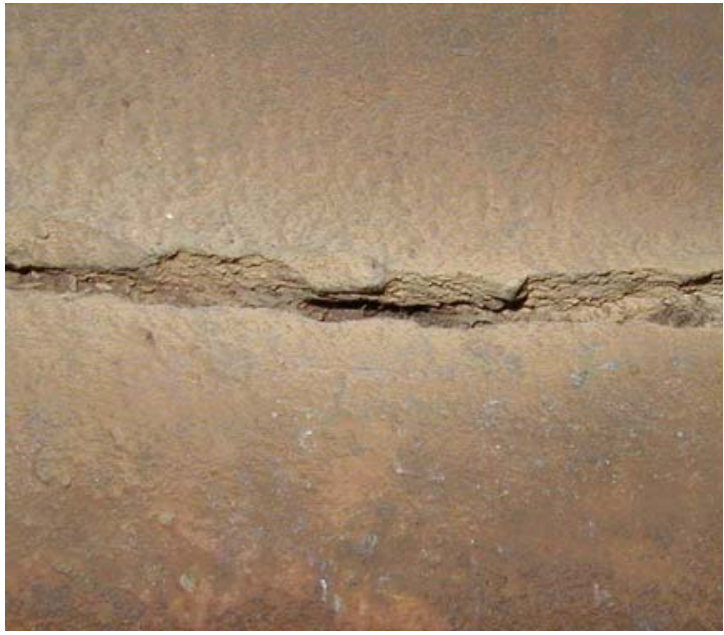

Figure 2. Camera's View of Bell-and-Spigot Joint Seam

location. The brushing module will then be activated to clean the joint by rotating cleaning flails against the pipe wall while the brushing module is moved back and forth across the joint location. Proper cleaning of this joint will be visually confirmed by the operator through the camera and may require one or more passes depending on the amount and tenacity of the debris coating the pipe wall. The CT unit is then used to withdraw the train back to the next joint where the cleaning process is repeated. This sequence is continued until all joints have been prepared for patching and the pipe-wall preparation train has been brought back into the pipeaccess fitting and withdrawn from the main.

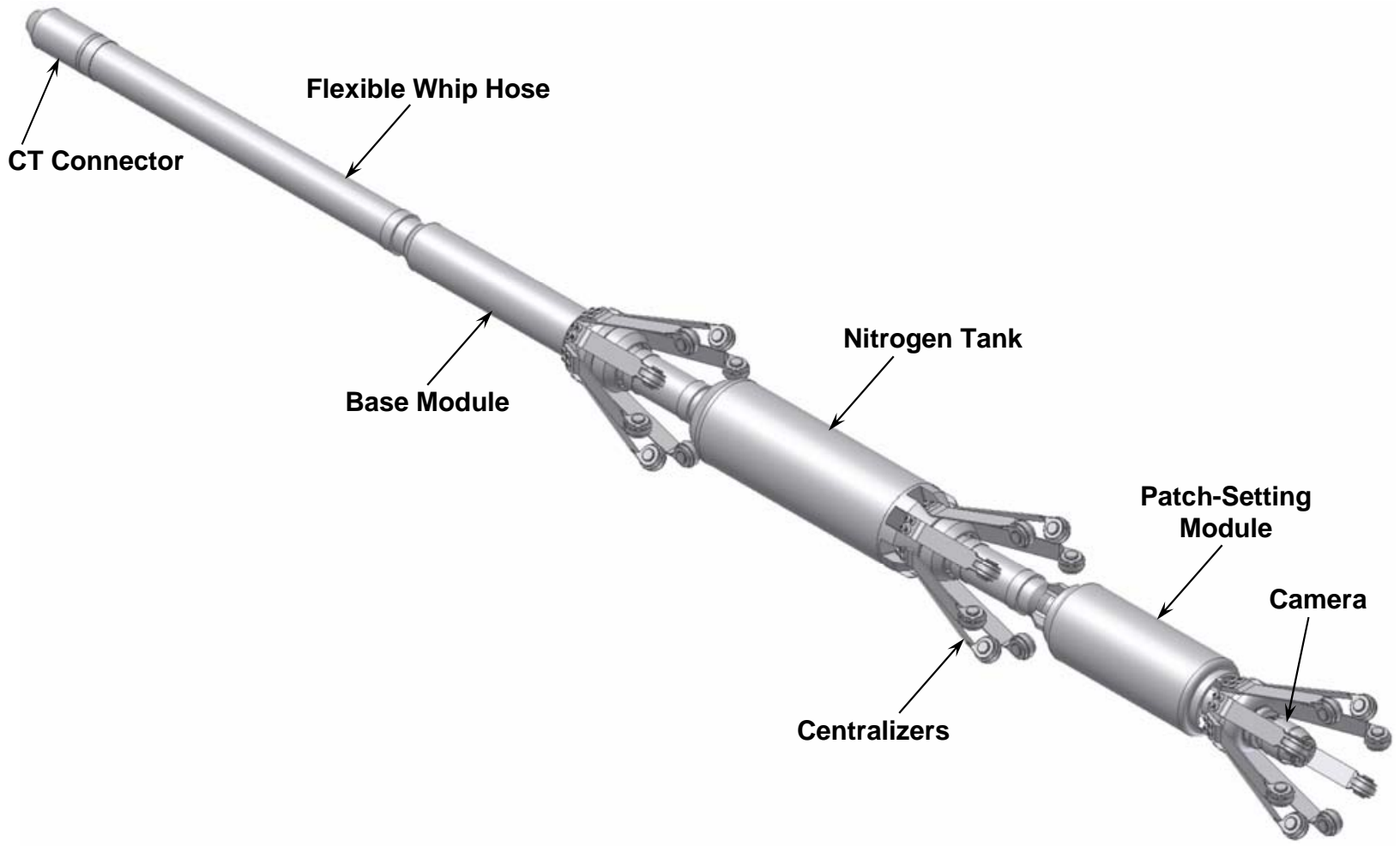

Figure 3. Patch-Setting Robot Train 
The PZT camera and brush modules are then removed from the train and replaced with the patch-setting and nitrogen canister modules (Figure 3). A stainless-steel patch sleeve is prepared and then slid over the carrier along with its polymer sleeve and polyester felt, which is saturated with epoxy.

The CT surface unit (Figure 4) is then used to deliver the patch-setting train to the most distant bell-and-spigot joint. This location is confirmed both with the quadrature encoder footage counter and visually by camera. Once the camera is located exactly at the bell-and-spigot-joint gap, the fine-resolution odometer on the camera is set to zero. The CT unit is then used in conjunction with the camera's odometer to move the patch-setting train forward by a known, fixed distance which assures the patch is properly aligned with the bell-and-spigot joint. A control command is then issued from the surface unit to the base unit to release nitrogen from the stainless-steel pressure vessel behind the patch-setting module into the expandable rubber bladder. This causes the bladder to inflate and locks the stainless-steel sleeve into position via its interlocking, ratcheting barbs. The epoxy cures and reaches full strength within 12 hours. During the interim, a gas-tight seal is assured by the polymer sleeve which has been energized against the joint by the hoop stress of the stainless-steel sleeve.

After the first patch is set, the bladder is deflated to allow withdrawal of the robot train from the patch. (Note: The volume and rate at which the nitrogen is bled from the inflation bladder results in no appreciable dilution of the BTU quality of the natural gas.) The assembly is then withdrawn from the main to be fitted with another patch. The next closest joint in the main is repaired next. This process is repeated until all joints are patched.

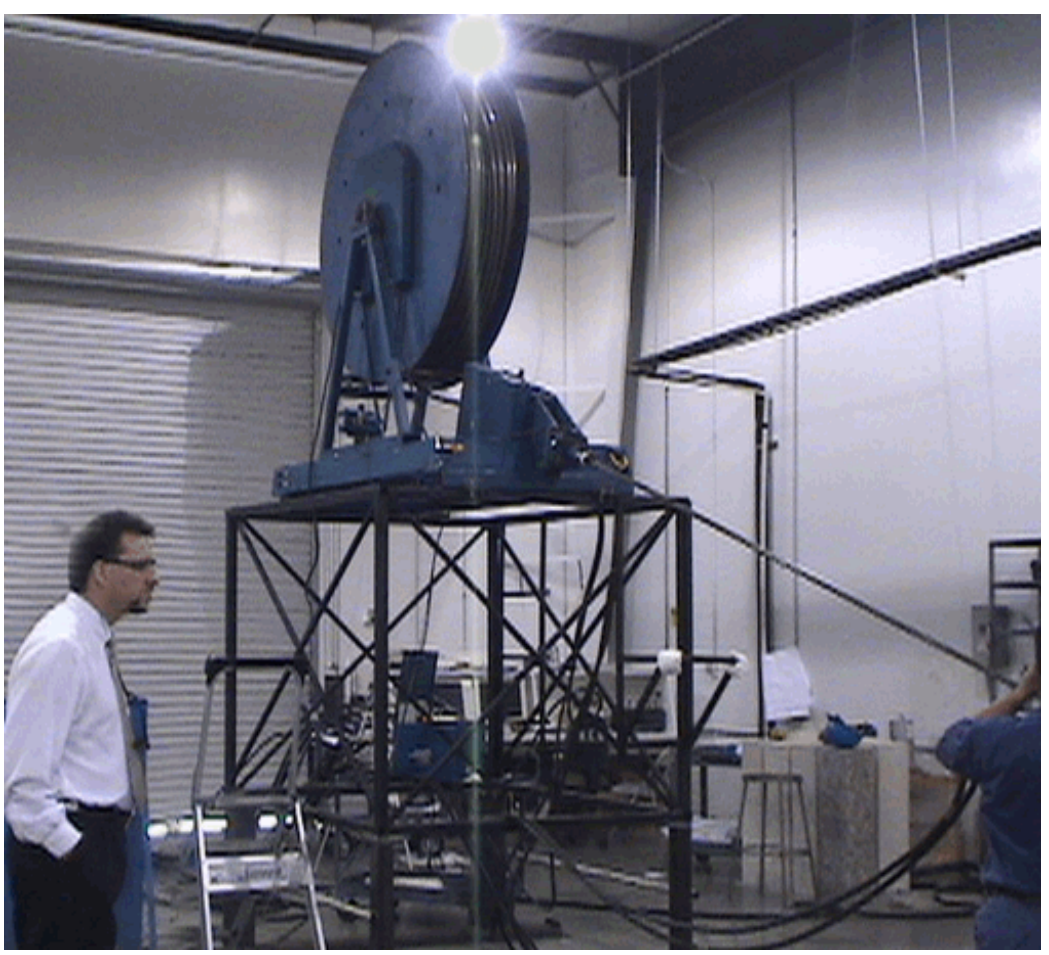

Figure 4. Coiled-Tubing Locomotion Unit 


\section{Results and Discussion}

The project work structure consists of the 11 tasks described below. Specific results and progress are described under each task. Work planned for the future is discussed at the end of the chapter.

\section{Task 1 - Program Management}

A Research Management Plan, consisting of a summary of the program's technical objectives and the technical approach for accomplishing these objectives was described and documented in a written report to DOE. The report included task descriptions, schedules and planned expenditures as well as major milestones and decision points.

In addition, a Technology Assessment was also prepared. The assessment was to establish the state of the art of the technologies to be developed along with those technologies against which it must compete. The report, presented in Appendix A, describes each jointrepair technology and identifies both positive and negative aspects of using each. The initial comparison (Table 1) showed that the proposed robotic technology will provide significant advantages for repairing cast-iron joints.

Table 1. Comparison of Cast-Iron Pipe Joint Repair Methods

\begin{tabular}{|c|c|c|c|}
\hline Joint Repair Method & Main Condition & $\begin{array}{l}\text { Repairs per } \\
\text { Excavation }\end{array}$ & Comments \\
\hline $\begin{array}{l}\text { External Bolt-on Repair } \\
\text { Sleeve }\end{array}$ & $\begin{array}{l}\text { in service (no impact on } \\
\text { gas delivery) }\end{array}$ & 1 & $\begin{array}{l}\text { conventional technique, most } \\
\text { common for steel pipes }\end{array}$ \\
\hline External Encapsulation & $\begin{array}{l}\text { in service (no impact on } \\
\text { gas delivery) }\end{array}$ & 1 & $\begin{array}{l}\text { most common repair technique for } \\
\mathrm{Cl} \text { joints }\end{array}$ \\
\hline Internal Encapsulation & $\begin{array}{l}\text { in service (no impact on } \\
\text { gas delivery) }\end{array}$ & $\begin{array}{l}\text { 10-12 repairs each } \\
\text { direction }\end{array}$ & $\begin{array}{l}\text { dependent on condition of jute } \\
\text { sealant }\end{array}$ \\
\hline Cured-in-Place Pipe & $\begin{array}{l}\text { out of service (interrupts } \\
\text { gas delivery) }\end{array}$ & $\begin{array}{l}\text { entire pipe segment; } \\
\text { up to } 40 \text { joint repairs }\end{array}$ & $\begin{array}{l}\text { rarely used due to length of time } \\
\text { main must be taken out of service }\end{array}$ \\
\hline $\begin{array}{l}\text { Internal Repair Sleeve } \\
\text { (Conventional) }\end{array}$ & $\begin{array}{l}\text { out of service (interrupts } \\
\text { gas delivery) }\end{array}$ & up to 40 joint repairs & $\begin{array}{l}\text { rarely used due to length of time } \\
\text { main must be taken out of service }\end{array}$ \\
\hline $\begin{array}{l}\text { Internal Repair Sleeve } \\
\text { (Robotic) }\end{array}$ & $\begin{array}{l}\text { in service (no impact on } \\
\text { gas delivery) }\end{array}$ & $\begin{array}{l}\text { 40-80 repairs each } \\
\text { direction }\end{array}$ & $\begin{array}{l}\text { independent of condition of jute; } \\
\text { significant savings possible versus } \\
\text { other techniques }\end{array}$ \\
\hline
\end{tabular}

(Advantage / Disadvantage)

\section{Task 2 - Establishment of Detailed Design Specifications}

Design of a system to inspect, prepare and patch cast-iron gas main joints under live conditions represents a substantial technological advancement over systems designed for small steel distribution lines. Key differences between small-diameter steel pipes and large-diameter cast-iron pipes should be identified and used to set benchmark design targets for hardware sizes and component functionality. The following subtasks were undertaken to support this benchmarking effort: 
2.1 Identify Mechanical, Material and Operational Differences between SmallDiameter Steel Mains and Large-Diameter Cast-Iron Mains. The entry system for steel lines can be attached by welding (not an option with cast iron). This carries numerous concerns that must be addressed for the entry/access system, including means to fasten the entry fitting to the main, implementing a continuous seal with long-term reliability, and designing an entry system that can tolerate settling of the joints over time and provide sufficient reinforcement of stiffness of the main both during and after the repair.

2.2 Prototype Size Selection. Large-diameter cast-iron gas mains in the U.S. range in size from 20 to $91 \mathrm{~cm}$ (8 to 36 in.) nominal diameter. Since there will obviously be size-specific requirements to be addressed, a size had to be selected for the prototype system. This was completed through discussions with the GTI Distribution Task Group (DTG) Advisors. It was expected that the selected size will be either $20 \mathrm{~cm}$ (8 in.) or $30 \mathrm{~cm}$ (12 in.) since $30 \mathrm{~cm}$ and smaller sizes comprise $95.5 \%$ of cast-iron mains in the US.

2.3 Perform Pushing/Buckling Tradeoff Analyses. Based on candidate coiled-tubing (CT) products, efforts will be aimed to define "sensitive" design targets for hardware that will be inserted into the cast-iron main. These will include drag forces, weights of the components, bending requirements on the CT, and stiffness concerns for flexible joints between the hardware modules on the robot trains.

Deliverables for this task included a list of performance and size specifications that provide the basis for follow-on detailed design activities.

Mechanical, material and operational differences between small-diameter steel mains and large-diameter cast-iron mains were defined. Primary challenges posed by large cast-iron mains involve (1) larger variation in inside pipe dimensions (being addressed by a ratcheting sleeve design that can effectively lock into place over a range of pipe IDs); (2) presence of more debris (being addressed through the use of much more aggressive wall cleaning equipment and the possible use of a plow to move debris away from the bell-and-spigot joint area); and (3) the fact that the entry fitting for cast iron must be a bolt-on design (no welding) and entry hole size should be minimized to prevent cracking of the brittle cast iron.

Discussions with several utilities, including KeySpan Energy, Consolidated Edison and Public Service Electric \& Gas, showed that utilities prefer the first prototype be designed for operations inside nominal 12-inch diameter cast-iron pipes. As a result, design efforts were focused on producing detailed designs for the entry fitting, cleaning elements and repair sleeves for this size application. A prototype wall-cleaning device and a bolt-on entry fitting for 12-inch cast-iron mains were designed.

The CT pushing/buckling analysis (Task 2.3) was completed early in the effort. A theoretical analysis of buckling limits showed that the maximum distance a 1-in. string of CT can be pushed into a straight 12-in. main is near $800 \mathrm{ft}$. Of course, in practical application the maximum distance achieved may be significantly less if bends are encountered, the pipe has significant levels of debris that build up in front of the module, or service taps protrude into the ID pipe such that they prevent further advance of the robot train. A typical maximum inspection distance from the access fitting is more likely in the range of $400-500 \mathrm{ft}$. This limit will be 
investigated in more detail during future field tests now planned. A summary of the CT buckling analysis as related to maximum travel down the gas main is presented in Appendix $\mathbf{B}$.

\section{Task 3 - Design/Fabricate Ratcheting Stainless-Steel Repair Sleeves}

Commercially available repair sleeves are designed for application under "dead" main conditions (i.e., the mains are not in service and are not pressurized). With current designs, a pressure gradient would displace the sealing epoxy prior to curing, thereby creating leak paths. In addition, repair sleeves for large cast-iron mains must be tolerant of misalignments in the belland-spigot joints. Such misalignment can prevent thorough sealing when using existing designs of repair sleeves.

The sleeve must conform tightly to the interior shape of the joint. A repair sleeve with ratcheting notches will make this possible. Designs will be tested on cast-iron pipe samples. Test sample joints will be specially fabricated with intentional misalignments to further test as necessary. To address these critical requirements, work efforts will be directed to:

3.1 Determine Geometrical Spacing of Interlocking Barbs. This spacing design must allow sufficient adjustment for misalignment of bell-and-spigot segments of the joints. Samples will be obtained to perform testing with misalignment conditions observed in the field.

3.2 Perform Sensitivity Analyses. Sealing design parameters must be evaluated with respect to sleeve geometry and the amount of compression ("squeeze") on the patch during application. Patches must be able to lock into place while tolerating misalignment as well as lock in such a fashion to provide ample sealing over all required surfaces. Other aspects to be examined include the design thickness of the felt and the impact of this thickness on sealing effectiveness.

Two iterations of the interlocking sleeve design were foreseen. The first design will be thoroughly tested and evaluated. After any adjustments are made to the first design, a second set will be fabricated and evaluated. Deliverables for this task were the final design of the ratcheting repair sleeves, complete with specifications for fabrication and assembly. Several prototypes were built and tested following the second design iteration.

Early in the project, the first design iteration for the repair sleeves was prepared. This design was based on modifying existing sealing products from a commercial sleeve manufacturer (Link-Pipe Inc.) so that their sleeves can operate in pressurized gas mains, provide a redundant seal, and minimize their overall diameter before they are expansion-set across the bell-and-spigot joint. The current commercial sleeve design from the manufacturer does not work in pressurized mains and has only one seal method. In addition, the project approach is to minimize sleeve diameter for simplifying launching of the sleeve into the main and allowing it to ride off the bottom (invert) to minimize its contamination with debris.

Figure 5 illustrates critical design features of the new repair sleeve. A 28-gage, corrugated stainless-steel sleeve (316 SS) is used as the innermost member. Its function is to provide a mechanical means for energizing the urethane seal sleeve against the cast-iron wall to form the first leak seal and to allow the epoxy-saturated polyester carrier to cure to form a 
second (redundant) leak seal. The sleeve gage (28) is a reduction from the 24 gage normally used. Its use will enable the sleeve to be coiled in a smaller diameter without yielding. Analysis indicated that the design can be rolled into a diameter of about $55 \%$ of the pipe ID versus $75 \%$ of the pipe ID for 24-gage sleeves. Corrugations, consisting of folds spaced on 1-inch centers, improve structural stiffness of the device so it does not deform during setting.

The most obvious trait of the urethane seal sleeve is its grooves (ribs). This new design compensates for axial shortening that would otherwise occur if a non-ribbed sleeve were allowed to radially expand significantly. The end elements feature increased thickness and act as an O-ring once the seal is expanded. Their thickness, coupled with low durometer, should provide an effective pressure seal across a range of cast-iron surface conditions as well as easily compensate for variation in pipe ID. AutoCAD machine drawings of the molds to produce these sleeves in both 8- and 12-inch sizes were prepared.

The final element of the

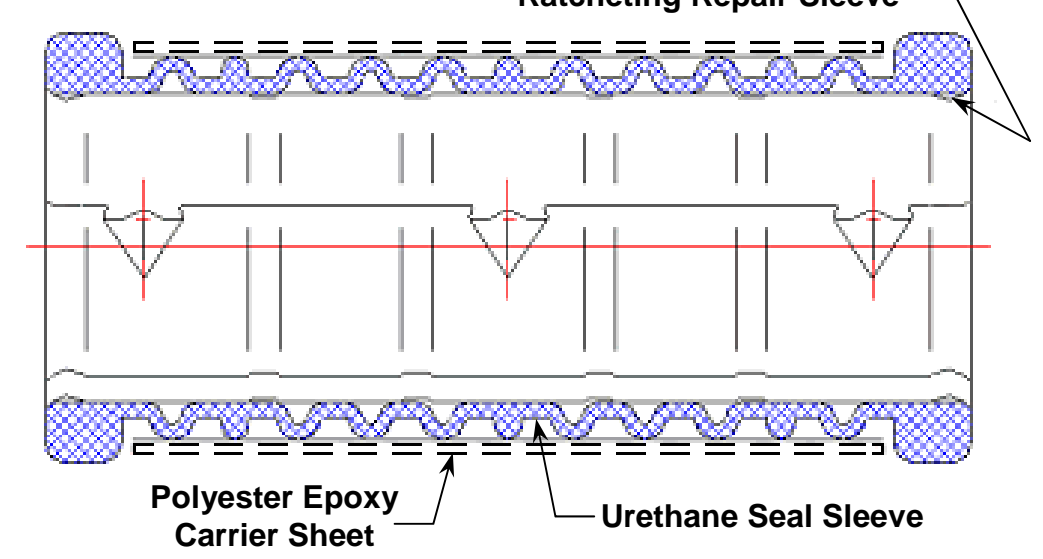

Figure 5. Ratcheting Repair Sleeve design is a polyester jacket which will carry the epoxy resin. At present, a thixotropic epoxy is being used that provides about 1 hour of working time before curing begins to create the final seal.

Work progressed to fabrication and full testing of the second-generation 12-inch repair sleeves featuring ratchets and polyurethane seal sleeves. Components of the sleeve design are shown in Figure 6. The sleeve is 12 in. long x 7.5 in. OD in its collapsed (unset) state. Figure 7 shows a sleeve with epoxy applied ready for insertion into the gas main via the inflation module.

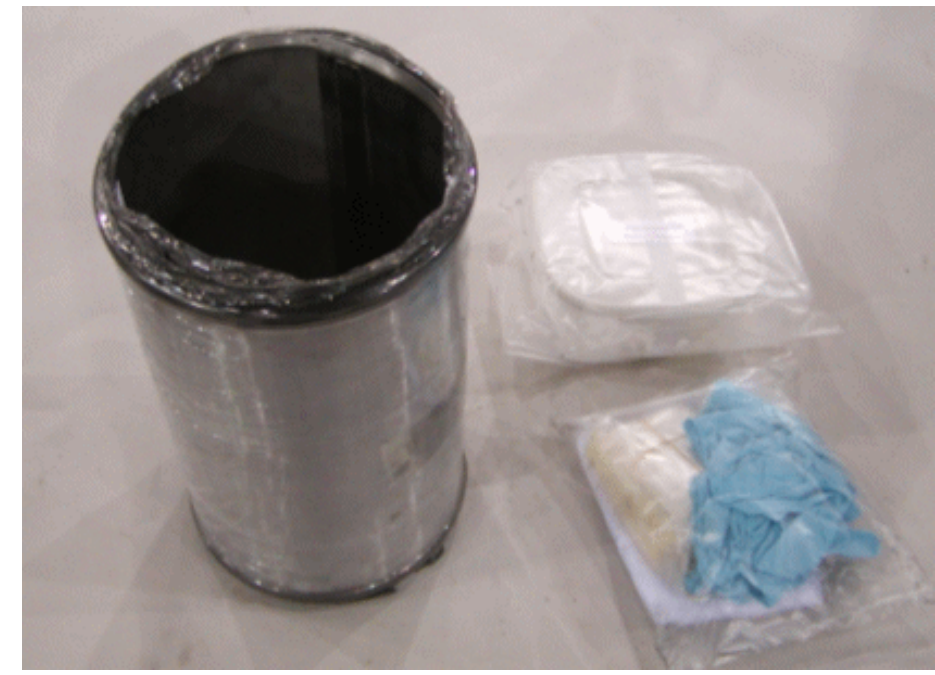

Figure 6. Repair Sleeve Components 


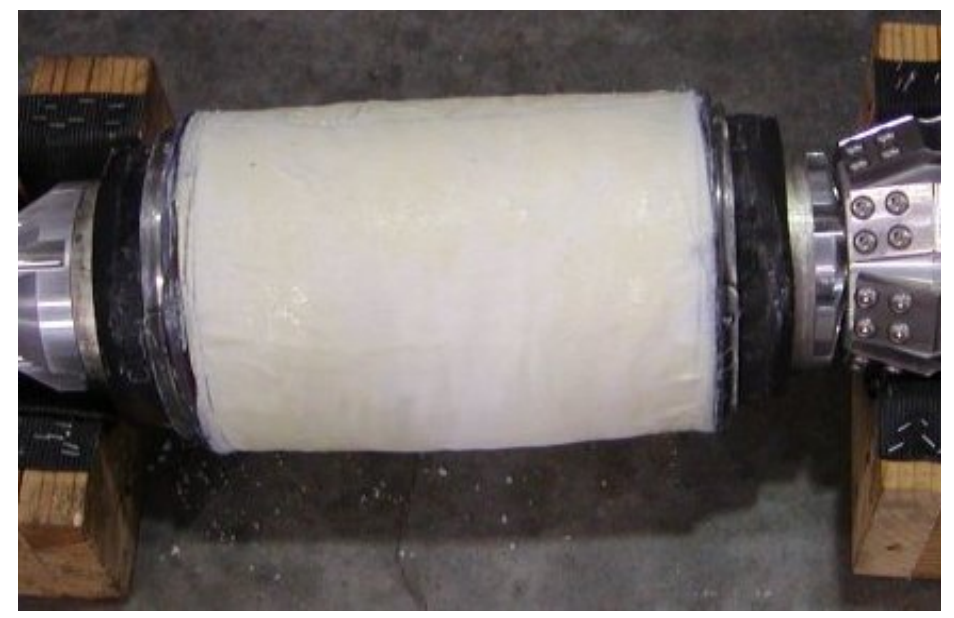

Figure 7. Complete Repair Sleeve with Epoxy Applied

Mock-up tests were conducted in the shop to set new 12-inch sleeves inside sample cast-iron joints (Figure 8). The first step was to use the cleaning module to clean debris and scale from inside the joint in preparation for running the sleeve (Figure 9).

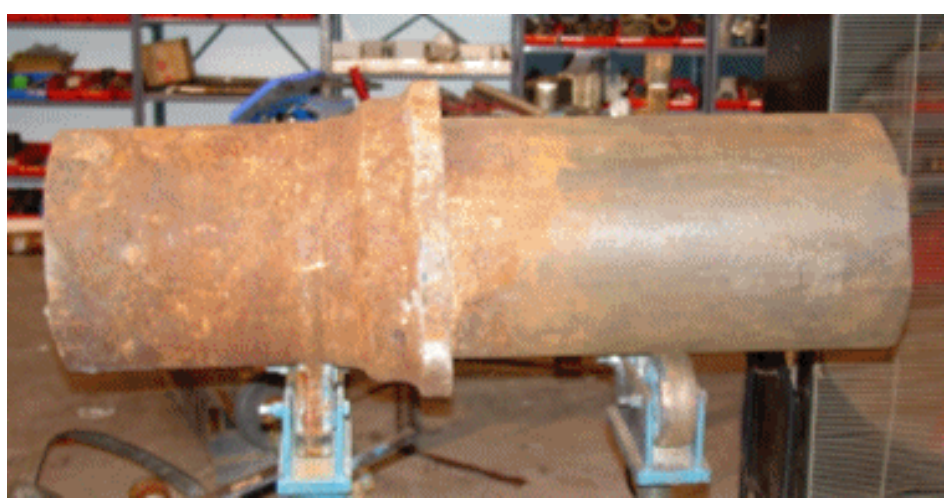

Figure 8. 12-Inch Cast Iron Pipe Sample

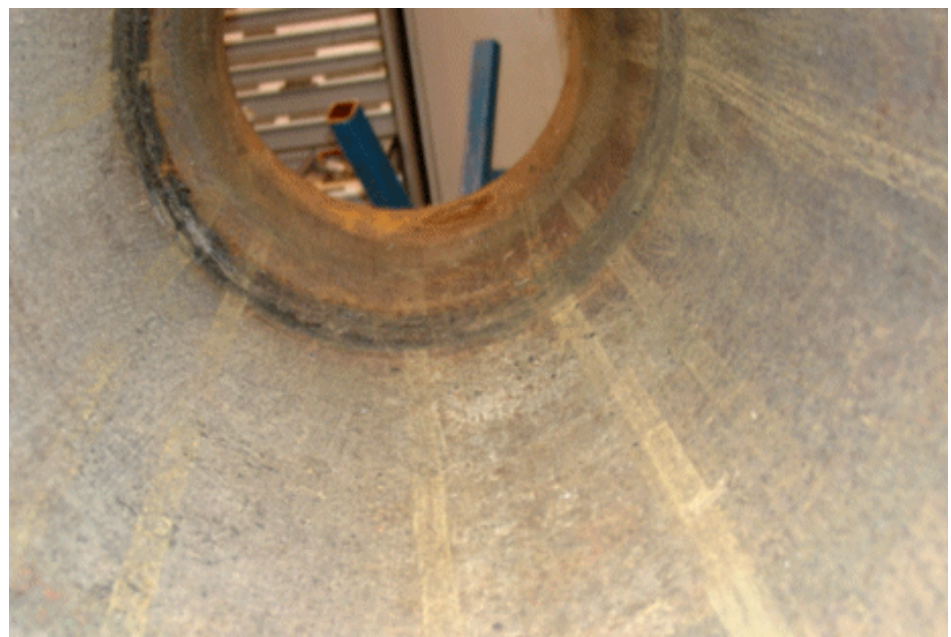

Figure 9. Cast-Iron Pipe ID after Cleaning

Next, a patching sleeve was successfully set at a maximum inflation pressure of 30 psig (Figure 10). 


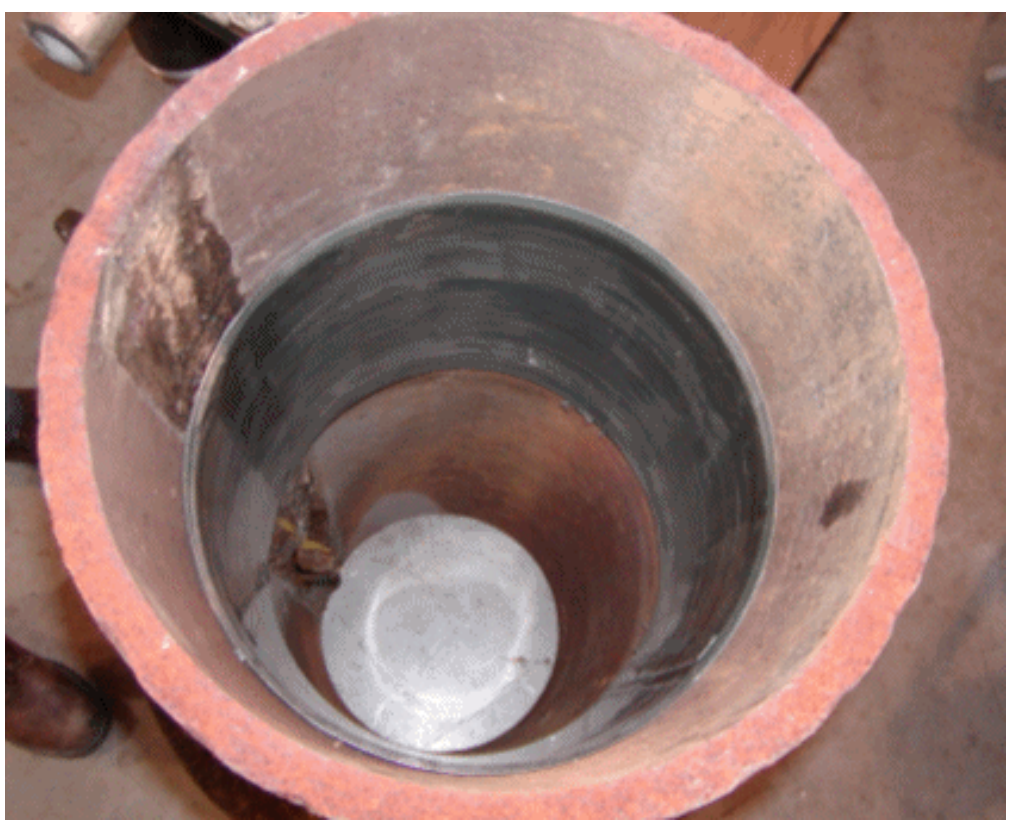

Figure 10. Successfully Installed Repair Sleeve

Additional tests of the complete patching module are described under Task 4 below.

\section{Task 4 - Design, Fabricate and Test Patch-Setting Robotic Train}

To set patches under live main conditions, the patching hardware must meet several key criteria. It must be able to be inserted and removed from gas mains without damage. It must be able to be positioned using CT. Its physical layout must not impede gas flow through the main (thereby maintaining gas delivery to customers). Lastly, it must be able to set patches with high reliability. To support the design, the following subtasks were undertaken:

4.1 Analyze Weight and Drag. Hardware must be designed to perform required patch-setting functions while minimizing weight and drag, as these are key drivers in determining the insertion (push) range and therefore the number of joints which can be repaired from each entry point.

4.2 Analyze Reactive Force Limits. The patch-setting equipment will be designed to effectively and reliably set patches while not exerting excessive reactive forces on the cast-iron pipe.

4.3 Test Patch Integrity. Testing will be conducted to verify that patches seat properly and to verify that sufficient epoxy comes into intimate contact with the cast-iron joint segments.

4.4 Safety Testing. Testing will be conducted throughout the design and testing phases to ensure that the hardware poses no safety risks to the operating gas main. All hardware elements that are operated in the main must not allow a leak path of gas to the surface. All elements will be purged and pressurized with $\mathrm{N}_{2}$. Differential pressure between the main and inside the hardware elements will be monitored to ensure that a positive differential is maintained. This same approach will be followed in the next task. 
Deliverables for this task will be the patch-setting robotic train along with its corresponding electrical/electronics schematics and mechanical drawings.

Various patch-setting inflation modules were designed, built and used to install the different generations of ratcheting repair sleeves. The final sleeves are set by inflating the bladder to $30 \mathrm{psig}$ and maintaining pressure for 5 minutes before deflation. This provides sufficient time for the urethane sleeve to be compressed against the pipe and the ratchets to engage and lock.

Setting tests were successful, so efforts were directed to design of the control electronics to operate the solenoid-controlled valve attached to a pressurized canister of nitrogen. Figure 11, Figure 12 and Figure 13 illustrate key aspects of the equipment. Unlike other robotic elements, natural gas is bypassed to prevent interruption of customer service through the central pipe and not in the annular space between the outside of the robotic element and the cast-iron main.

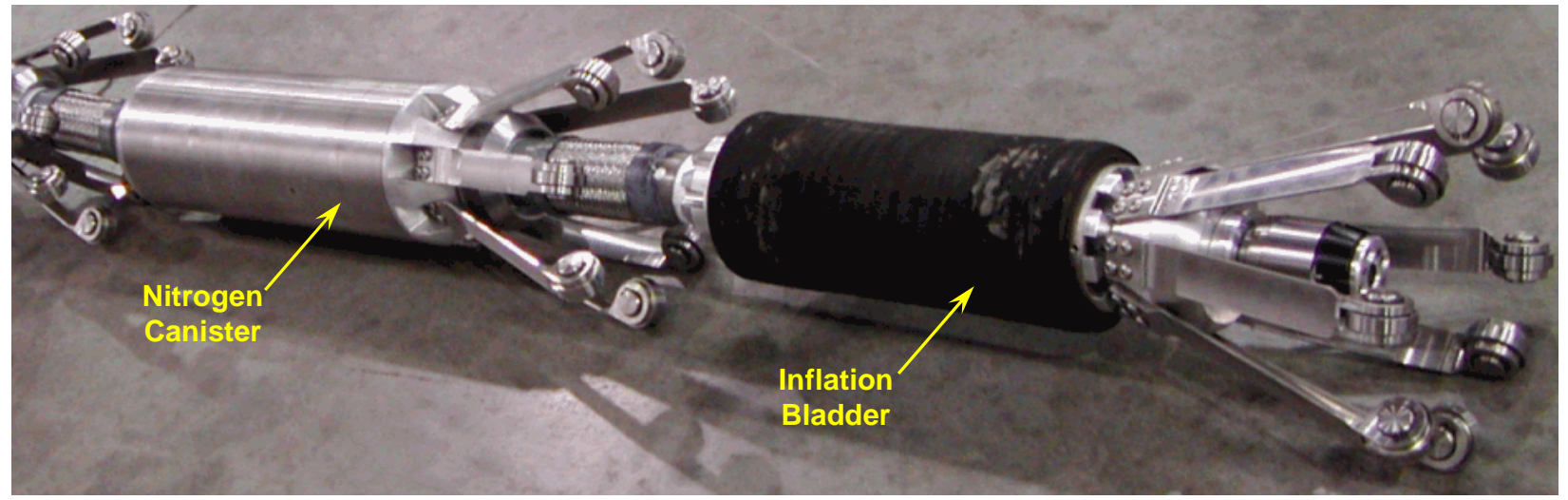

Figure 11. Patch-Setting Module

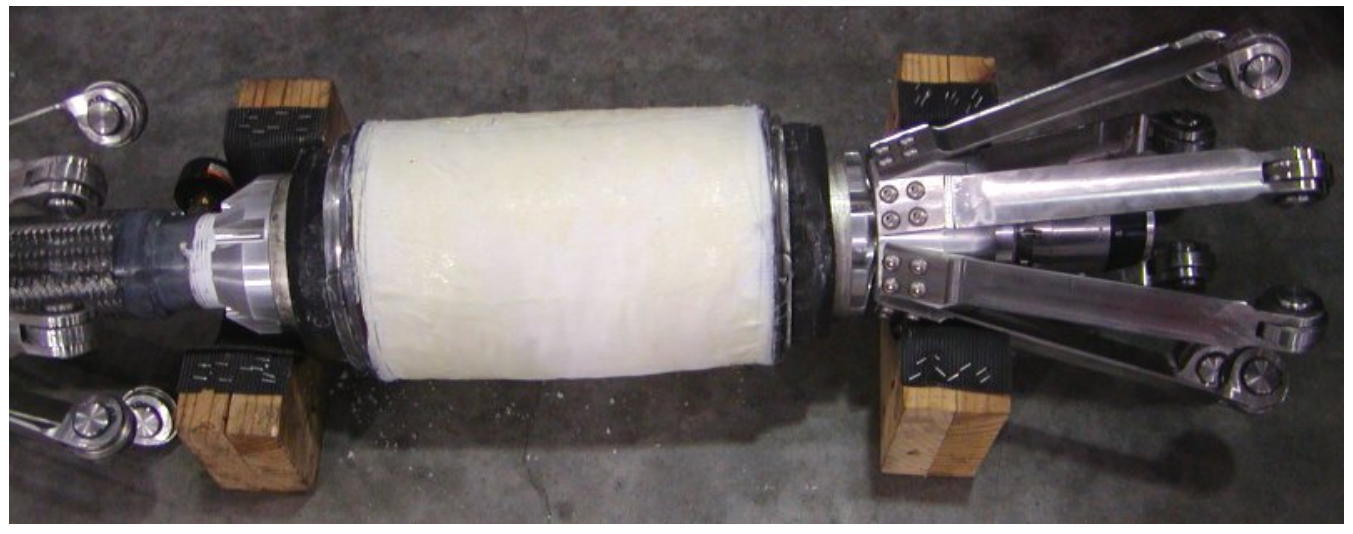

Figure 12. Prepared Patch on Bladder 


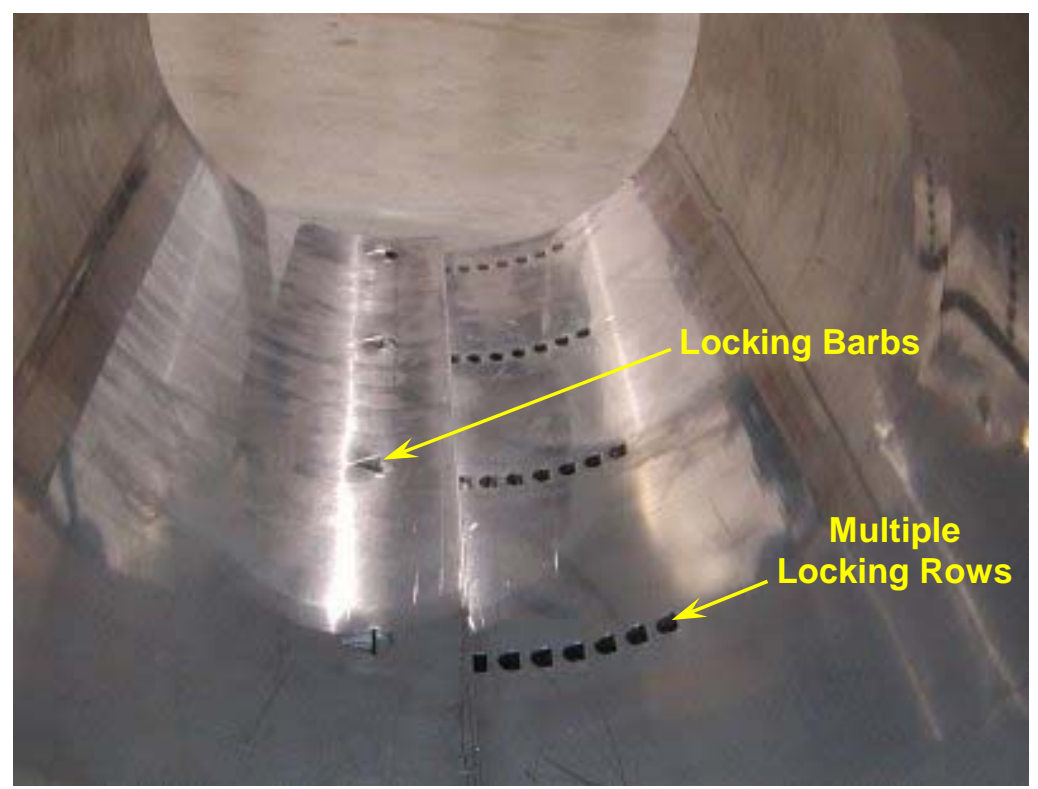

Figure 13. Locking Ratchets on Patch

The patch-setting control system consists of a solenoid valve which allows $\mathrm{N}_{2}$ pressure to be admitted into the inflation bladder under computer control; a pressure chamber for storing the nitrogen charge and pressure relief valves which allow adjustment of the charge pressure to compensate for differences in the gas main operating pressure. Figure 14 depicts the pneumatic inflation circuit.

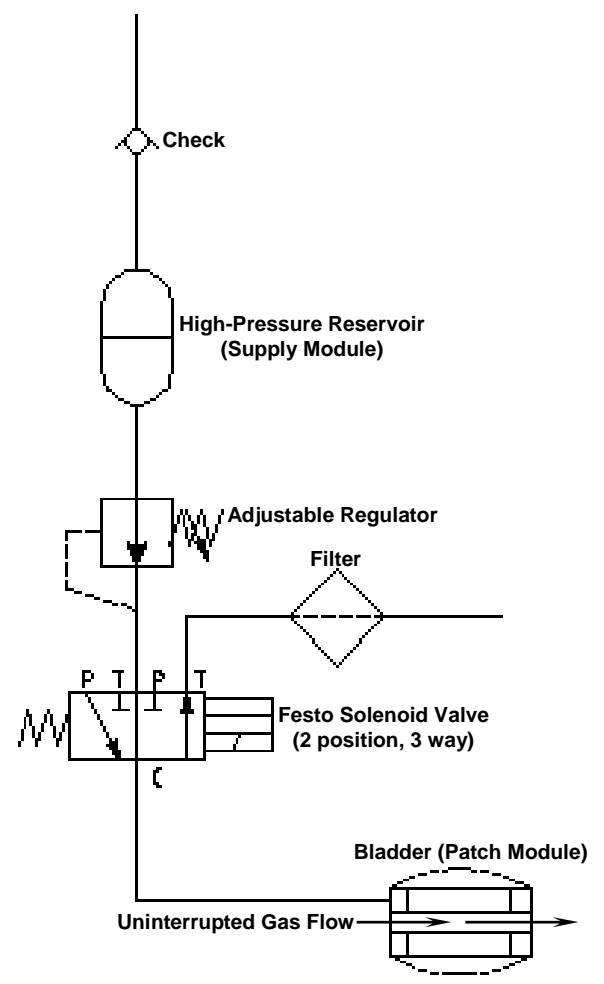

Figure 14. Pneumatic Inflation Circuit 
While setting new patches with the original inflation bladder, it became apparent that the bladder material (Figure 15) was not adequate. The bladder was observed to fail after a limited number of inflation cycles along the line where the end of the inner sleeve contacts the gum rubber. Options for modifying the bladder include using another compound having a higher tensile strength, or further increasing the thickness of the gum rubber. Figure 16 shows a failed gum-rubber sleeve. Alternatives for modifying the gum-rubber sleeve were investigated.

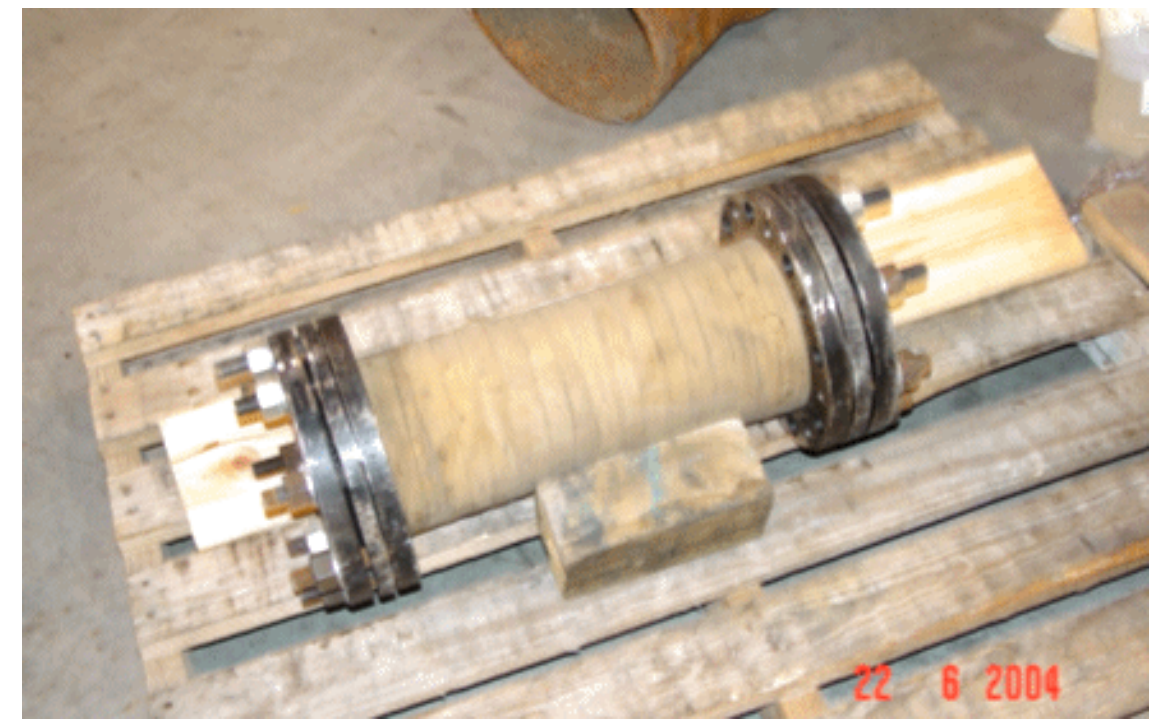

Figure 15. Inflation Bladder

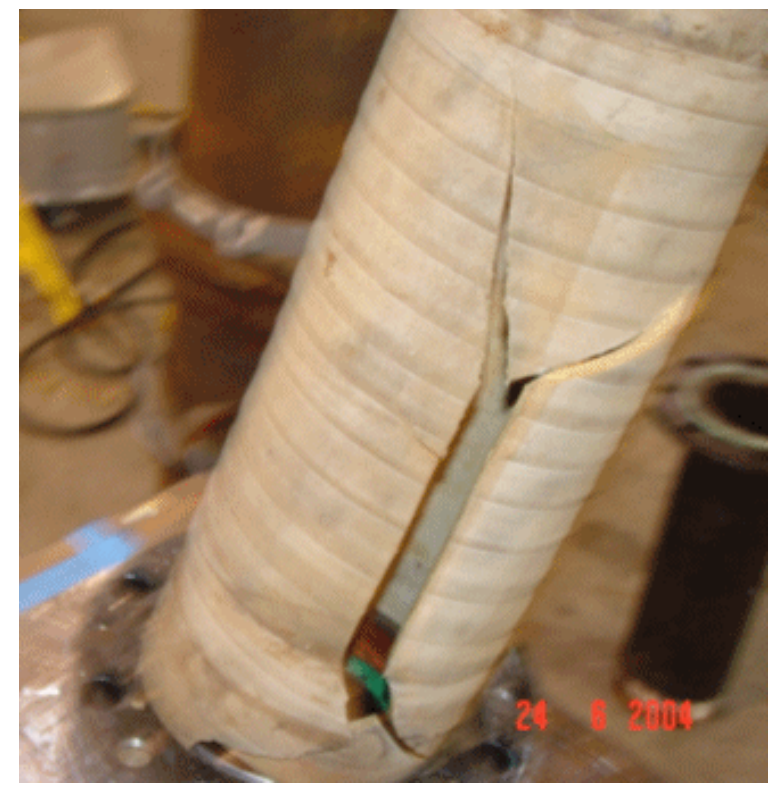

Figure 16. Ruptured Inflation Bladder 
During the twelfth quarter, the team acquired and tested a commercial inflation bladder (Figure 17) from the company that manufactures the patch assemblies. Initial OD of this system is $6 \frac{1}{2}$ inches and total length is 16 inches without any centralization hardware added. The bladder is constructed from heavy fiber-reinforced elastomer bonded to an aluminum tube. The bladder requires gas at 40 psi to fully inflate.

Patch-setting tests were conducted using this off-the-shelf inflator. This included:

1. The ends of a sample cast-iron joint were capped (Figure 18) and the internal pressure raised to $2 \mathrm{psi}$ to check for leaks around the joint. Two small leaks were observed using soap spray in the jute

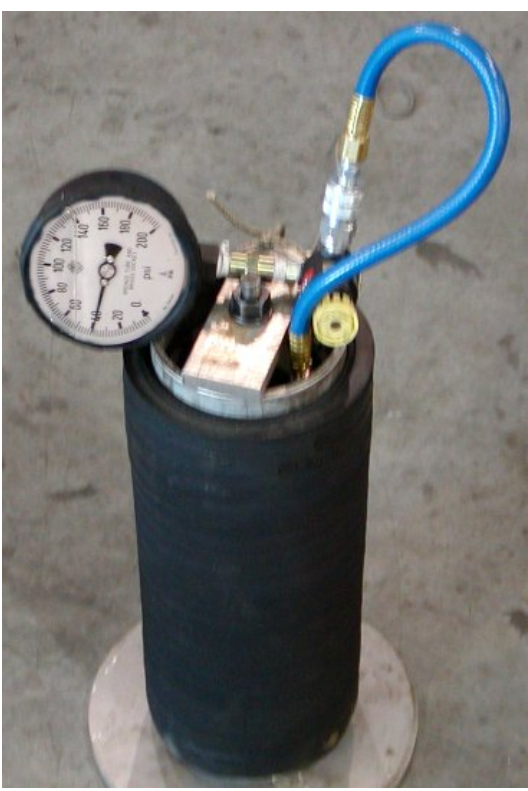

Figure 17. New Inflation Bladder area of the joint. These were marked.

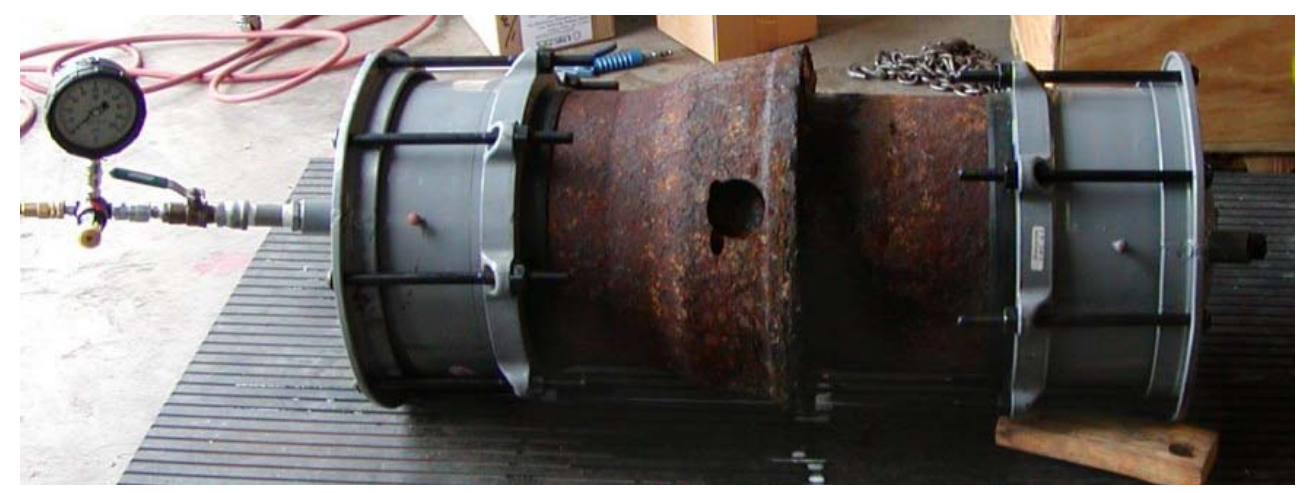

Figure 18. Cast-Iron Joint Tested for Leaks

2. Caps were removed from the test joint and the pipe ID was cleaned across the joint area prior to patching.

3. A new patch and patch-setting bladder assembly were prepared. The patch was placed at the center of the length of the bladder, and was held in place by slightly inflating the bladder to grip the patch.

4. The patch/bladder assembly was inserted into the joint via a special fixture that allowed the patch to hang in the center of the joint (Figure 19). 


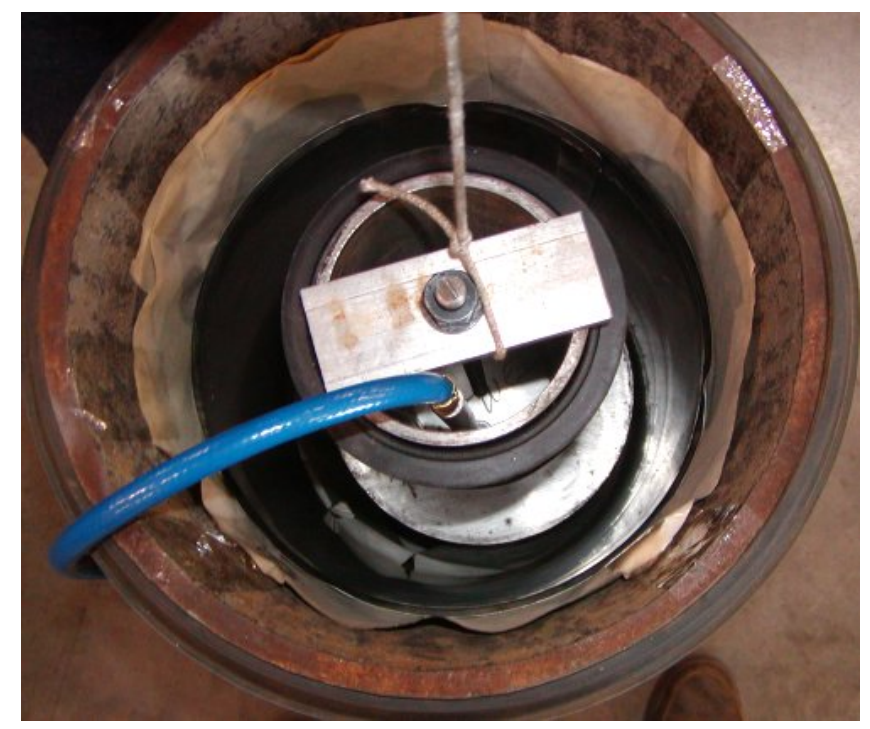

Figure 19. Bladder/Patch Assembly Hung in Joint

5. The bladder was inflated to $40 \mathrm{psi}$ (maximum recommended pressure). It required over 10 minutes to completely inflate.

6. Distinct clicking noises were heard during inflation as the ratchets engaged deeper. After inflation was complete, the bladder was left in place an additional 5 minutes.

7. Pressure was released on the inflator bladder, which was then removed from the cast-iron joint. The end caps were again placed on the joint and the inside volume was pressurized to 2 psi. Locations of previous leaks were inspected and tested with soap spray. No leaks were detected.

After these tests were completed, a careful inspection of the set patch revealed that the two outermost rows of ratchets did not engage as deeply as the two inner rows (Figure 20). It appeared that the inflation bladder needed to be about 2 inches longer on each end to fully engage the patch sleeve ratchets as currently configured.

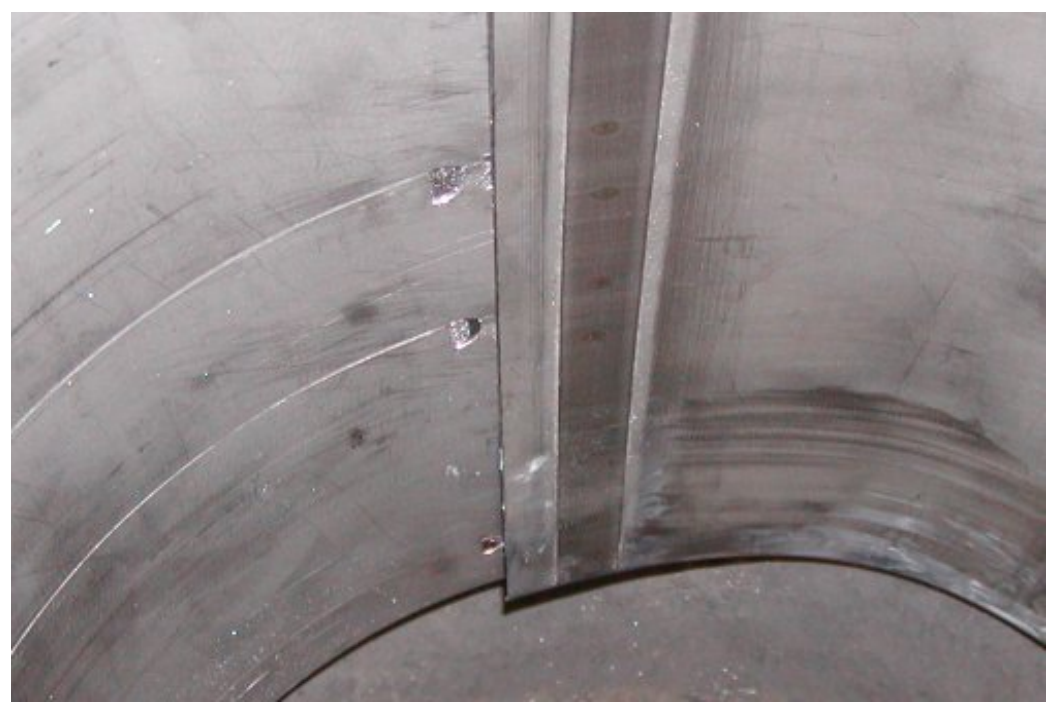

Figure 20. Partial Ratchet Engagement After Patch Setting 
Even though the patch set successfully and all leaks were sealed, it was desired to modify the patch or bladder design to allow deeper ratcheting toward the outer edges of the patch. Since use of a standard bladder design is preferred, changes to bladder design were avoided. Another solution was conceived and pursued. The patch manufacturer was asked to stamp two additional rows of ratchets into the sleeve midway between the existing rows. Several prototype sleeves with this modification (that is, a total of six rows of ratchets) were ordered and tested.

Prior to the full-scale demonstration described under Task 8, the latest generation of sleeves was tested at MTl's shop using the completed inflator, supply, and base robot modules. A sample bell-and-spigot joint (Figure 21) was selected and placed at the end of the test main. The purpose of this test was to verify the improved ratchet engagement of the sleeve as well as to function-test the robots as an assembled unit. This test verified performance of the control circuitry of the base module for full inflation and deflation time requirements, the supply module for charge pressure and volume, and the inflation module for centralization.

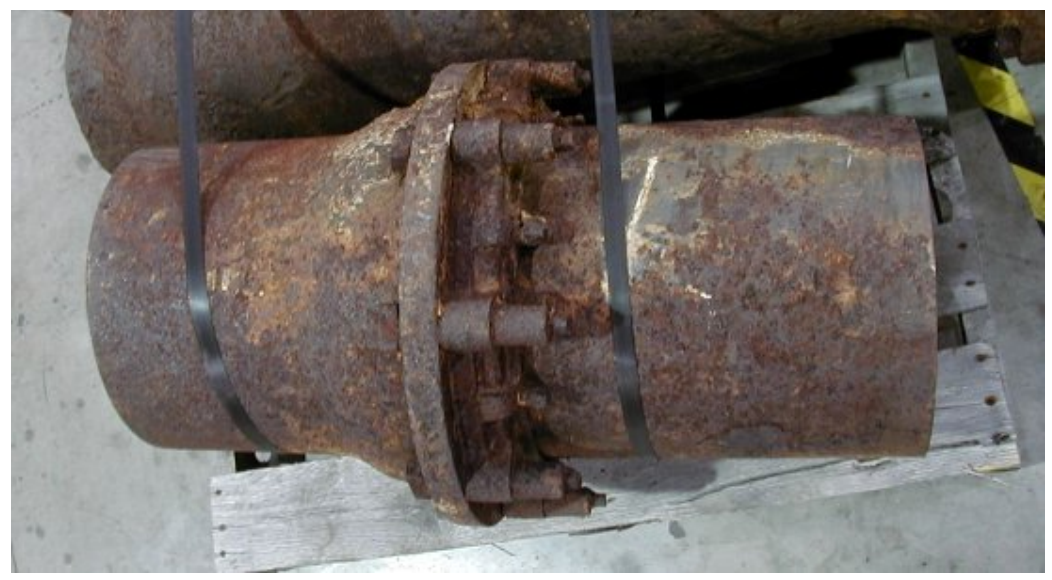

Figure 21. Sample Cast-Iron Joint for Full-Function Tests of Patching Module

The joint was cleaned with the brush module attached to the end of the coiled tubing. A patch was prepared and installed on the patch module. The patch was run into the main and set by the robot train. Test results were very encouraging. The full inflation time was reduced to less than 2 minutes. A second inflation cycle to full setting pressure verified the nitrogen tank was charged to the proper pressure (350 psi) and had sufficient volume to cycle the inflator twice for each patch set. Deflation times where also acceptable (less than 2 minutes). Observation of assembly centralization showed that the centralizer arms needed to be increased in thickness to provide a larger spring constant and more accurately centralize the module. Inspection of the patch after the tests (Figure 22) confirmed that the additional ratchets in the final sleeve design provide a more uniform ratchet engagement along the length of the patch seam. 


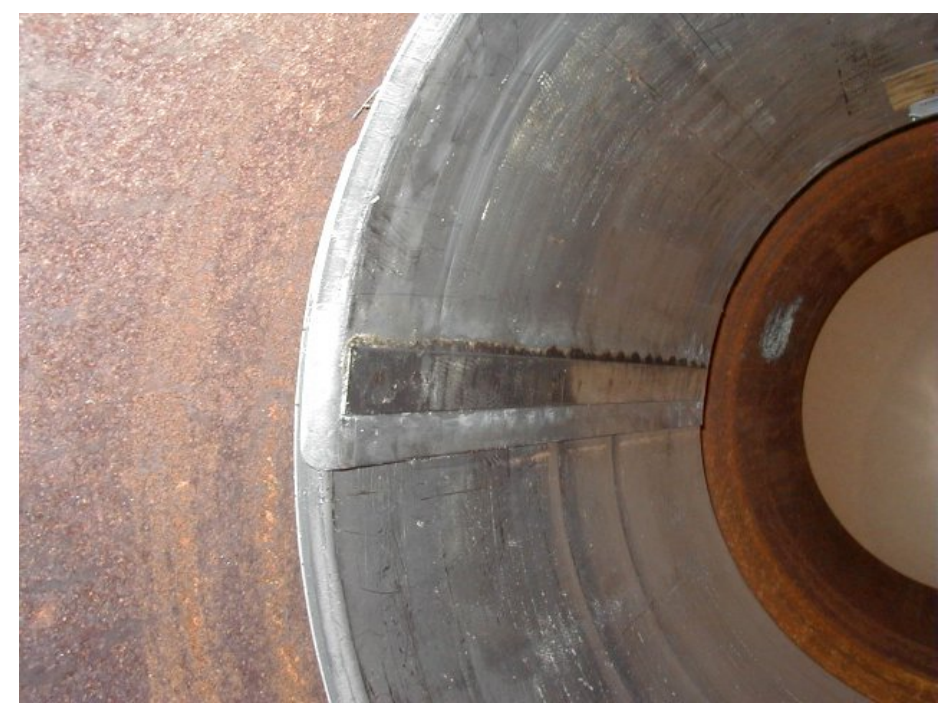

Figure 22. Final Patch Design Set in Test Joint

These full-scale validation tests of the complete system were conducted and are described in detail under Task 8.

\section{Task 5 - Design and Fabricate Pipe Wall Cleaning Robot Train with PZT Camera}

Cast-iron gas mains are operated at much lower pressure than their steel counterparts; consequently, their interior conditions are often very different. Lower pressures in cast-iron mains allow moisture and debris to seep in through leak points if sufficient hydrostatic head (from the local water table) is present outside of the main. In addition, the interior of cast iron is generally not as smooth as steel, due to corrosion and surface roughness from the original manufacturing process. Other complications arise from deposits of tar residue on the bottom of the main, the source of which dates back to when mains carried "manufactured" gas. Molecularly heavier tars and other impurities settled out on the bottom of the mains and then combined with particulate matter to form a hard crust. Since this crust is porous, it must be removed prior to applying a patch repair sleeve. In addition, the pipe ID must be clean and smooth to ensure that the epoxy adheres properly to the wall. To address these challenges, the following subtasks were addressed:

5.1 Analyze Deposits and Scales. Expected deposits in typical cast-iron mains will be investigated and the most effective way(s) to remove them defined.

5.2 Design Equipment to Identify Deposit Types via Camera. The team will design/select camera and

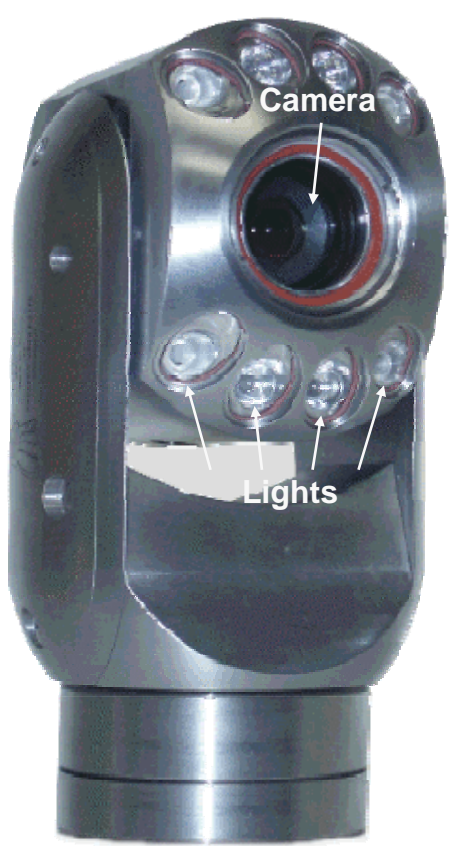

Figure 23. PZT Camera lighting systems to provide sufficient performance to make positive identification and then select appropriate means to prepare the surface. 
5.3 Design and Test Cleaning/Brushing Equipment. Equipment will be designed to remove scales and deposits found inside cast-iron pipe. Laboratory and field tests will be conducted on line pipe to ensure that appropriate cleaning is performed by the system.

Deliverables for this task will be the Prototype Pipe Wall Cleaning Robot Train with pan/zoom/tilt (PZT) camera along with its corresponding electrical/electronics schematics and mechanical drawings.

\section{Inspection System}

Analysis of commercial PZT cameras was completed in the second quarter and a preferred design selected. The inspection camera (Figure 23) measures 4 inches OD $\times 10.5$ inches overall length. It features $270^{\circ}$ of tilt, $340^{\circ}$ of pan and a $72: 1$ zoom ratio. Its eight highintensity argon lights were found to provide excellent illumination in tests conducted inside sealed 12- and 24-inch pipes. Specifications are summarized in Figure 24.

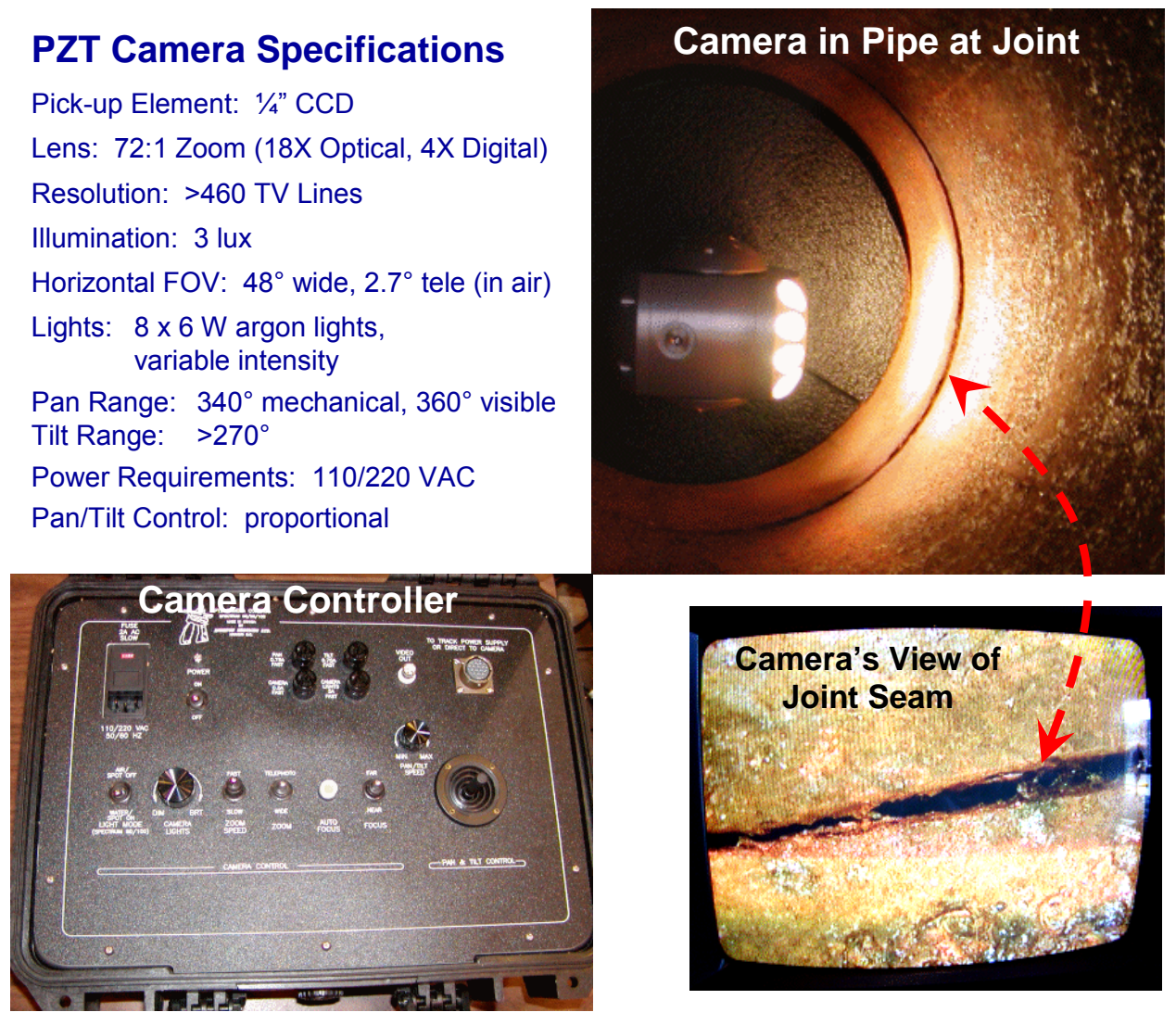

Figure 24. PZT Camera Specifications

A 16-conductor wire bundle is used in normal operations when the camera tether is 100 feet or less. However, using a 16-conductor bundle becomes inefficient inside $1000 \mathrm{ft}$ of smalldiameter CT. A preferred approach is to power and operate the camera using fewer (seven) wires. Two of these will be large-diameter twisted pair to supply high-voltage DC, four smaller wires to transmit digital control signals, and one to transmit video images. This change required development of a microcontroller-operated switching power supply inside the robot base module 
and a data-acquisition system at the surface to convert the analog proportional joystick controls for pan, zoom, tilt, light intensity, etc. to digital signals.

The robotic system's PZT camera control electronics and operating software were developed and implemented in both the surface and downhole modules. Camera surface hardware consists of a 95-VDC power supply capable of sourcing up to $2.1 \mathrm{Amps}$ for operating camera illumination lenses and physical orientation within the pressurized gas main; a personal computer having an RS-485 bidirectional communications port; a 15-inch color monitor for displaying camera images; and a rack-mounted video cassette recorder. Downhole hardware consists of the camera head and the camera control electronics. The latter are housed inside the base module that is common to all robotic trains.

DC power is supplied to the downhole camera control electronics over an 18-gage twisted pair. Use of a single high-voltage power source at the surface was chosen over individually supplying all of the regulated voltages needed to operate the camera for two important reasons: (1) it is a highly efficient means of transferring electrical power down the long cables inside the steel CT and (2) it minimizes the total number of conductors required for the umbilical (only seven required, as mentioned above).

Table 2 summarizes key attributes of the surface DC power supply and two of the downhole DC/DC voltage conversions. Camera controls are displayed and operated using a software applications program written inside the LabVIEW environment. The program allows users to control the following functions through a point and click format:

- Camera Power (On/Off)

- Camera Illumination (Lights On/Off, Lights Dim/Bright)

- Camera Pan (0-340 )

- Camera Tilt $\left(0-270^{\circ}\right)$

- Camera Zoom (18X optical; 4X digital)

- Camera focus

The LabVIEW platform features excellent visual appeal
Table 2. Surface Power Supply for Camera

\begin{tabular}{|c|c|c|}
\hline \multicolumn{3}{|c|}{ Manufacturer - Vicor } \\
\hline $95 \mathrm{~V}$ & $2.1 \mathrm{~A}$ & $200 \mathrm{~W}$ \\
\hline $12 \mathrm{~V}$ & $4.2 \mathrm{~A}$ & $50 \mathrm{~W}$ \\
\hline $7.5 \mathrm{~V}$ & $6.7 \mathrm{~A}$ & $50 \mathrm{~W}$ \\
\hline
\end{tabular}

through its virtual instrument displays, can be easily reconfigured and expanded to add new control capability as each new robot module is brought on line, and has excellent digital and analog support libraries. The user-selected commands are digitized and then communicated to the downhole camera control electronics via the RS-485 communication link. The RS-485 design and protocols were selected on the basis of their ease of implementation, low cost, and demonstrated ability to support reliable communication over conductors up to $4000 \mathrm{ft}$ in length, well in excess of the 1000-ft span required for this effort. A 20-MHz PIC micro-controller receives the RS-485 messages and actuates the commands accordingly.

The physical printed circuit board produced (Figure 25) is a four-layer board made of FR4 material, measures 3 inches wide $\times 10$ inches long, and is housed inside the robotics base module. Worthy of note are the large heat sinks for the DC-to-DC power converters used to take the single DC voltage supplied from the surface and generate $+24 \mathrm{~V},+12 \mathrm{~V}$ and $+5 \mathrm{VDC}$ regulated power for the various camera functions. 


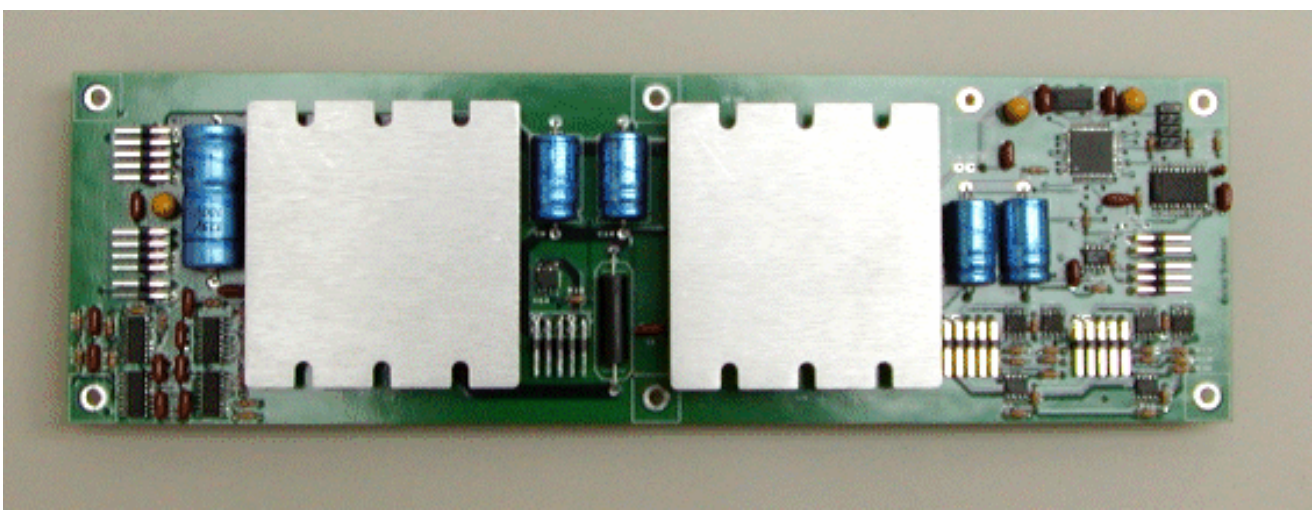

Figure 25. Downhole Camera Control Circuit Board

The PIC controller (PIC16F877) is a 20-MHz CMOS FLASH-based 8-bit micro-controller. It features 256 bytes of EEPROM data memory, self-programming, an ICD, eight channels of 10-bit analog-to-digital (A/D) converter, two additional timers, and two capture/compare/PWM functions. The synchronous serial port can be configured as either three-wire Serial Peripheral Interface $\left(\mathrm{SPI} \mathrm{I}^{\mathrm{TM}}\right)$ or the two-wire Inter-Integrated Circuit $\left(\mathrm{I}^{2} \mathrm{C}^{\mathrm{TM}}\right)$ bus and a universal synchronous/asynchronous receiver/transmitter (USART). This controller is designed for more advanced $A / D$ applications in automotive, industrial, appliances and consumer applications.

Camera control software and the display were finalized. Figure 26 shows the camera display/control functions as presented on a laptop computer.

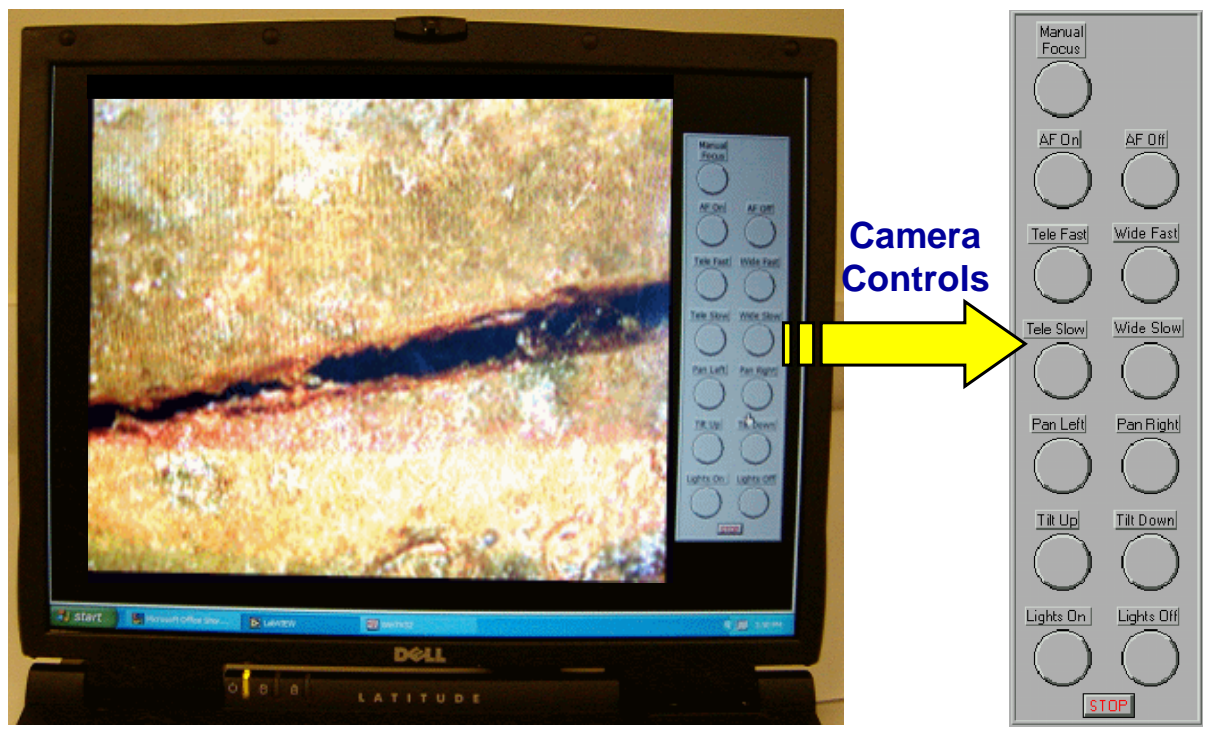

Figure 26. Camera Display and Control Software

\section{Pipe Wall Cleaning Assembly}

A four-arm assembly for cleaning the pipe wall prior to installing the repair sleeve was developed and improved early in the effort. It was suitable for removing a wide range of debris including very hard deposits. It had a collapsed diameter of 6.4 inches and could open up to 13 inches under centripetal action. 
The arm assembly was designed to be packaged as a complete robotic element. This included both design and fabrication of the drive motor, motor controller electronics, cleaning head housing and collapsible arm (Figure 27). The completed robot assembly was tested by cleaning several 12-inch cast-iron bell-and-spigot joints (Figure 28). Tests showed the design to be very effective. The most efficient cleaning occurs at rotary speeds of $300 \mathrm{rpm}$ with forward and backward translation across the joint at speeds of 4 inches per minute. This corresponds to a total of approximately 5 minutes per joint.

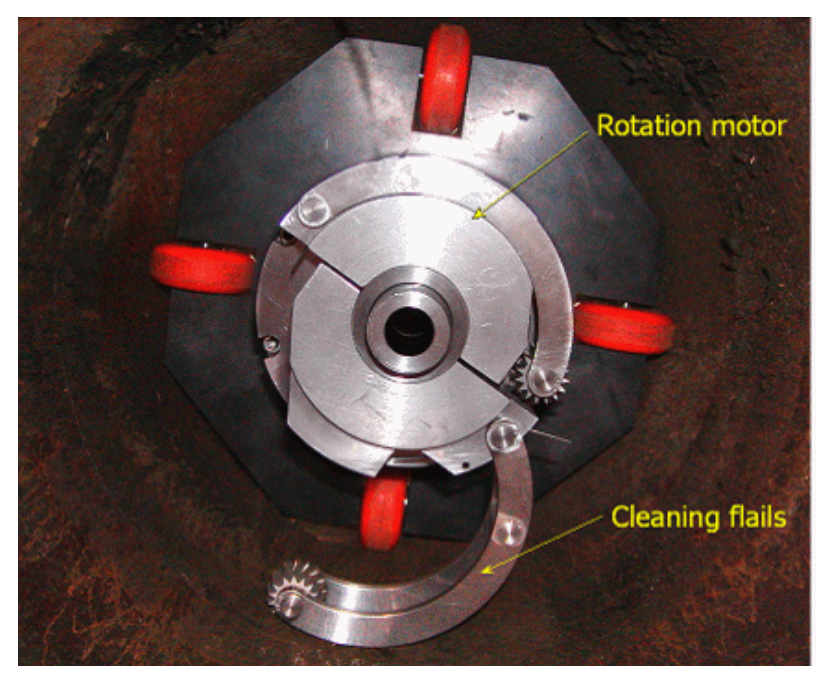

Figure 27. Pipe Wall Cleaning Assembly

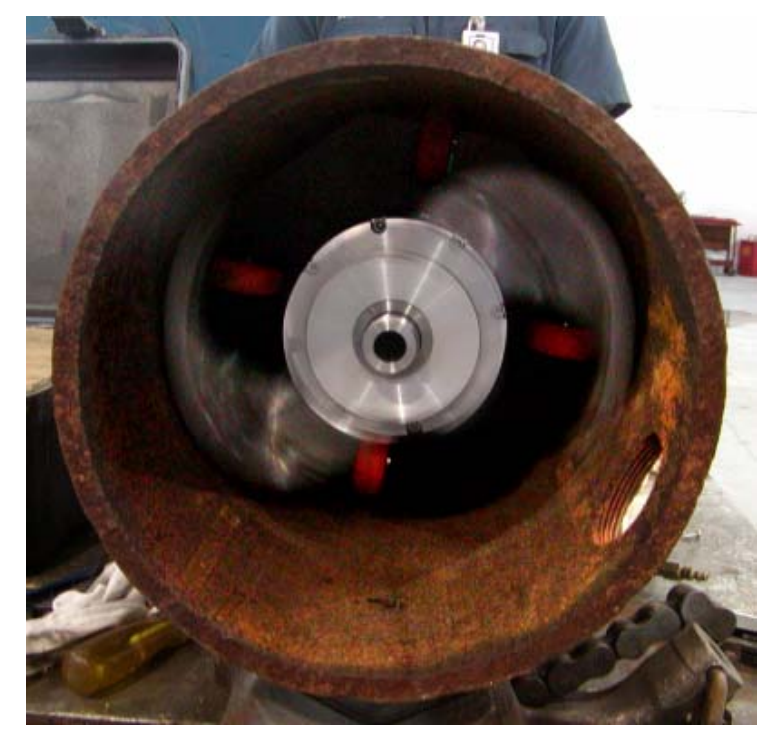

Figure 28. Pipe Wall Cleaning Test

For the final design of the cleaning assembly (Figure 29), the module shown above was shortened and the steel housings were replaced with aluminum to reduce weight. The initial test module used fixed centralizers, while the final system incorporates collapsible centralizers. (Note that the centralizers are removed in Figure 29.) Power is supplied to the motors from an on-board power supply located in the base module. 


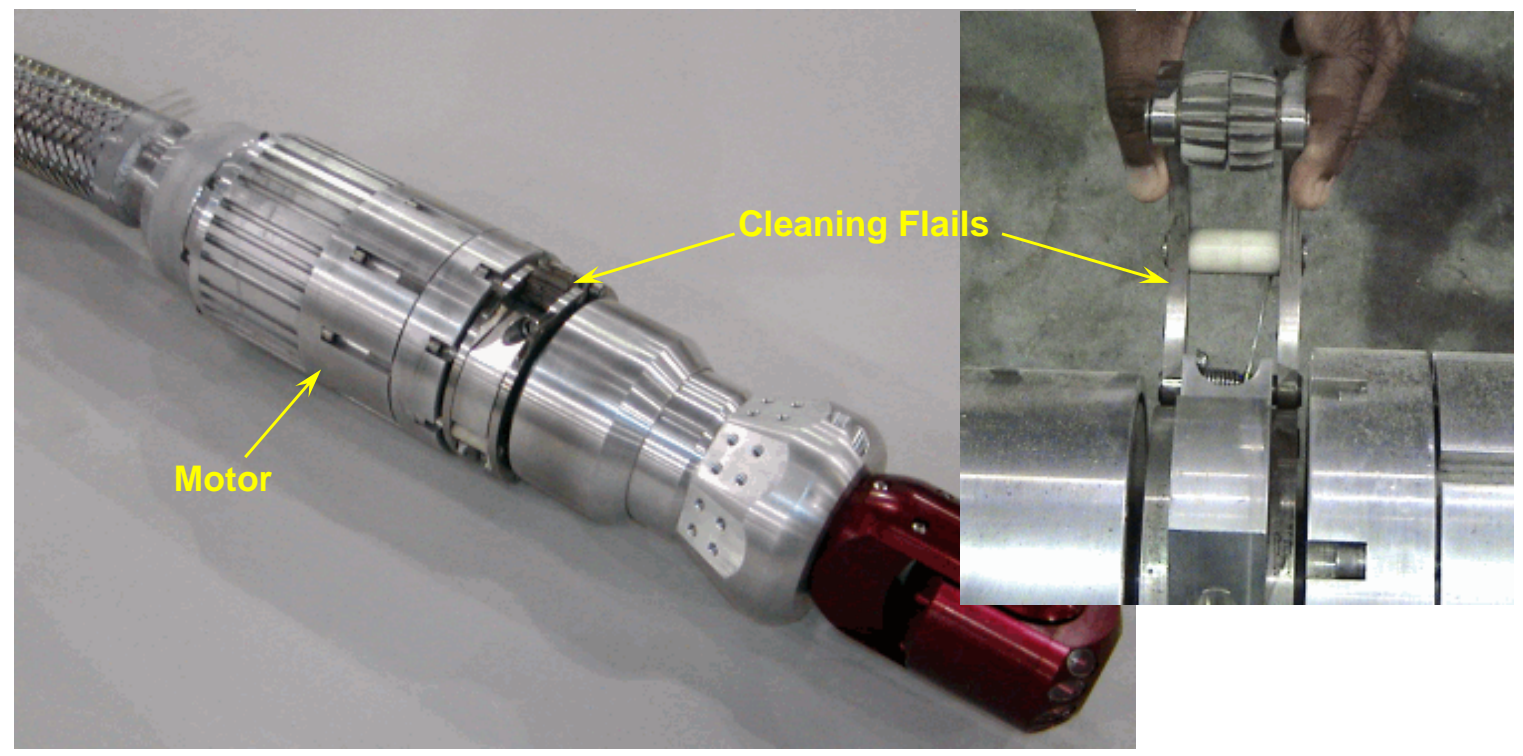

Figure 29. Final Design of Cleaning Module

\section{Field Tests of Small Robotic System}

In August 2004, the small-diameter pipe repair robot was field tested for inspecting and repairing 4-inch cast iron bell-and-spigot joints. Because much of the small system's design and performance closely tracks that used in the large-diameter system described herein, these field tests provided valuable experience and insight for design improvements for the large-diameter cast iron pipe repair system.

Several important recommendations were developed based on these field tests. (These are summarized under "Lessons Learned/Recommendations for Large-Diameter System" under Task 9 below.) The following recommendations regarding cleaning, debris collection and debris removal were suggested for the large-diameter repair system.

1. Cleaning flails were very effective. (No change is recommended for large system.)

2. Brush module should be added to move debris away from area surrounding the joint.

3. A magnetic coupon catcher might be added to remove existing coupons created by service tee connections. In the large system, this catcher might mount to the camera and employ the tilt function to capture the coupon.

After these field tests, four designs were developed for improving debris removal for the large-diameter system. Magnetic assemblies were considered to be practical for removing coupons and other large debris. Dirt is another significant challenge in low-pressure mains that have been invaded by ground water. Options were considered for sweeping debris from the joint area. It is currently planned to attach a sweeper arm to the camera that can push debris forward past the joint. The design to be implemented into the system is described below. 


\section{Sweeper Arm Mounted to Camera}

Both ferromagnetic and non-magnetic debris will need to be collected and/or removed from the joint area. It will likely be sufficient to sweep (or plow) the debris forward so that the area surrounding the pipe joint is clean prior to running a patch. The most straightforward approach is to attach a sweeper arm to the camera assembly (Figure 30). This provides the capability to position the brush anywhere on the circumference of the pipe.

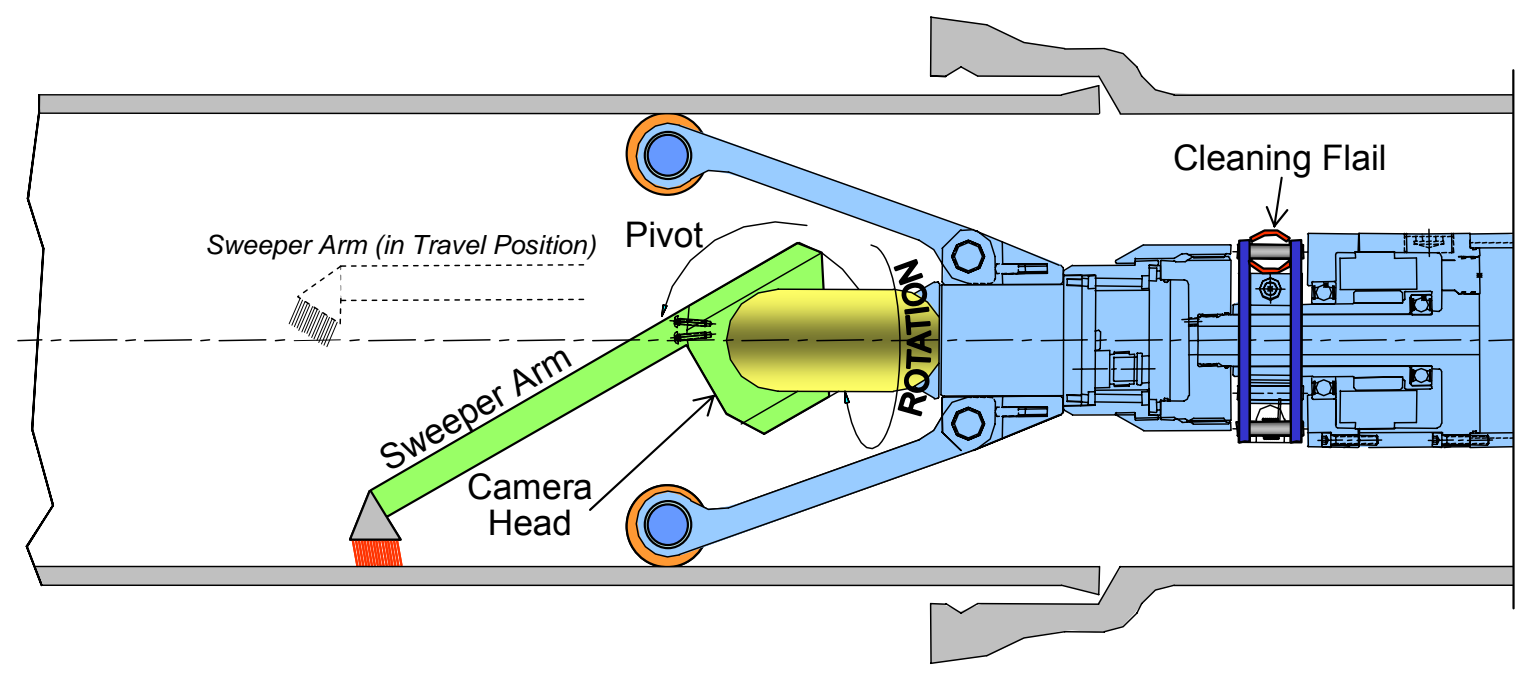

Figure 30. Camera-Mounted Sweeper Arm

Sweeper brushes would be designed specially for each pipe ID to fit the radial curvature of the pipe wall. Width of the brush (how many degrees of pipe wall covered by each stroke) will need to be determined based on weight capacity of the camera. Several passes may be required to sweep the area adjacent to a joint, with camera head rotation providing brush positioning as needed.

An advantage of a camera-mounted debris arm is that the cleaning operation is necessarily directly in the camera's view. This allows the operator to effectively monitor and control the cleanup of debris, and to know for certain when coupons and other large obstacles have been moved or captured.

The disadvantage of this approach is that the camera head needs to be modified. Another potential disadvantage is that the debris arm will be directly in front of the camera at all times and block part of the field of view. However, since the camera can be rotated on its axis to view the entire ID of the main, this loss of viewing field can be compensated for.

\section{Cleaning Module Motor Heat Tests}

The motors that power the cleaning flails were tested for any problems with heat build-up during extended (continuous) operation downhole. The system was run in a simulated cleaning operation inside a section of cast-iron main. Temperatures of both motors were monitored during a 30-minute test. Results (Figure 31) showed that heat build-up reached a maximum value after about 20 minutes and will not be hot enough to damage any downhole components during extended system operation. 


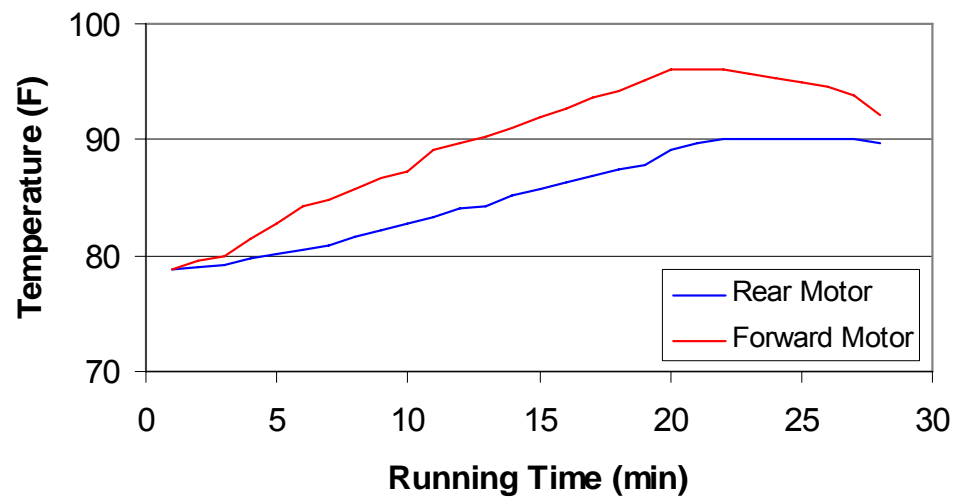

Figure 31. Cleaning Module Motor Heat Tests

\section{Task 6 - Design and Build Surface Control and Monitoring System}

Surface control and monitoring electronics are being designed to operate inside the LabVIEW platform operated on a high-end laptop computer. The team completed the control software and visual display for the PZT camera and control software for operating the pipe wall cleaning head. Work continued with development of control software for setting the patch inside the pipe. Final packaging will be consistent with construction field-ready practices. Deliverables for this task are the prototype surface control and monitoring system.

Near the end of the effort, the final control module was fabricated and installed in fieldready packaging. The controller assembly (Figure 32 and Figure 33) was designed with two power supplies. These are configured in parallel and will provide more than sufficient current to power the camera and other downhole motor assemblies. The module was tested with the CT surface equipment in the laboratory (including running power and signals through $1000 \mathrm{ft}$ of CT on the spool) to confirm correct function and that power supplies will not overheat in normal system operation. System requirements for electrical current and operating temperatures were well within the safe range for these components.

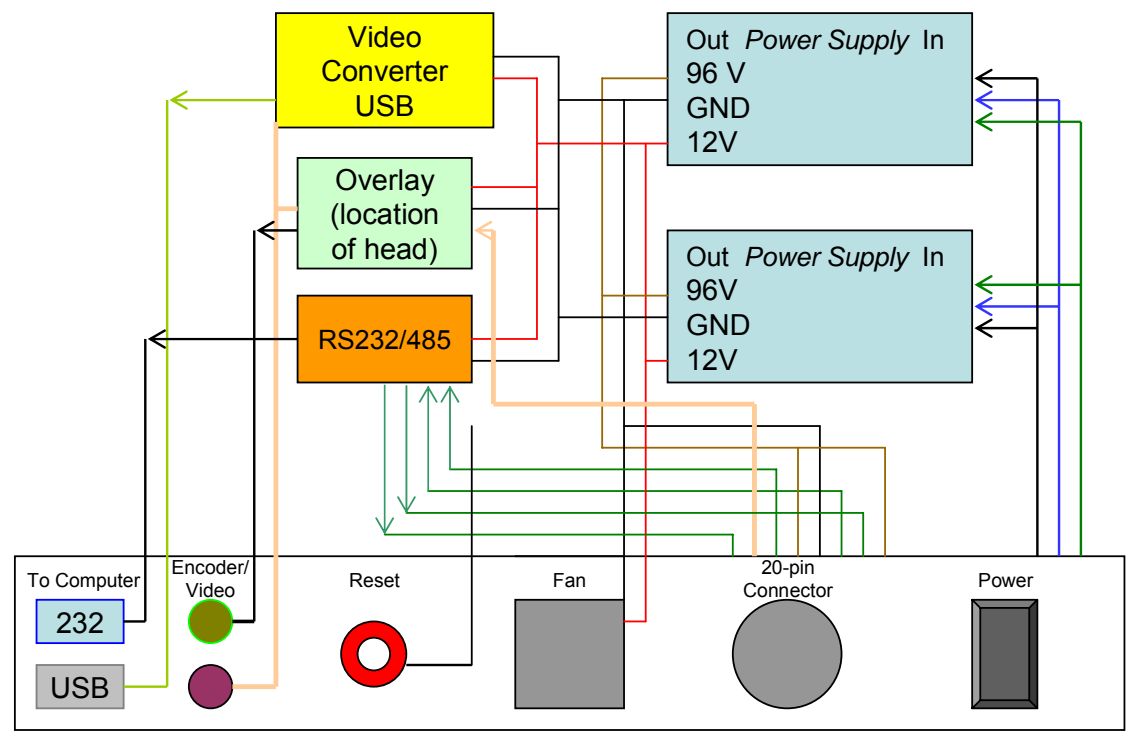

Figure 32. Schematic of Surface Control Module 


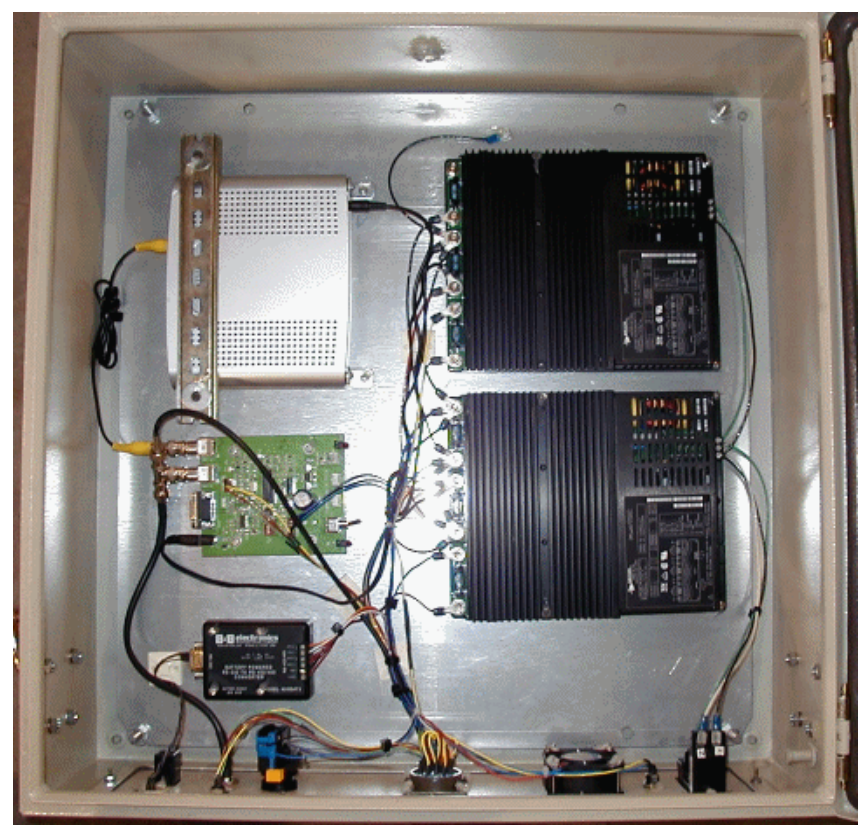

Figure 33. Surface Control Module Components

The control module was completed (Figure 34) and fully tested in the shop tests conducted late in the project. Control software is based on LabVIEW and was programmed and tested for controlling (1) the camera, (2) brushing operation and (3) patch inflation system. LabVIEW RS232 commands are converted to RS485 to transmit the command over the $1100 \mathrm{ft}$ conductor bundle to the base module. The composite video signal from the module has distance encoder information overlaid onto it in the control module. It is then converted to digital video for capture and display on the laptop computer.
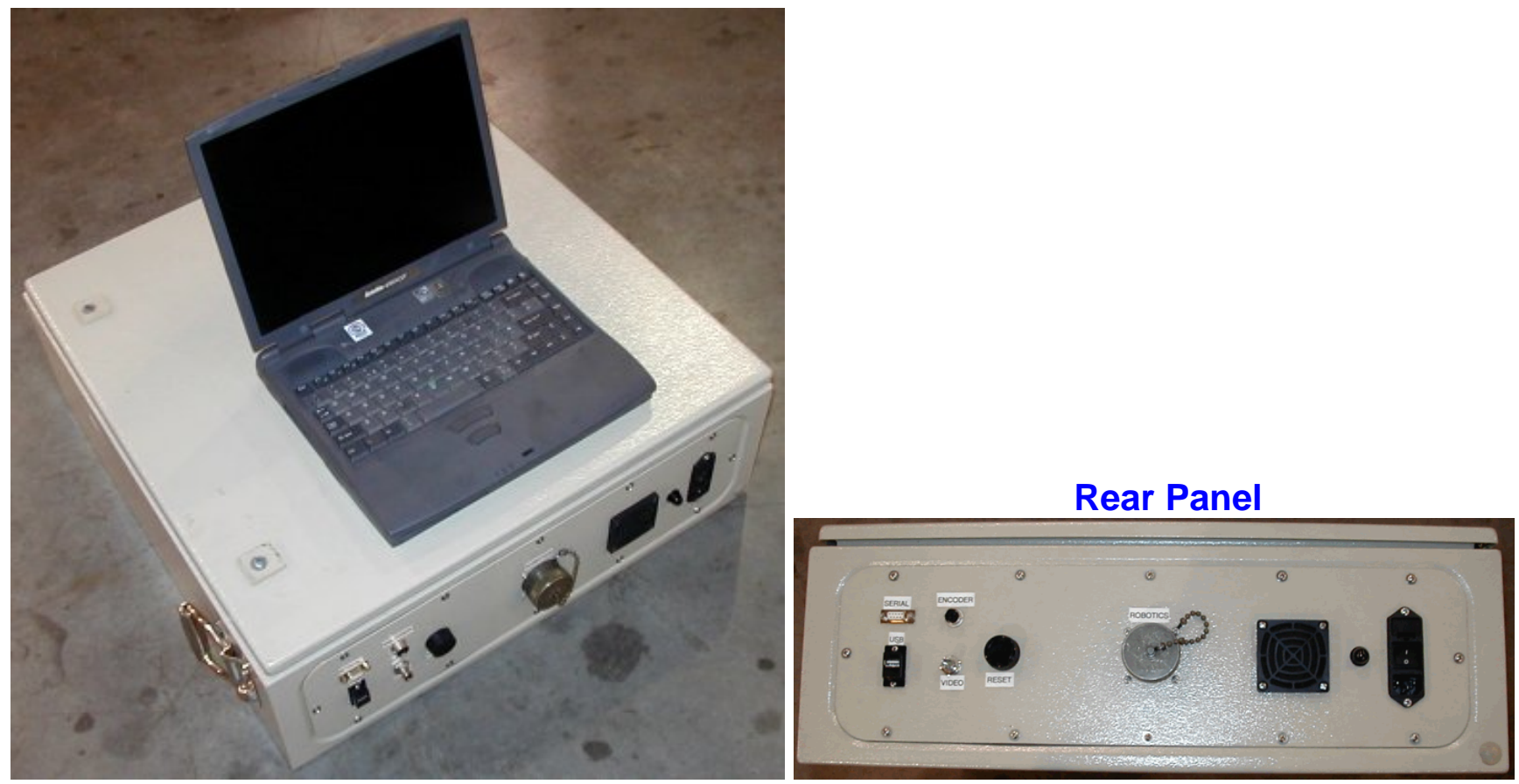

Figure 34. Control Module and Computer 


\section{Task 7 - Design and Fabricate Large-Diameter Live Access System}

Since the entry fitting system for cast-iron pipe cannot be welded directly onto the castiron pipe body (as is possible with steel pipelines), some other means of attachment must be used. One choice is to weld the longitudinal seams of the split entry fitting to itself and then to provide an end seal against axial movement and a circumferential face seal by end-bolting two end pieces. A second approach (adopted in the final design) is to bolt the two halves together along the longitudinal length. The entry fitting will enable a port to be cut into the main for inserting all joint-patching equipment. The entry fitting must provide sealing for conducting repair operations, as well as maintain a safe seal over the life of the pipeline since the entry fitting will not be removed from the main. Subtasks include:

7.1 Perform Stress Analysis. A certain portion of the main's cross section will need to be removed for access. The entry-fitting system must possess mechanical properties that ensure that basic mechanical integrity of the main/joint is not compromised. The design must take into account bending/flexure loading, settling, reactive forces, and other environmental factors.

7.2 Design Seal that will be maintained Under Loaded Conditions. The fitting and seal design must be robust to accommodate any flexural loading conditions. Seals must remain "energized" at all times during entry and inspection when the main is exposed.

7.3 Perform Sealing Analysis. The appropriate material must be selected to meet temperature, environmental, and lifetime requirements. An effective seal must be maintained in the event of settling and varying ground conditions.

MTI and GTI previously met with a leading fitting manufacturer. Numerous designs were subjected to an in-depth review with both the manufacturer and with several utilities who operate significant lengths of large-diameter cast-iron pipes. These efforts produced a recommended design that satisfies standards in place at each of the utilities interviewed.

Early in the project, the access fitting was produced in a 4-inch prototype size to validate the design prior to embarking on the fabrication and testing of a 12-inch version (which is considerably more expensive). Sealing tests at pressures up 100 psig were successfully conducted along with preliminary hole-cutting tests. Figure 35 illustrates its key components.

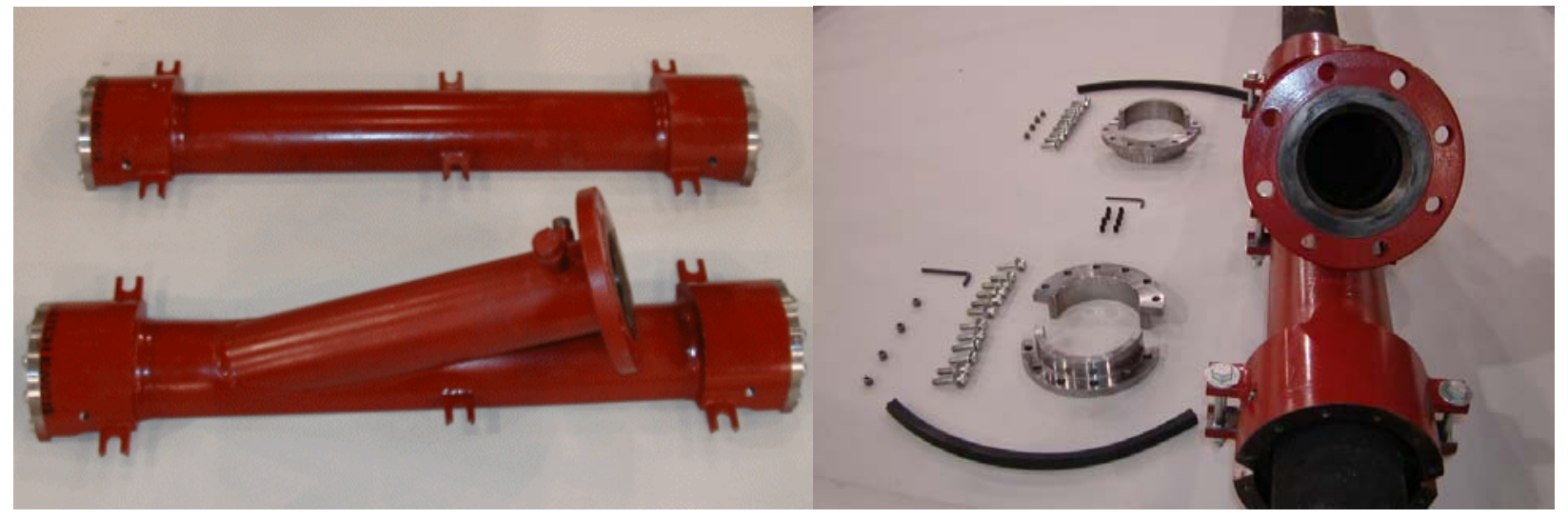

Figure 35. Cast-Iron Entry Fitting (4-inch Prototype) 
Later, a detailed design for a 12-inch bolt-on fitting was completed and the design was manufactured. Two special assemblies were also designed for procedures required before and after inspecting the pipe and running patches. The assembly to drill the access hole through the side of the main was designed and fabricated, as well as that for setting a bridge plug within the fitting to allow removal of equipment and the gate valve prior to setting a blind flange to permanently reseal the main. These assemblies are described below.

\section{Large-Diameter Bolt-On Fitting}

The large bolt-on fitting (Figure 36) is designed for 12-inch cast-iron pipe with a wall thickness of 0.5 inches. Actual OD of the pipe is 13.20 inches. The fitting consists of an upper and lower half and two split end flanges. End seals are skive cut to allow them to be placed around the main. The seam seals are strip material cut to length and trapped in place with a machined shoulder along the length of the seam. The end rings of both upper and lower halves are equipped with lifting eye ports and lock screw ports to allow centralization onto the main and to provide resistance to axial and rotational movement relative to the main.

Prior to the fitting being placed onto the main, a core catcher is welded to the main at about the center of the excavation length. A tool is used which pilots over the core catcher and within the riser pipe of the upper half of the fitting to align the fitting with the core catcher. Strip seals are glued into the seam gland slot of the lower half of the fitting and trimmed flush with the end ring pilot bore shoulder. Cap screws secure the mating halves on each end. Other cap screws are mounted in tabs along the seam length. Lock screws are used at each end on the fitting to centralize the fitting over the main before final torque is applied along the seam to seat the seal. Skive-cut end seals are placed around the main and into a counter-bore provided on each end of the fitting. Split end rings are placed over the main and cap screws are used to secure them to the fitting. Final torque is applied to seat the seal.

Unlike the smaller bolt-on fitting, no welding is required for larger gas mains, due to low operating gas pressures (<2 psi). 


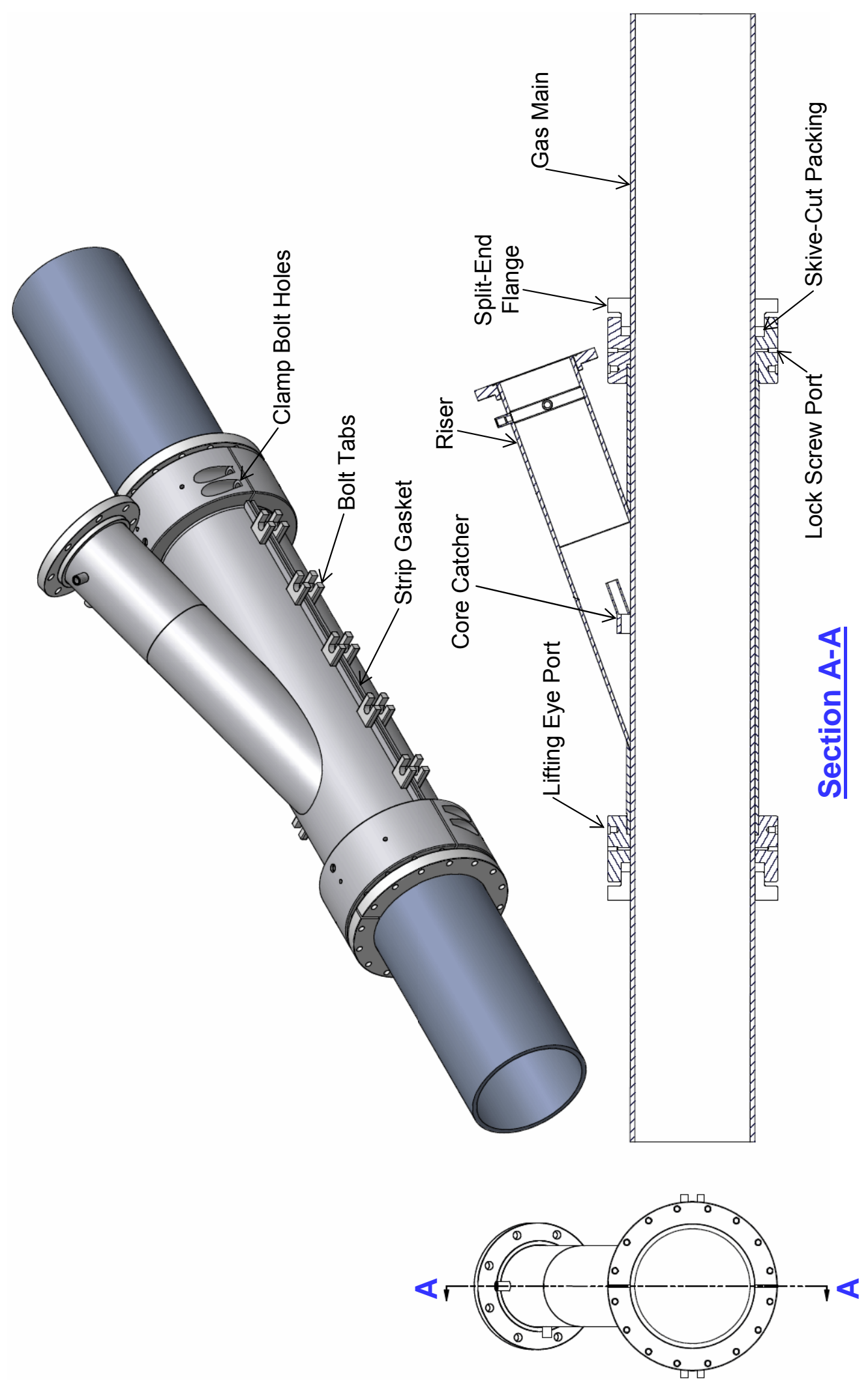

Figure 36. Bolt-On Fitting for Live Access into 12-in. Cast-Iron Mains 


\section{Shop Tests of Live Access System}

The bolt-on access fitting was assembled on a joint of ductile-iron main and mock-up tests conducted with the drilling assembly and plug-setting assembly. Initial fitting tests showed that various adjustments to the internal dimensions were needed to increase tolerances to allow smooth passage of components through the fitting. The fitting was then returned to the machine shop, modified as required and then reassembled in MTI's shop.

As stated, initial assembly of the fitting includes correct positioning and attachment of the coupon catcher onto the main (Figure 37). After correct alignment, the coupon catcher is welded onto the main and the upper half of the fitting is lowered into position (Figure 38).

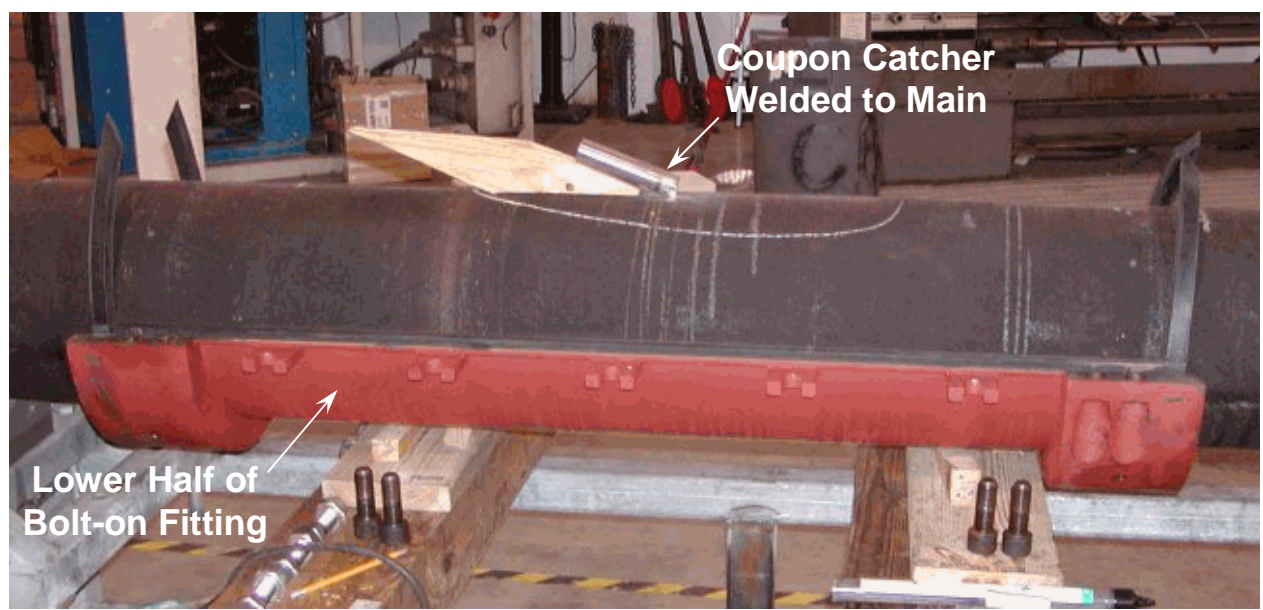

Figure 37. Initial Assembly of Large-Diameter Bolt-On Fitting

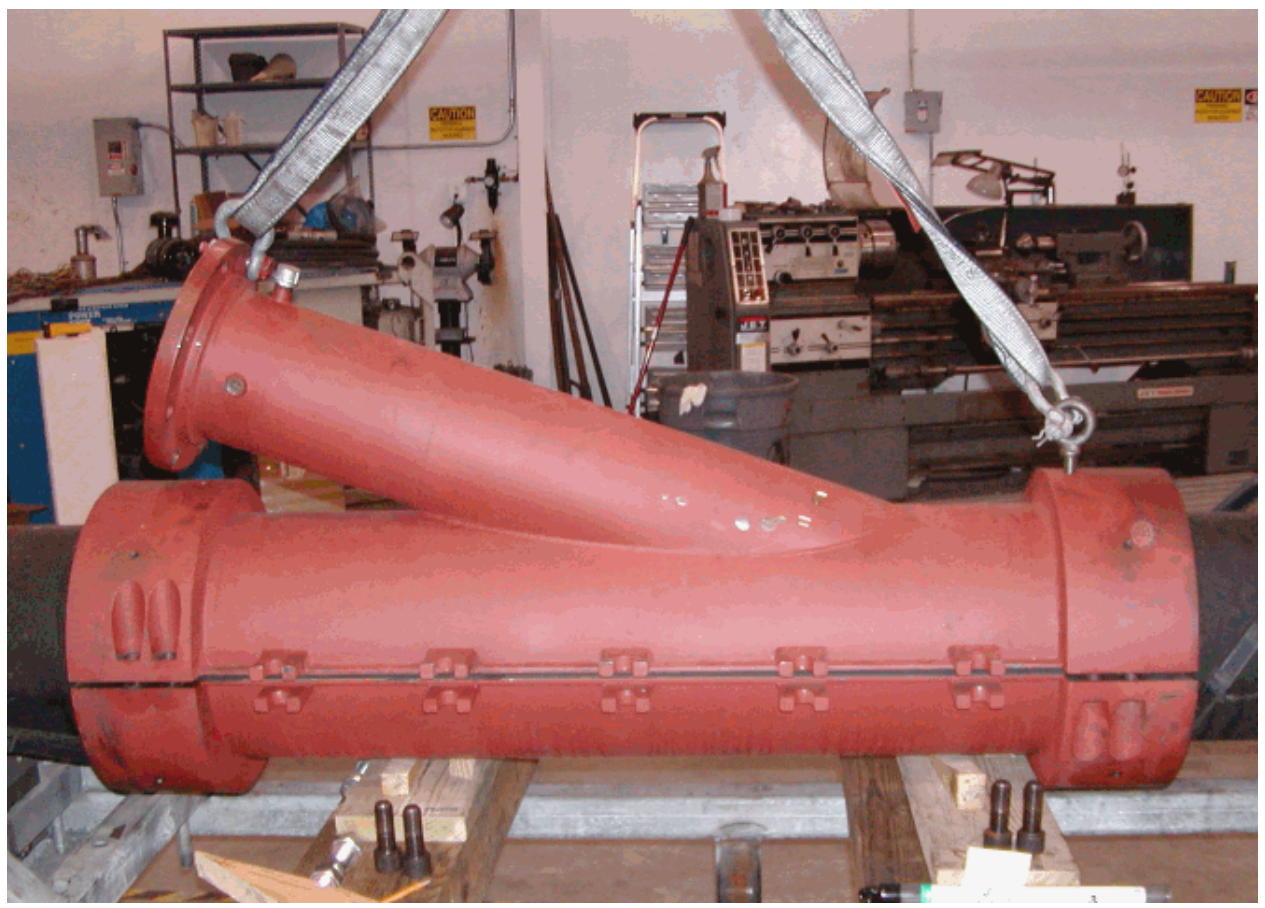

Figure 38. Bolt-On Fitting Lowered into Position 
The fitting is shown after being completely made up to the pipe in Figure 39 . The assembly was pressure tested successfully to 5 psi.

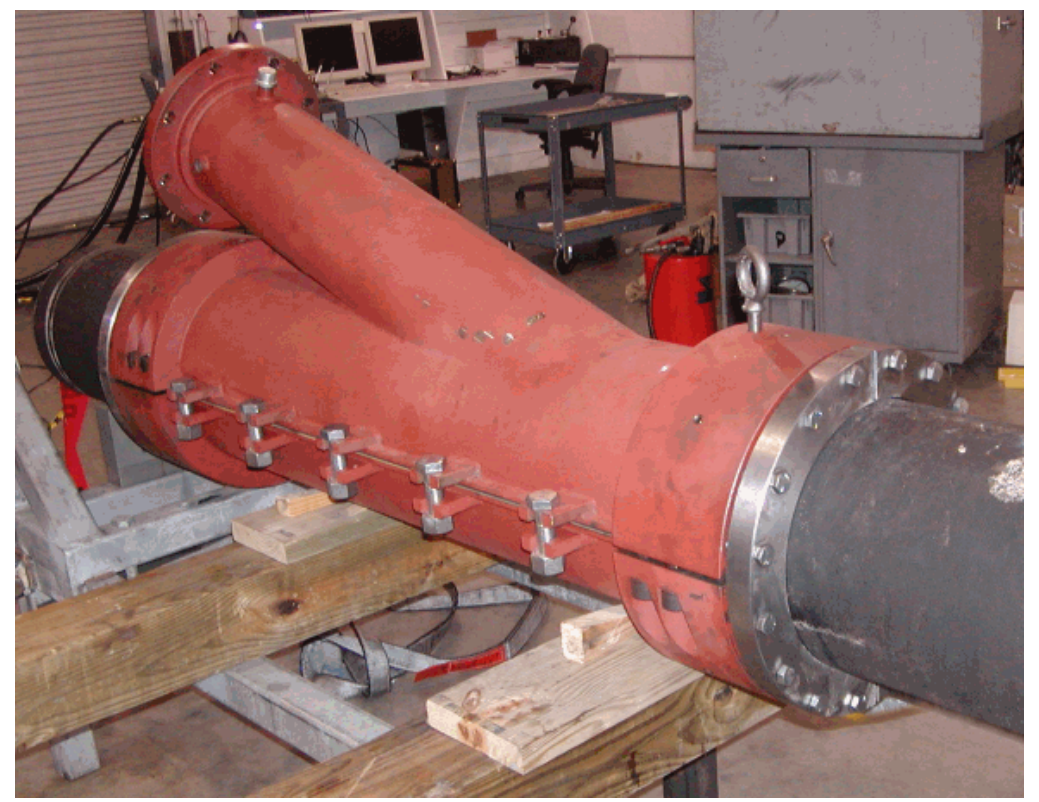

Figure 39. Large-Diameter Bolt-On Fitting Installed

Mock-up tests in MTI's shop showed that the large-diameter bolt-on fitting and the subassemblies were ready for full-scale patch setting tests in the shop. These were conducted late in the project and are described under Task 8.

\section{Large-Diameter Drilling Assembly}

After the bolt-on fitting is attached to the main and pressure tested, a control valve is attached to the flange provided on the end of the riser. The valve is used to control gas flow as the drilling assembly is removed after the entry hole is cut and as robot components are launched and retrieved from the main. A cutter shroud is attached to the top of the control valve. The shroud is used to house the cutter after the entry hole is cut and provides a gas seal until the control valve is closed. This shroud remains attached after the drilling assembly is removed and is used for launching and retrieving operations.

The drilling assembly (Figure 40) consists of a cutter attached to a drive shaft which is attached to a drive motor. The motor is mounted to an adaptor which is threaded into the jack screw translation shaft. A jack screw sleeve is mounted between the motor adaptor and the translation shaft. As the jack screw sleeve is threaded into the shroud end cap, thrust force is applied to the translation sleeve which forces the cutter toward the gas main. Rotational reaction forces are carried through a hexagon drive provided on the extension portion of the jack screw stationary shaft and the end of the bore of the translation shaft. The stationary shaft is locked to the cutter shroud with a sealed lock pin which is removed when the cutter is retracted back into the shroud after the entry hole is cut.

A cutter centralizer guides the cutter through the riser inside bore as it moves toward the main. A wire spear mounted on the end of the drive shaft engages the core catcher as the cutter 
is advanced. Once it is engaged and the entry hole is cut, the spear retains the coupon within the cutter as the drilling assembly is retracted into the cutter shroud.

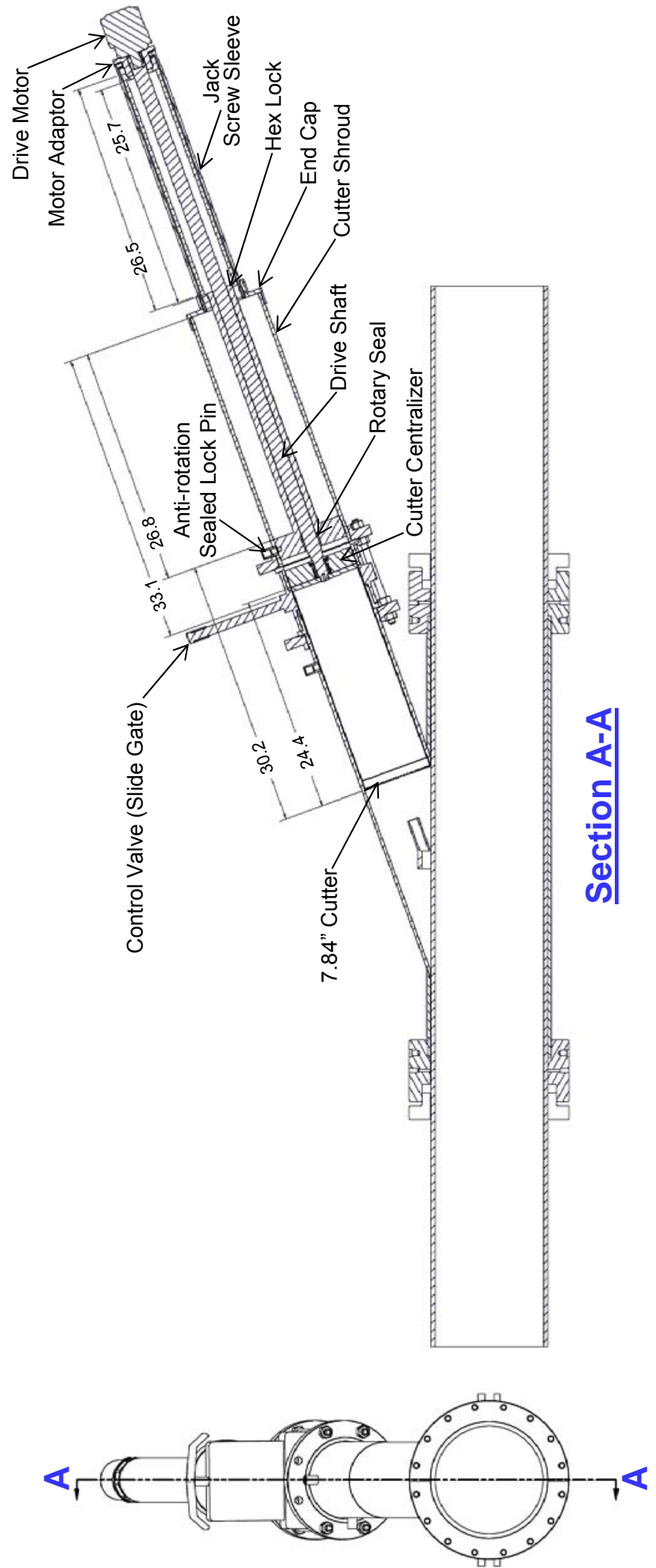

Figure 40. Drilling Assembly for Cutting Access Hole in 12-in. Cast-Iron Mains 
The project team sought to minimize the weight of each component. Correspondingly, several items are manufactured from aluminum. A lightweight thermoplastic gate valve was acquired for testing with the assembly (Figure 41). This option reduces the valve weight and overall drilling assembly length dramatically.

The lightweight PVC gate valve obtained was about 8 inches flange to flange and weighs $22 \mathrm{lb}$. Conventional steel ball valves for this size are about 18 inches flange to flange and weigh about $400 \mathrm{lb}$. These valves are not available commercially in lightweight materials. The PVC valve, although adequate for shop testing, is not suitable for field applications because it provides almost no structural support for the cantilevered drilling assembly mounted to its outer flange. To address this need, an aluminum slide gate valve (Figure 42) was designed by the team, detailed, and manufactured. It was not ready for use at the time of the shop tests, but will be used in future shop

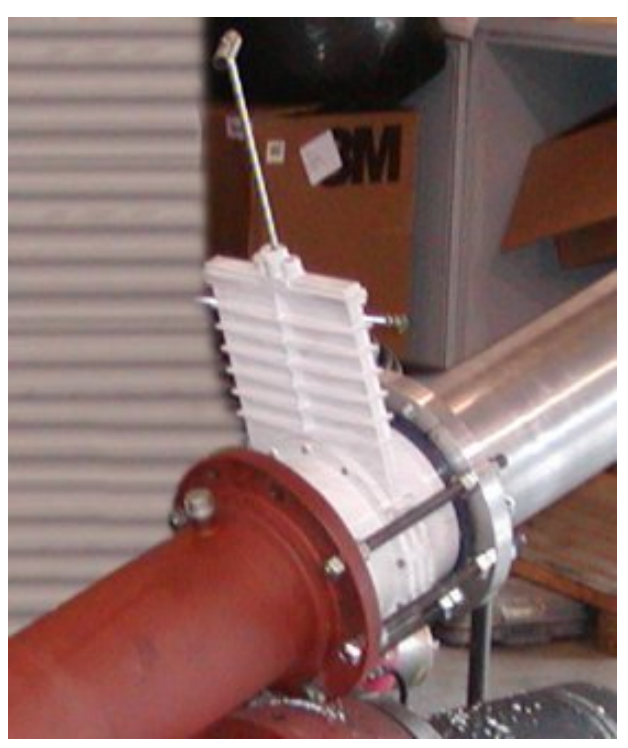

Figure 41. PVC Control Valve and field tests.

A rotary shaft seal is provided to reduce the seal area and thus the forces produced by the gas main internal pressure. Tooling (a large wrench) is provided to allow the operator to manipulate the jack screw sleeve by hand to maintain close operator feedback during drilling operations.

To support use of the 12-inch entry fitting, a saw cutting system was designed to cut an angled hole into the pressurized cast iron gas main. Since the angle of entry is near $20^{\circ}$, the body of the saw must be very deep to receive the elliptical coupon as it is cut. A hole saw for cutting an 8-inch angled hole was designed, manufactured and tested (Figure 43). In the left side of the figure, a saw blade is shown on top of a saw body prior to attachment. The hole saw is powered by a hydraulic motor which is powered by a 50 horsepower, diesel-driven hydraulic power supply. This same power supply also operates the CT unit.

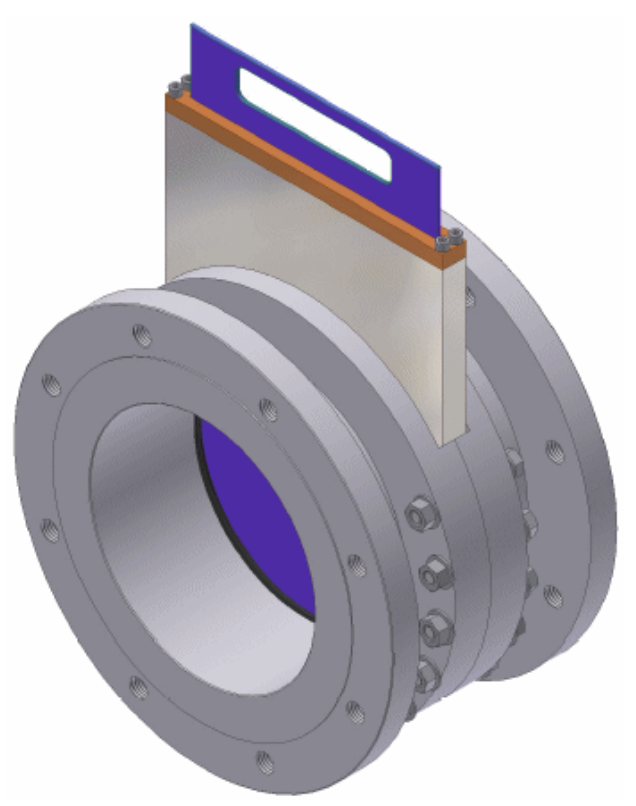

Figure 42. Aluminum Gate Valve 


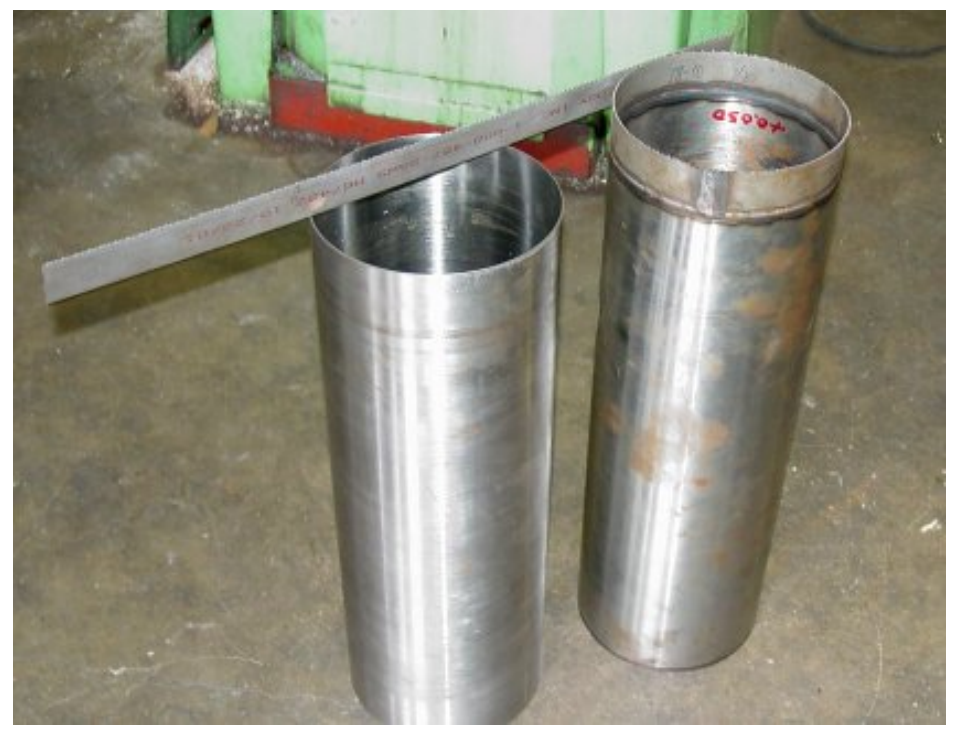

Figure 43. Hole Saw for Cutting Access Hole in Gas Main

The drilling assembly (Figure 44 and Figure 45) was fabricated and tested multiple times in the shop for fit and function.

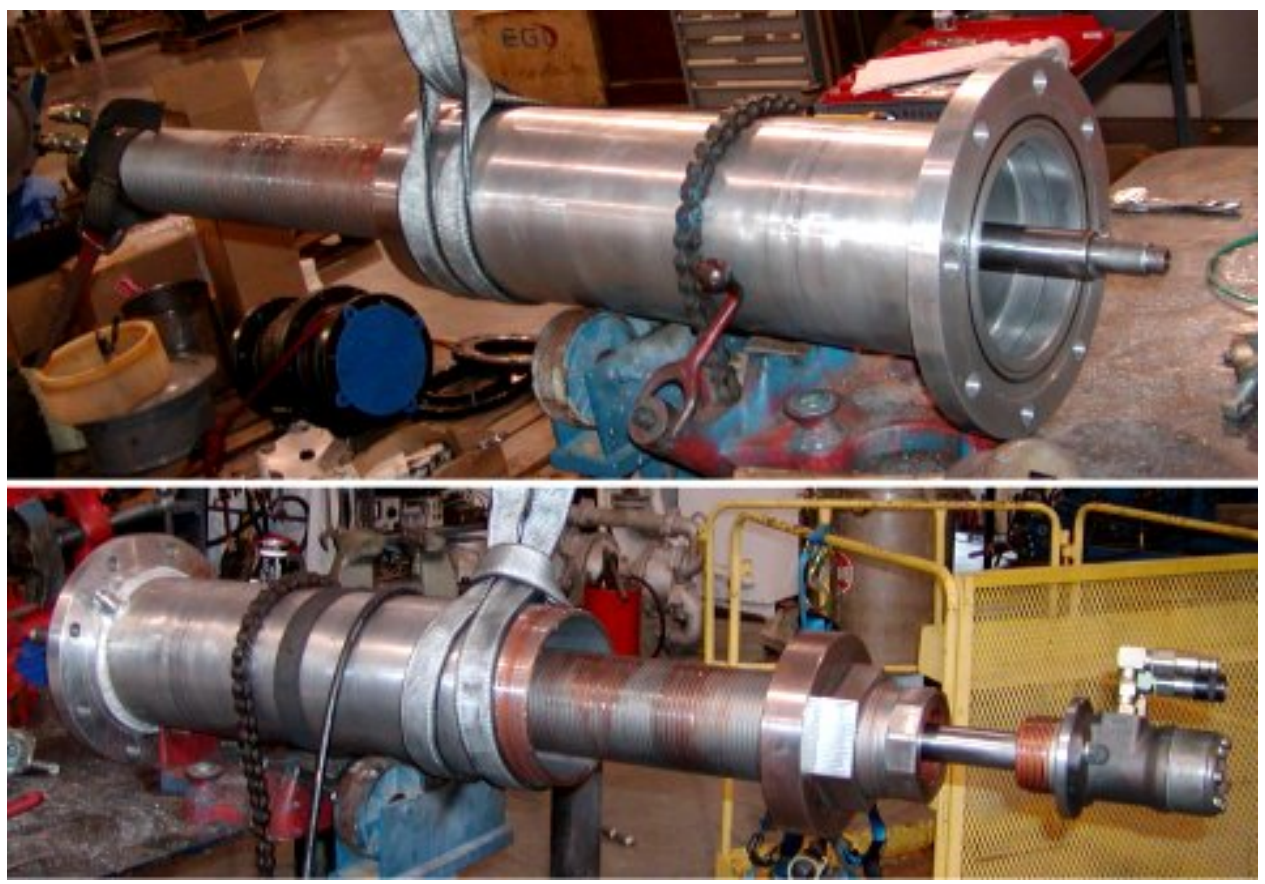

Figure 44. Drilling Assembly for Large-Diameter Pipe 


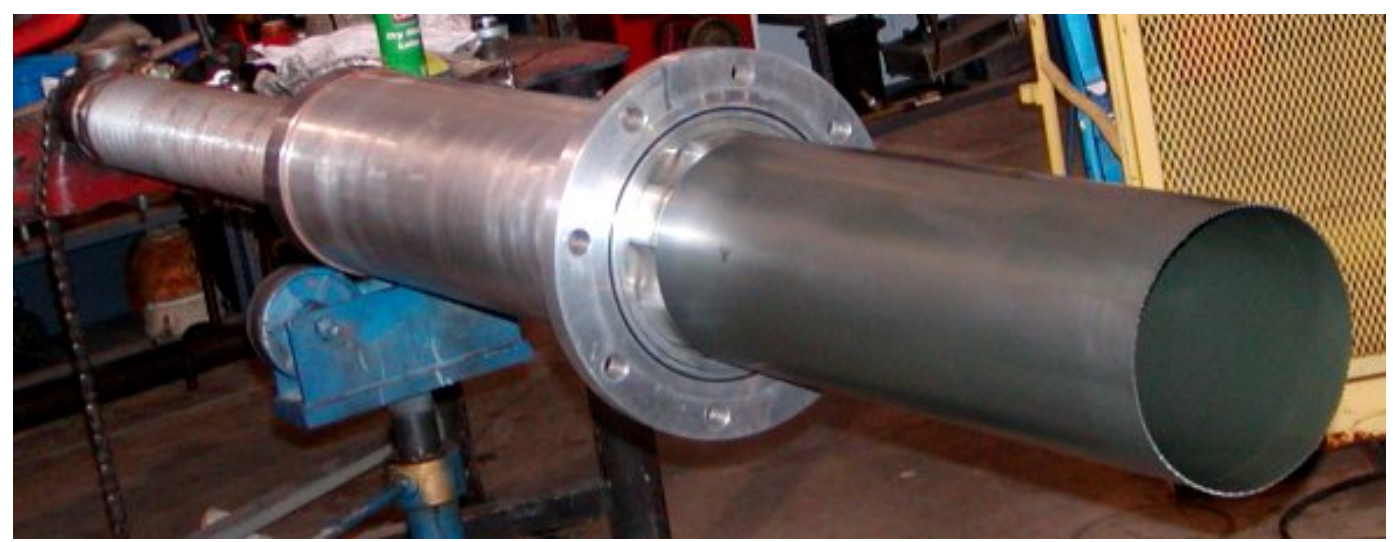

Figure 45. Drilling Assembly with Hole Saw

Assembly procedures were developed that avoid the need for a crane at the site. All elements of the drilling assembly can be lifted, manipulated and aligned by hand. Procedures are summarized below.

\section{Assembly of Drilling System}

1. Attach slide gate valve and cutter shroud to clamp on fitting.

2. Attach thrust ring and radial bushing to drive shaft.

3. Install centralizer onto drive shaft.

4. Attach core catcher brush to drive shaft.

5. Attach cutter to drive shaft.

6. Install drive shaft subassembly into fitting/valve/shroud assembly.

7. Install jack screw stationary shaft over drive shaft and into cutter shroud. Secure jack screw stationary shaft to shroud with sealed lock pin (align lock hole to pin port).

8. Assemble jack screw translation sleeve, jack screw sleeve, thrust bushing and motor adaptor. Secure parts by threading motor adaptor into jack screw translation sleeve (left hand thread).

9. Install cutter shroud end cap onto jack screw sleeve about 6" from thread start end.

\section{Coupon Removal}

1. Rotate jack screw sleeve counter clockwise back to recorded stand-off distance.

2. Remove cap screws and lock washers. Separate motor from motor adaptor.

3. Disengage sealed lock pin from jack screw stationary shaft.

4. Pull motor to draw jack screw stationary shaft and cutter into the cutter shroud.

5. Close valve. 


\section{Disassembly of Drilling System}

1. Remove set screws and disassemble motor from shaft.

2. Remove cutter shroud end cap from cutter shroud with counterclockwise rotation.

3. Remove jack screw sleeve subassembly from shaft.

4. Remove cutter/jack screw stationary shaft and drive shaft from shroud.

The drilling assembly was tested successfully several times in MTI's shop (Figure 46). In all cases the coupon was engaged and retrieved successfully (Figure 47 and Figure 48). These results showed that the large-diameter drilling assembly was ready for full-scale patch-setting tests in the shop. These were conducted late in the project and are described under Task 8.

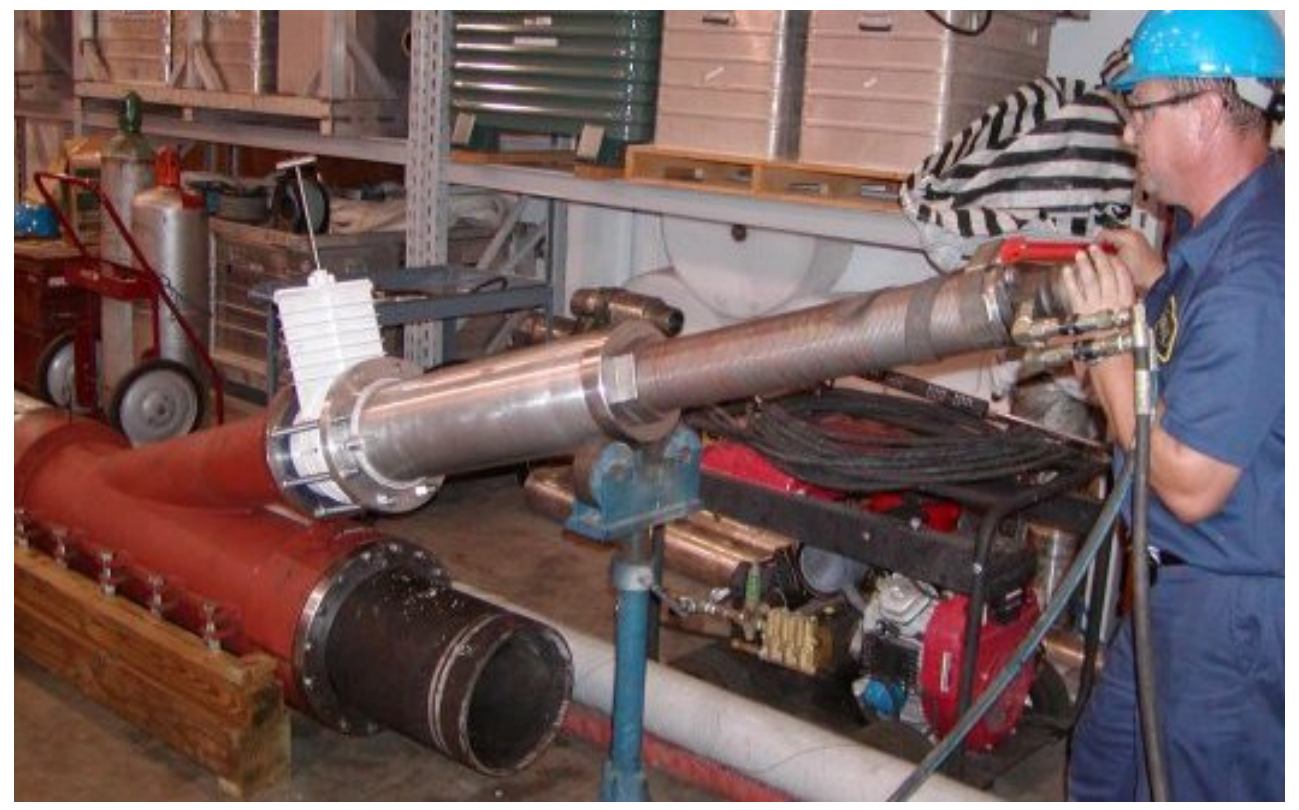

Figure 46. Testing Drilling Assembly

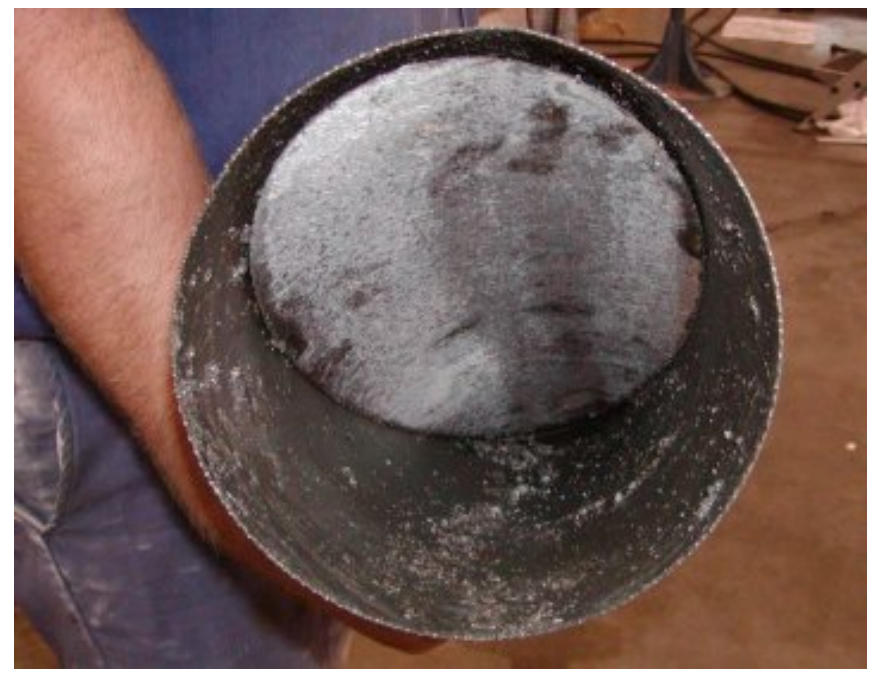

Figure 47. Hole Saw with Captured Coupon 


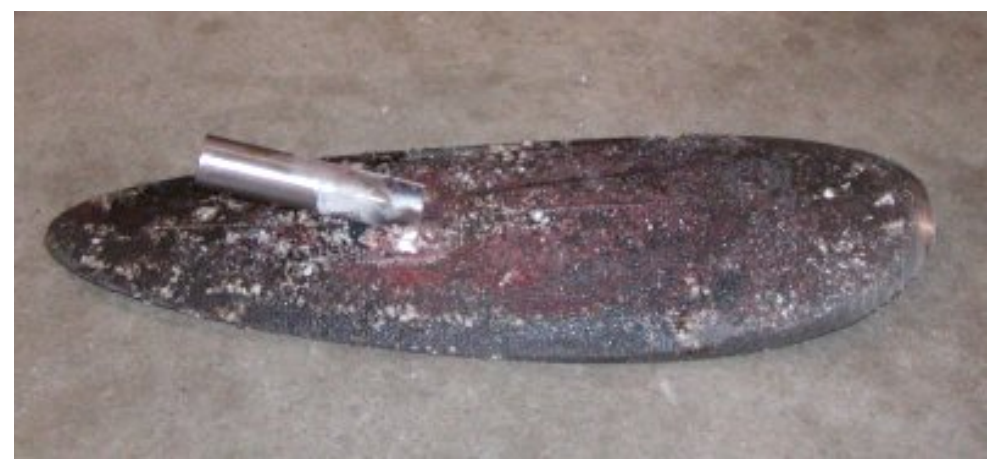

Figure 48. Pipe Coupon after Retrieval

\section{Plug-Setting Assembly Description}

After patch-setting operations are complete, an expandable plug is set into the fitting to contain gas flow as the control valve is removed from the access fitting. A special assembly was designed for this procedure (Figure 49). A blind flange is placed on the riser flange to complete the abandonment process. Because the expandable plug remains in place after the fitting is sealed, the blind flange can later be removed to re-enter the main as necessary without any flow of gas.

The expandable plug consists of an end plate, body, clamp screw and assembly screw. An elastomer element is placed between the end plate and body for sealing to the riser ID when compressed. The element is relaxed while lowered into the riser. The plug assembly is attached to a setting shaft which is placed inside the jack-screw stationary shaft. Once in place a sealed lock pin is threaded through a side port provided on the riser. The lock pin serves as an antirotation stop for the expandable plug body. A hex key is placed through the setting shaft and engages the clamp screw. Rotating the clamp screw with the hex key causes the end plate and the plug body to move together and compress the elastomer element. The element expands until it contacts the wall. The setting shaft and setting key are removed from the plug by retracting through the control valve and cutter shroud. After the shroud and control valve are removed, a second lock pin may be installed through a second port provided on the riser of the bolt-on fitting and a blind flange mounted to the riser flange. 


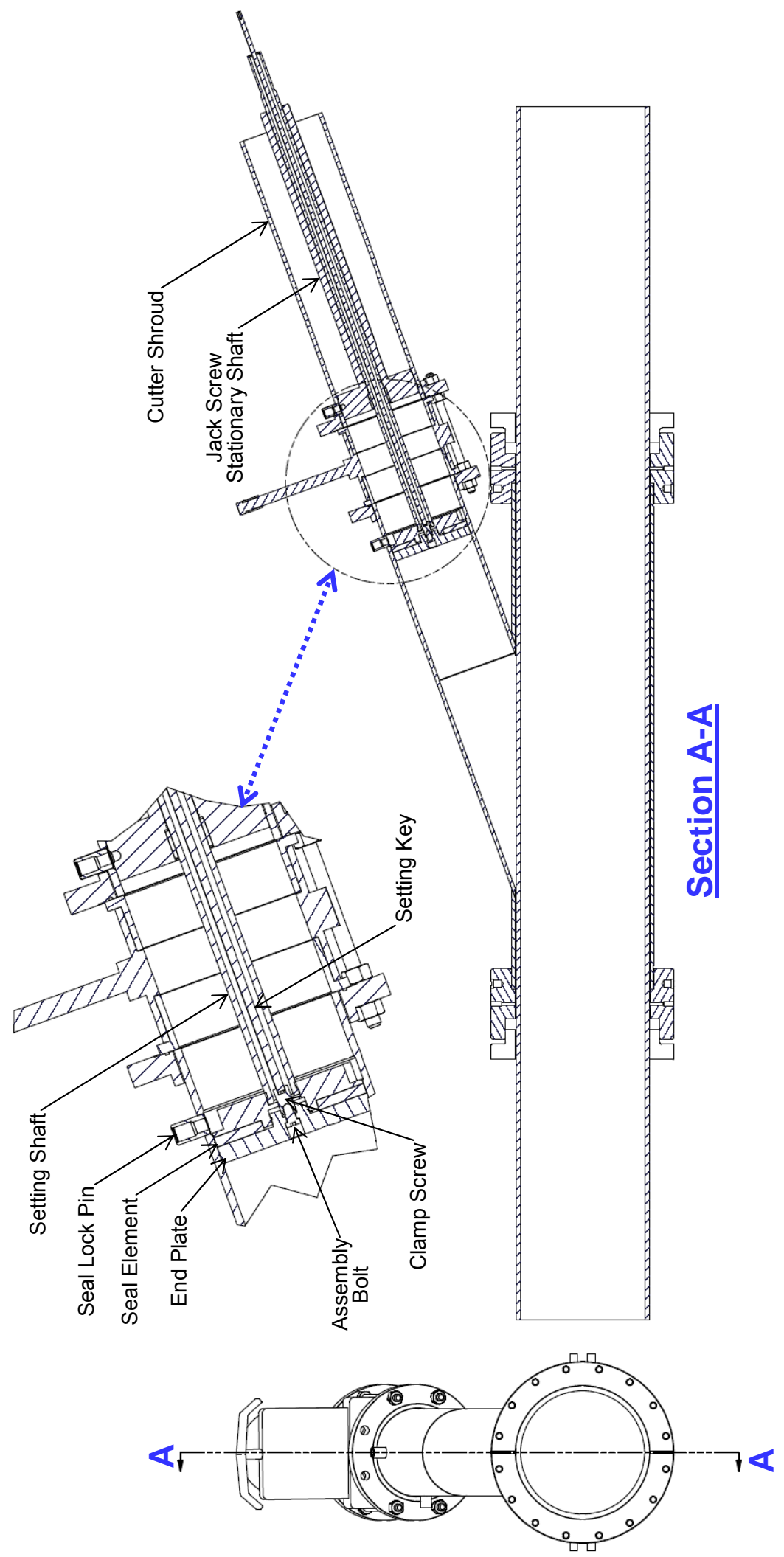

Figure 49. Plug-Setting Assembly for Resealing 12-in. Cast-Iron Mains 


\section{Task 8 - System Integration and Laboratory Validation}

While the previous tasks were aimed at addressing specific areas of the proposed work, some aspects of performance will be difficult to assess until components are integrated. Many aspects of the design cannot be accurately evaluated until an integrated test is performed. Some of these items are listed below along with potential means of mitigating difficulties encountered. The test plan will be written as the design progresses to ensure that all sensitive points will be examined as part of an integrated test program.

8.1 The team will accumulate valuable experience with the equipment to assure proficiency in the field, to verify that all elements work in concert, etc.

8.2 Actual push and pull loads will be measured, because these affect ultimate push range of the integrated hardware assemblies and therefore the number of cast-iron pipe joints which can be repaired from a single entry point

8.3 Measurement of actual end loads and reduction of these loads (if necessary) to achieve targeted performance

8.4 Evaluation of "whip" (flexible) joint design for fatigue resistance and stiffness under actual entry, translation and removal processes

\section{Laboratory Validation Tests}

Based on the satisfactory results of full function testing of each subsystem, a test main was prepared for a full-scale system demonstration at the MTI shop facility (Figure 50) on 26 August 2005. Team members from GTI, MTI and Noble participated, along with a representative from Public Service Electric and Gas Company. To properly align the CT unit with respect to the pipeline, a special frame was constructed to raise the unit, thereby simulating typical cover depths (3 to $4 \mathrm{ft})$.
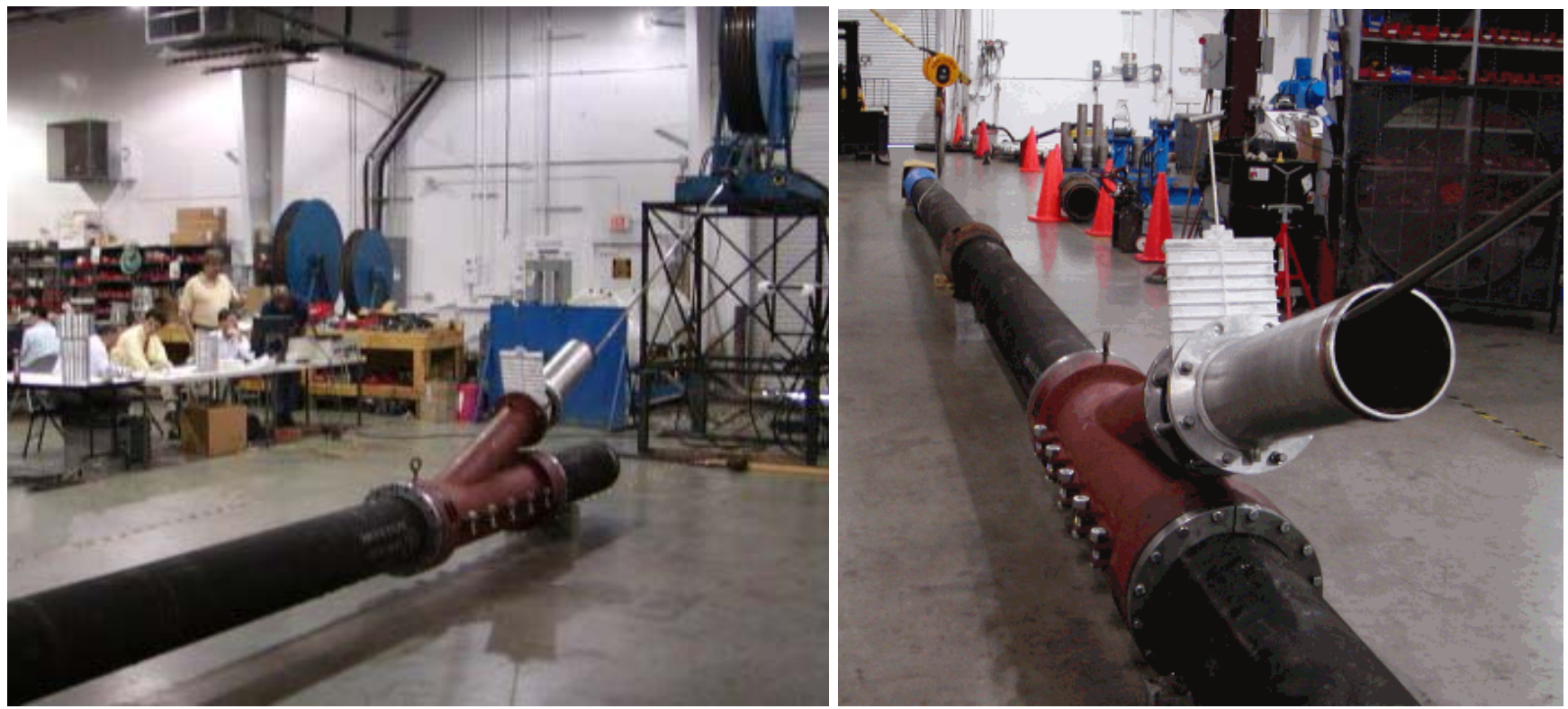

Figure 50. Shop Tests - Entry Fitting, CT Unit and Pipeline 
The test set-up included a pipeline consisting of two joints of ductile iron pipe surrounding a section cut from a cast-iron pipeline that includes a bell-and-spigot joint (Figure 51). Because of limited availability of cast-iron pipe, ductile iron mains were purchased from a local vendor. These are dimensionally the same as cast-iron pipe with the exception of the ID, which is coated with a concrete lining for water service. This concrete lining must be chipped away to prevent damage to the hole saw during drilling operations.

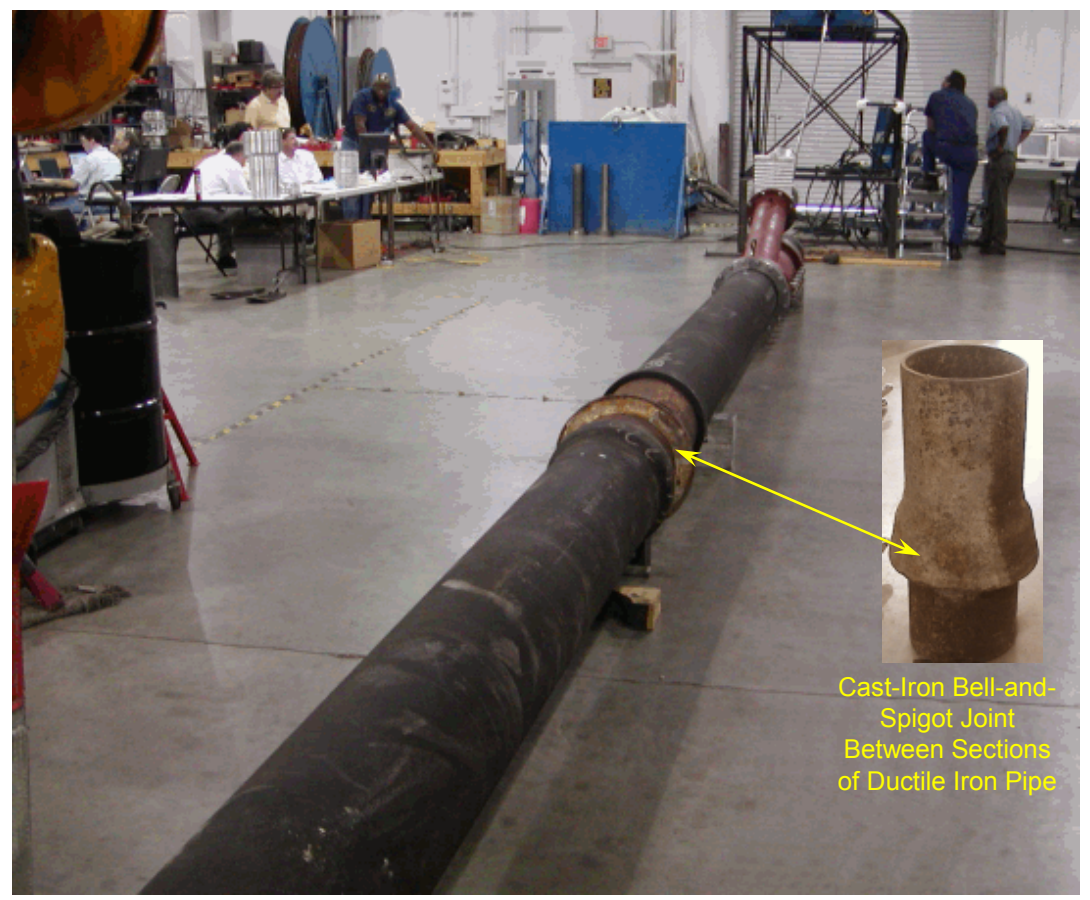

Figure 51. Shop Tests - Test Pipeline with Cast-Iron Joint

As the full-scale tests were initiated, a clamp-on entry fitting was assembled onto the first ductile iron pipe section and aligned to the coupon catcher that had been previously welded to the main. The first part of the demonstration included assembling the drilling tool according to written procedures (see Task 7). Components of the drilling system are assembled and aligned manually (Figure 52), thereby avoiding the need for lifting equipment at the field site.

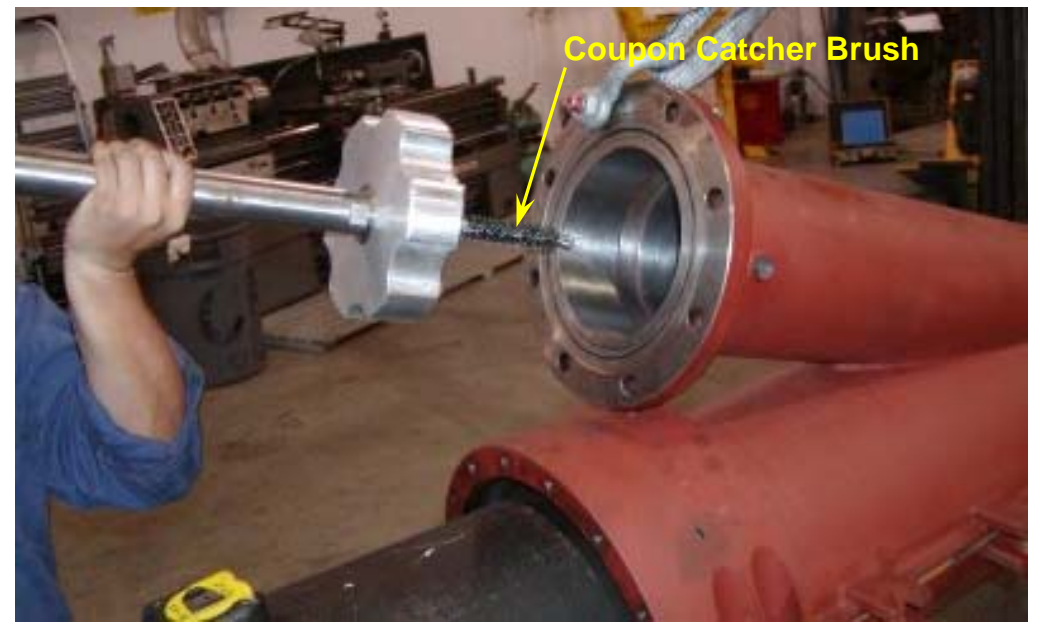

Figure 52. Assembling Drilling Components 
After assembly was complete, the operation to cut a hole through the main was begun and completed in less than one hour. The drilling assembly was then disassembled and the coupon retrieved successfully.

The second part of the demonstration included launching and retrieving the robot trains through the entry fitting with the CT unit. Unfortunately, some components of the launch equipment were not available because of manufacturing delays. Partial launching and retrieval was demonstrated, however, which included negotiating the entry fitting opening with the longest and largest robot modules. This was accomplished by sending CT through the test main and attaching the patch module train to the CT at the far end. The patch module train was then retrieved back to the entry fitting and pulled into the launch tube. The use of a launch spoon is critical for this operation. The launch spoon (Figure 53) lifts the robot into the riser so that the centralizer wheels do not become lodged in the thinnest part of the elliptical opening. After retrieval, the robot train was successfully re-launched through the opening and into the main.

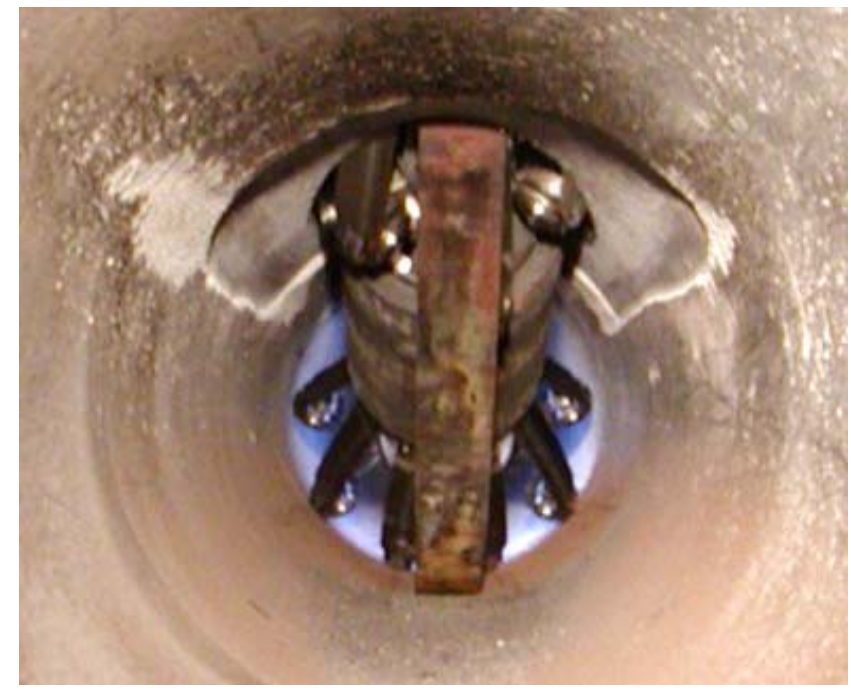

Figure 53. Launch Spoon (viewed from inside pipeline)

The third part of the demonstration included cleaning the bell-and-spigot joint to be patched, and preparing and setting the patch sleeve. For this operation, the cast-iron pipe joint was moved to the end of the test main so that participants could view the brush module as it cleaned the joint. Several passes across the joint with the cleaning module removed all scale from inside the joint. Based on the large amount of debris generated, participants agreed that some type of magnetic cleaning device would be required to remove the debris from the area to be patched to assure proper adhesion.

After cleaning operations were complete, the cast-iron joint was returned to its position between the ductile iron joints for patching operations. This was done to demonstrate the procedure of using the camera and the footage counter to accurately locate the patch within the joint. A new patch was prepared (Figure 54) and loaded onto the patching module bladder (Figure 55). The joint position was located and setting operations were activated as designed from the control console. 

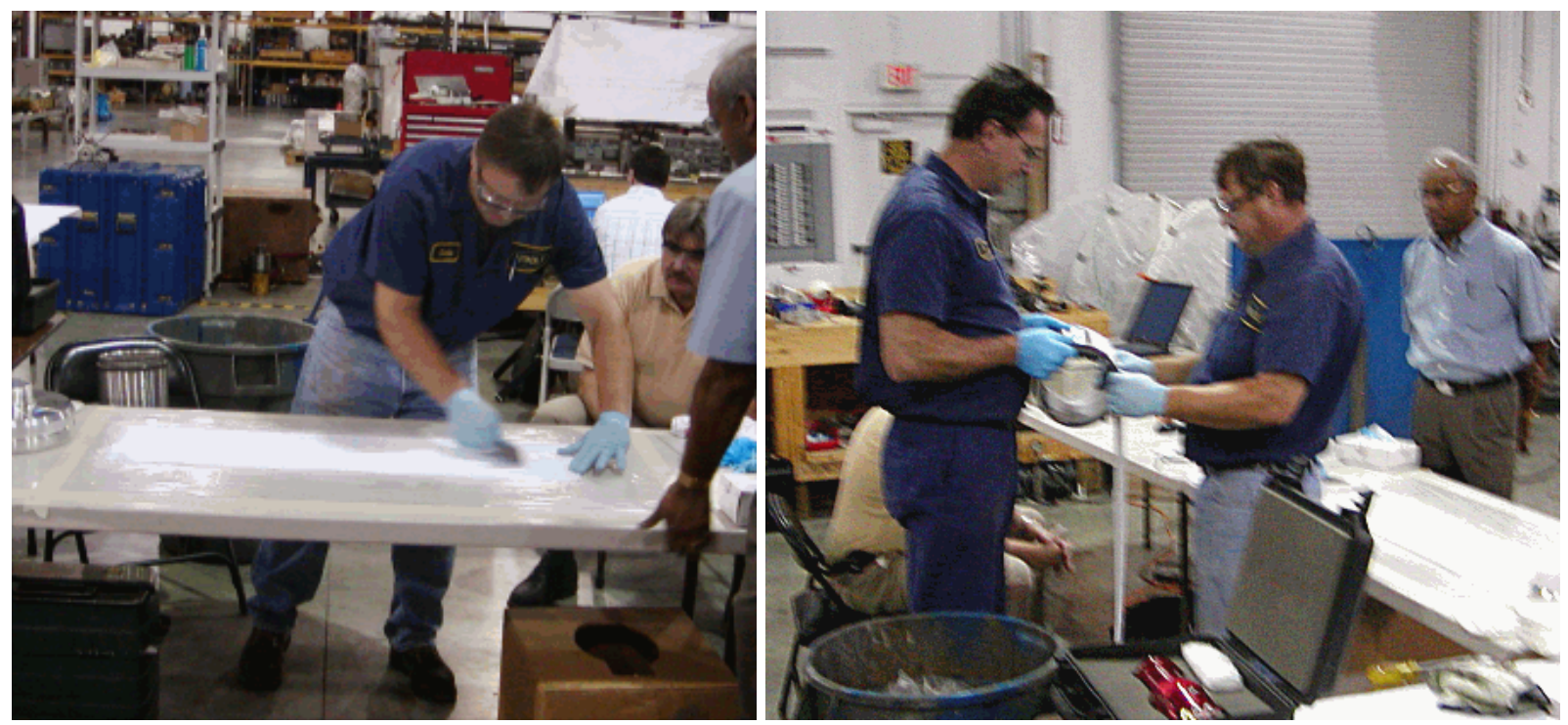

Figure 54. Preparing Patch for Setting in Pipe

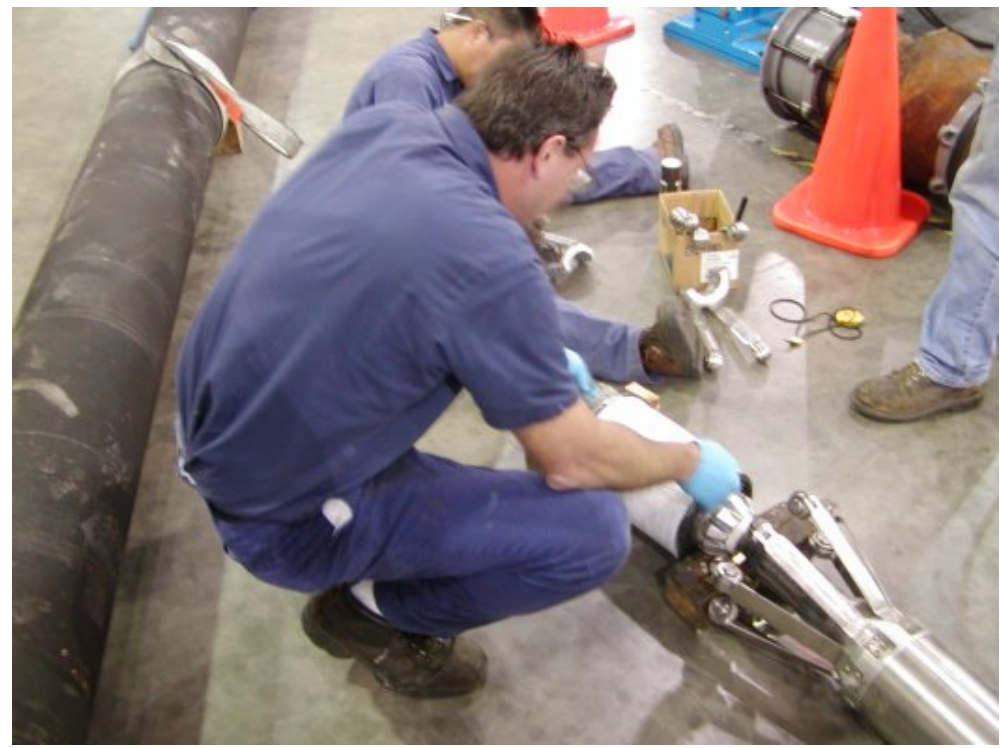

Figure 55. Installing Patch onto Inflation Bladder

After patch setting operations were complete, the patching module was withdrawn through the patch sleeve without problems. The cast-iron joint was then removed from the test main and visually inspected (Figure 56). (The joint is set upright in this photo.) 


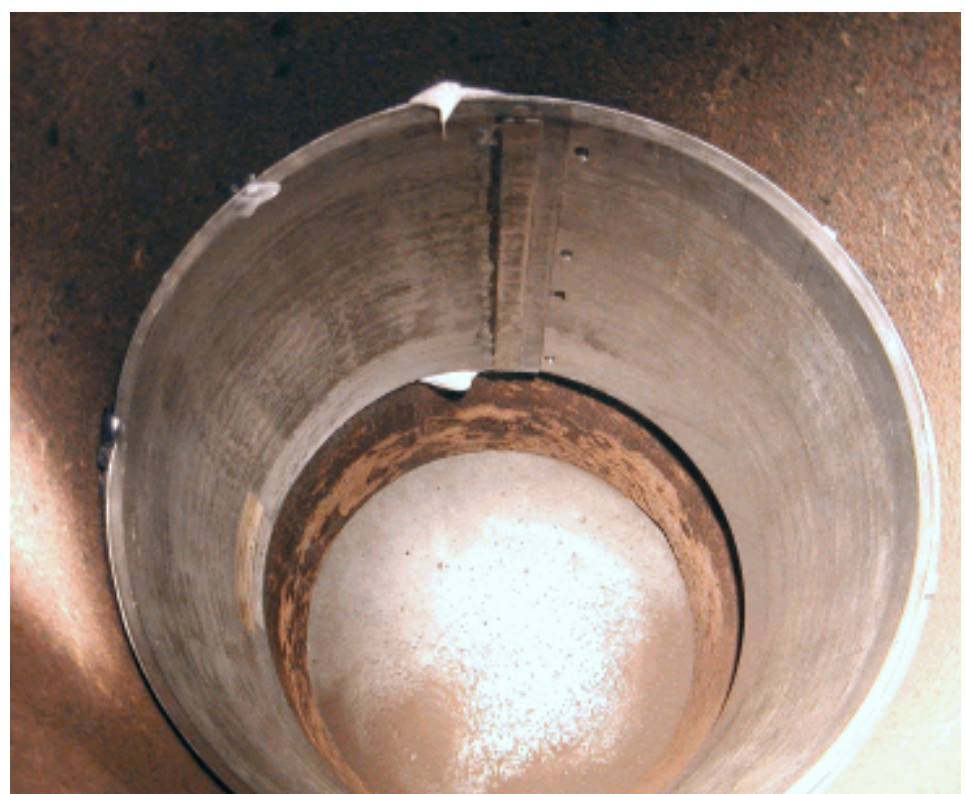

Figure 56. Successfully Patched Joint

After inspection, the patched joint was sealed with end caps which allow internal pressurization for verifying patch sealing effectiveness (Figure 57). The joint was pressurized to 10 psi. The joint was sprayed with a solution of soap and water to locate leaks; none were detected. Internal pressure remained steady at 10 psi after 1 hour of monitoring.

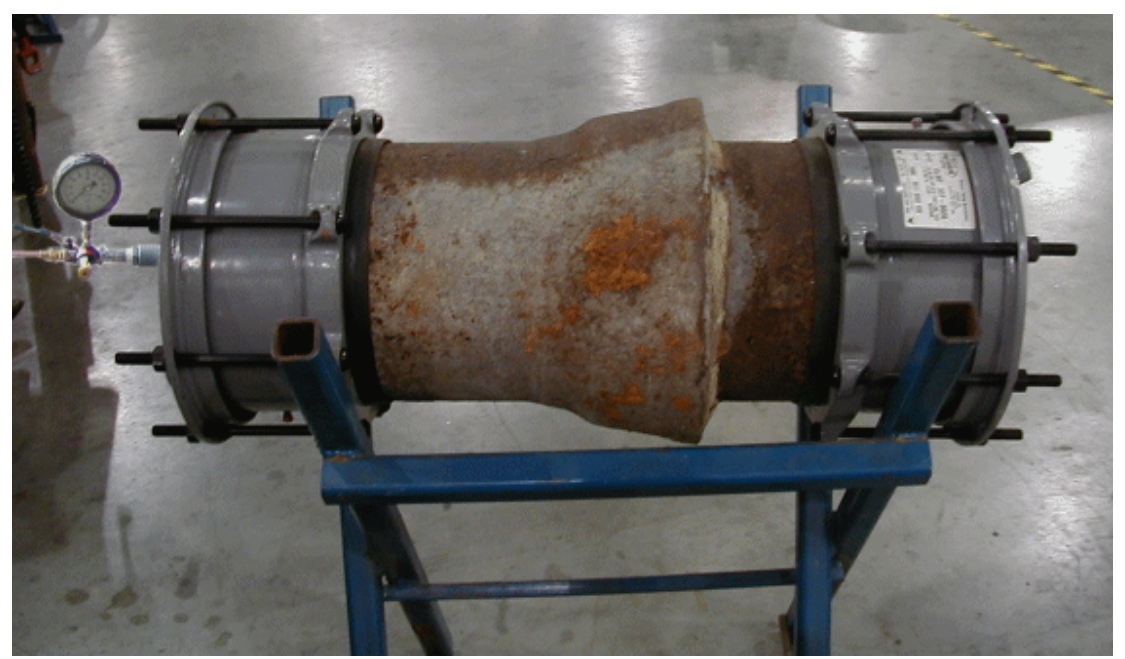

Figure 57. Patched Cl Joint Tested for Leaks

Following the shop validation/demonstration of system operation, a task list was prepared by all participants for moving forward to the final system to be deployed in the field in the second quarter of 2006.

\section{Task 9 - Field Testing and System Refinement}

The complete robotic patching system for large-diameter mains will be evaluated in a series of field tests. These tests will highlight improvements to "harden" the system for commercial viability. Iterative design improvements will be implemented and verified as 
required. Prior working relationships exist between the project team and the following major U.S. gas utilities: KeySpan Energy (Brooklyn Union Gas and Boston Gas), Consolidated Edison of New York, Public Service Electric \& Gas of New Jersey, and Baltimore Gas \& Electric. These utilities operate the vast majority of large-diameter cast-iron gas mains in the U.S. and are logical candidates for participating in field tests.

Near the completion of the project, discussions were ongoing between GTI, MTI, Public Service Electric \& Gas Company, and other utilities for scheduling field tests of the complete system. The team now plans to conduct these tests in the second quarter of 2006 in New Jersey and/or New York. These tests will be highly beneficial in establishing the economics of the robotic repair system as well as identifying further design refinements that will improve performance and reliability.

During the summer of 2004 , the small-diameter version of the joint-repair robotic system was field-tested in cooperation with Public Service Electric \& Gas in New Jersey. The field test consisted of inspection and repair of a series of 4 -inch cast-iron bell-and-spigot joints. Because much of this smaller system's design and performance closely tracks that used in the largediameter system, these test results were directly applicable to system design parameters for the large system. As such, a summary of these field tests is included below along with a list of design recommendations for the large-diameter cast-iron pipe repair system.

\section{Summary of Field Tests of Small Robotic System}

On August 24-26, 2004, MTI and GTI conducted field tests of the small robotic jointrepair system in a gas main provided by Public Service Electric \& Gas Company (Figure 58). The location was in a residential neighborhood in the town of Oradell, New Jersey.
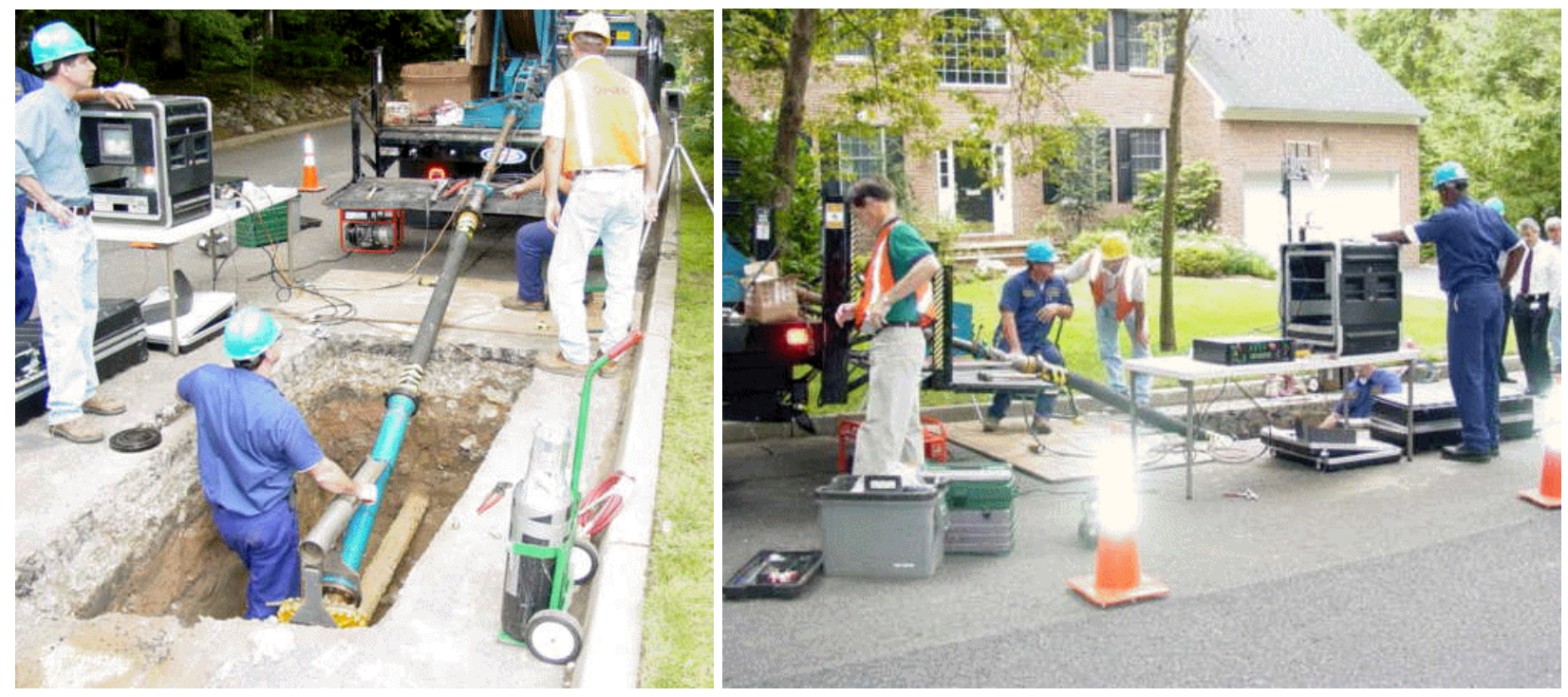

Figure 58. Field Test Site for Small-Diameter System

Over three days of field testing, a range of procedures were performed representing a typical joint-patching operation of bell-and-spigot joints on cast-iron pipe. After the main was 
uncovered and prepared for the tests, the coupon retention fitting was welded to the pipe. Next, the $20^{\circ}$ angled entry fitting was secured (Figure 59) and then seam-welded to the main.

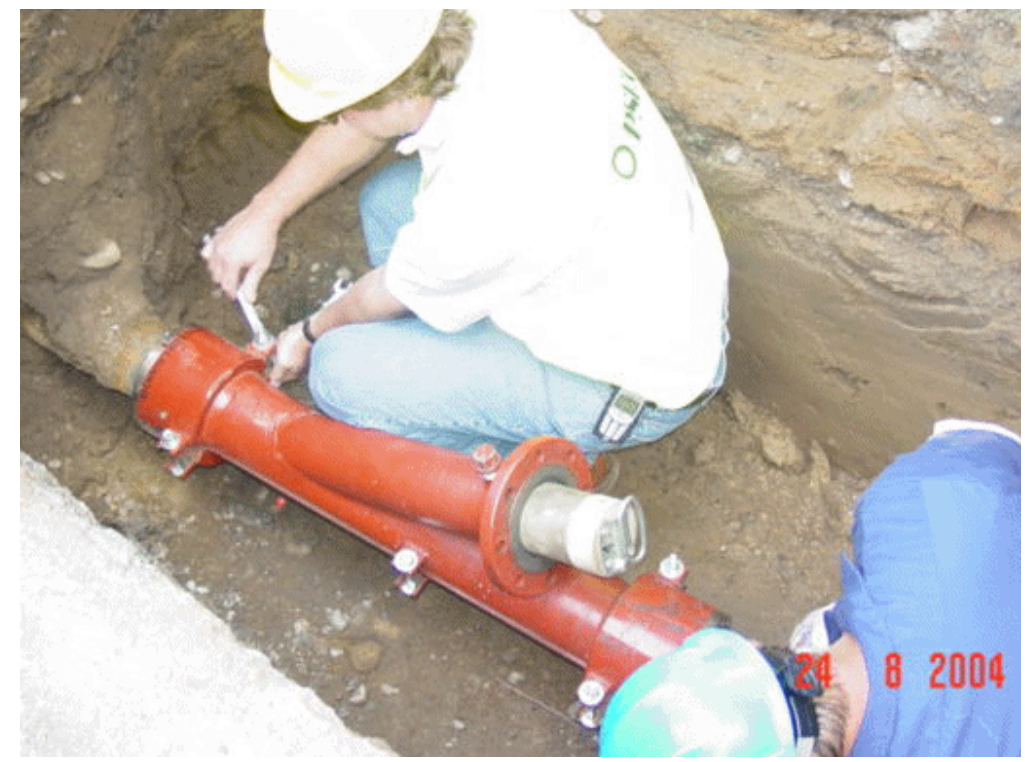

Figure 59. Attaching 4-in. Entry Fitting to Pipe Prior to Welding

A hole-saw assembly was then prepared for cutting through the wall of the main. The access hole was successfully cut through the pipe and the hardware for admitting the repair robots into the live gas main installed in a total time of 36 minutes.

The coupon was successfully retrieved. Next, a magnetic cleaning assembly (Figure 60) was run into the pipe for three passes to remove the vast majority of metal filings created by the sawing process.

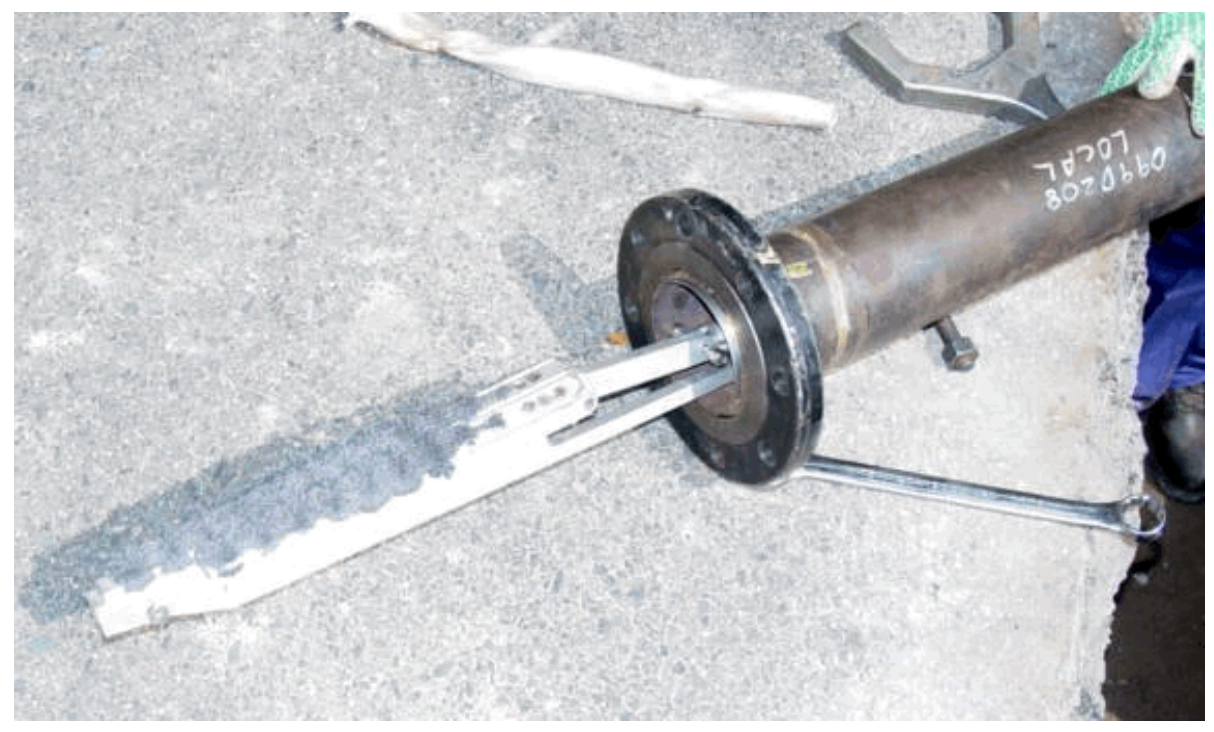

Figure 60. Magnet Assembly for Removing Filings

The first robot train assembly consisted of: (1) a CCD camera to inspect the main, (2) a brush module for cleaning the bell-and-spigot joints selected for repair, and (3) a base module which supplies electrical power, communication and control signals between the surface 
hardware and the in-pipe robot elements. After the assembly was passed through the entry fitting (Figure 61), the first run down the pipe was to inspect the environment and log the location of potential target joints and other features.

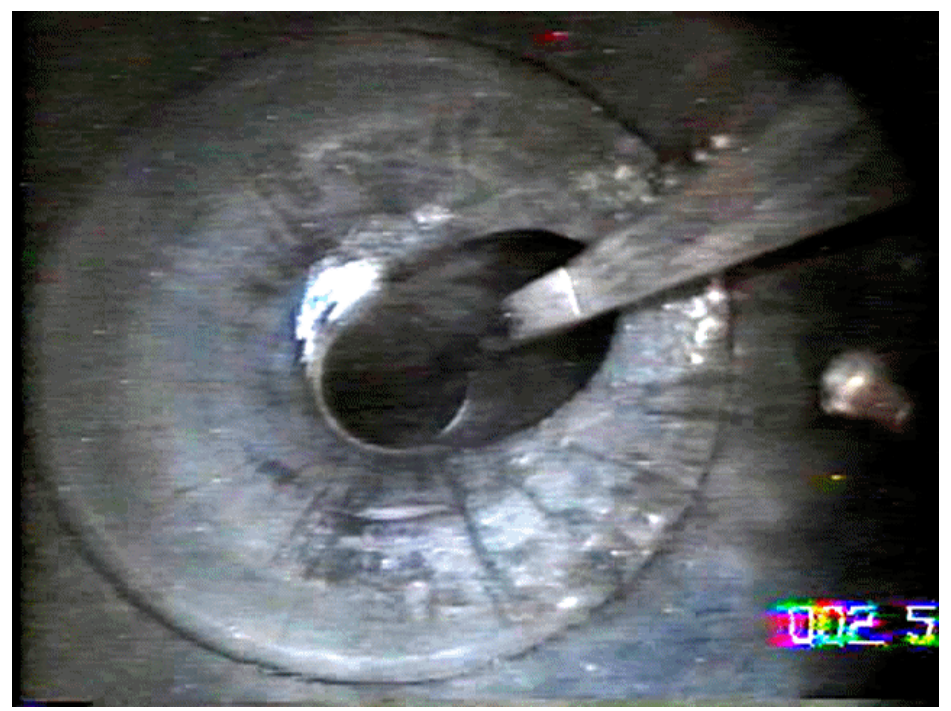

Figure 61. 4-in. Robot Moving through Entry Fitting

Several locations at pipe joints were brushed (cleaned) to remove debris from the pipe. Due to extremely low pressure and low gas velocity in the pipe, debris was not swept away from the joint but tended to fall and accumulate across the joint.

Next, a total of six sleeve patches were run into the pipe. These included two successful patches, two partially set patches, and two failed patches that were retrieved from the main. A summary of patching operations is presented below.

- $\quad$ Two sleeves (at $128.8 \mathrm{ft}$ and $93.7 \mathrm{ft}$ ) were run and set $100 \%$ successfully (Figure 62 ).

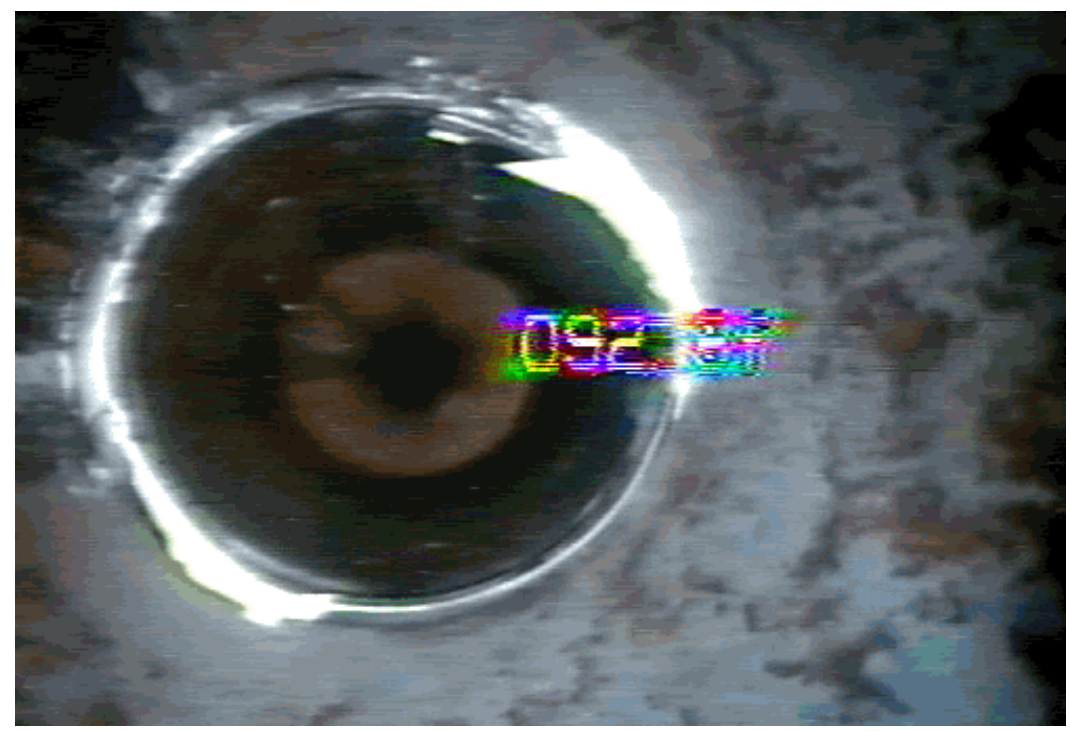

Figure 62. Successfully Set Patch at $93.7 \mathrm{ft}$ 
- One sleeve (at $58.6 \mathrm{ft}$ ) failed in the first attempt to set it, was carried with the assembly back to the entry point, and was then rerun and set successfully (although the ratchets did not engage completely (Figure 63)).

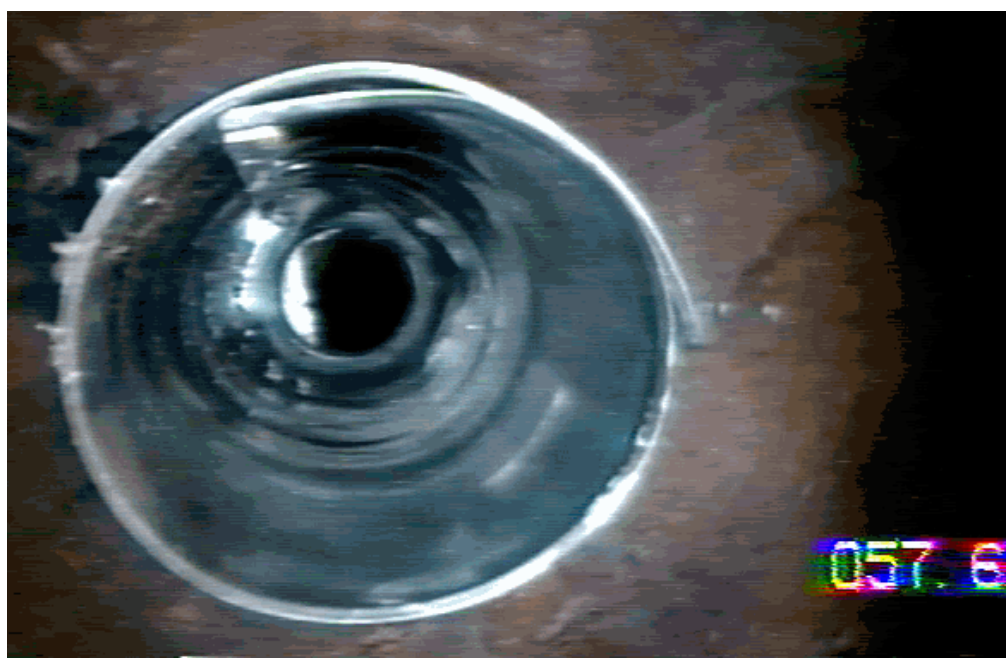

Figure 63. Partially Engaged Patch at $57.6 \mathrm{ft}$

- One sleeve (at $6.1 \mathrm{ft}$ ) was partially set (ratchets did not engage properly).

- Two sleeves were run (to $42.0 \mathrm{ft}$ and $24.1 \mathrm{ft}$ ) but were not able to engage the ratchets.

Potential causes for the failure of two patches to set are: (1) pipe ID may have been smaller than the first row of ratchets at these two bell-and-spigot locations, (2) debris levels may have been too high or (3) the bell and spigots were angularly misaligned. No problems were observed with the repair sleeve setting train either in the field or after its return to Houston. Consequently, the team believes that the patch-setting failures were due to geometric issues.

After all in-pipe operations were complete, the equipment was removed from the pipe and disassembled. A seal plug was then inserted into the $20^{\circ}$ riser section of the entry fitting. Once the seal plug is set, the gate valve was then removed from the main. A blind flange was then attached to the $20^{\circ}$ riser to create a second (redundant) gas seal and allow future re-entry into the pipe is so desired. The sealed entry fitting ready for burial is shown in Figure 64 .

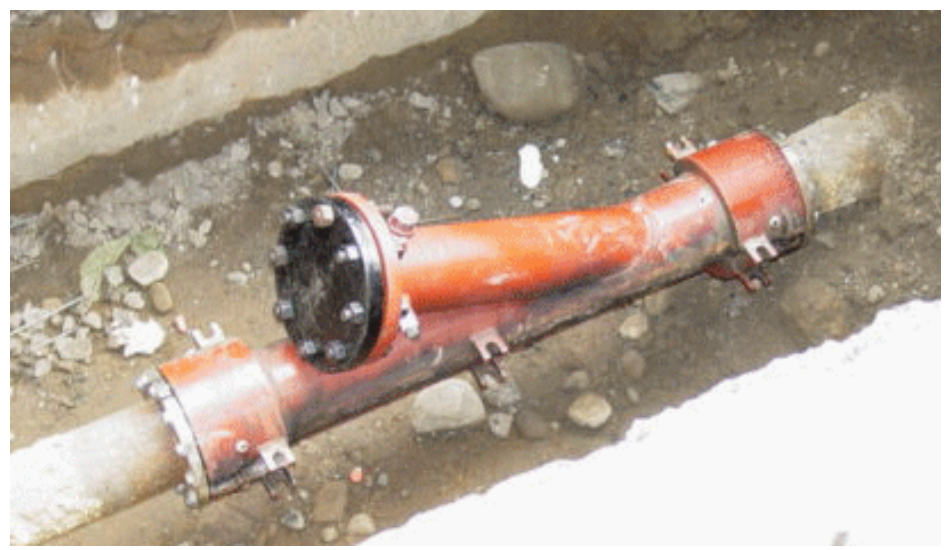

Figure 64. 4-in. Entry Fitting Ready for Burial 


\section{Lessons Learned/Recommendations for Large-Diameter System}

Based on the field tests of the smaller robotic system in 4-in. cast-iron mains, several valuable lessons were learned. The following recommendations were suggested and pursued for the large-diameter system:

\section{Entry Fitting}

1. Develop a bolt-on version of the fitting.

2. Coupon catcher design is finalized and successful.

3. Cuttings-removal magnet was very effective for small system and should be finalized similarly for large-diameter system.

4. Guide shoe design was very effective for small system, and should be finalized similarly for large-diameter system.

\section{Wall Cleaning}

5. Cleaning flails were very effective. No change is recommended for large system.

6. Brush module should be added to move (plow) debris away from area surrounding joint.

7. A magnetic coupon catcher should be added to remove existing coupons created by service tee connections. In the large system, this catcher might mount to the camera and employ the tilt function to capture the coupon.

\section{Patch Setting}

8. Carry sufficient moles of gas with the patch assembly to support at least two patchsetting procedures per run.

\section{Task 10 - Benefits Analysis}

Initial work on data collection for conducting benefits analysis was begun. Extensive field tests with the robotic system are scheduled for second quarter 2006 . These efforts will aid the project team in addressing the end-to-end process of implementing the proposed large-diameter cast-iron main repair system in a real-world field environment. After that point, more detailed time and cost data will be available for rigorously comparing the competing technologies.

An interim cost and time comparison was prepared during the final quarter of the effort. Results are summarized below.

\section{Competing Technologies}

\section{Bolt-On Repair Sleeves}

The simplest repair option for bell-and-spigot joints is to install a full-circle leak clamp externally over the bell-and-spigot joint. Each joint location is excavated, the pipe exterior cleaned and the rubber lined, stainless steel sleeve bolted into place. This option is routinely 
used to spot repair welded steel lines and variations of it have been used to bridge cast-iron joints in the past. However, this repair method is generally not used for cast-iron pipes because external encapsulation is considered to provide superior sealing characteristics.

\section{External Encapsulation}

The most common cast-iron joint repairs involve external encapsulation. Several utilities use keyhole tools and vacuum excavation to minimize the size (and therefore costs) associated with excavation and follow-on surface restoration. Once the bell joint is fully exposed and its entire circumference cleaned with pneumatic chippers and grit blasters, an encapsulation mold is placed around the joint. The mold is then filled with a synthetic rubber in its liquid state that cures to a flexible material that permanently adheres to the pipe yet allows the joint to move under thermal expansion/contraction cycles without leaking. These systems are suitable for lowpressure lines.

Primary benefits of external encapsulation are its relatively low costs and the ability to test that leaks have been stopped using a simple soap test before closing the excavation. The main drawbacks are the large (and expensive) excavation for larger pipes (12 inch and up) and the necessity to completely expose and clean the entire joint circumference.

\section{Internal Encapsulation}

Several groups are developing internally-applied anaerobic sealant for repairing leaking cast-iron joints. Products include the PLCS Mainspray and the EmBridge Energy/Con Edison Cis-Bot joint sealing robot. To date, these systems have demonstrated limited success and limited usage for a variety of reasons not related to the anaerobic sealant used.

For example, those systems which simply spray sealant at each joint location and depend on diffusion to wet the jute often do not completely eliminate leaks since full wetting of the packing material cannot be guaranteed. In fact, in some situations large amounts of jute material may have actually broken out and have become displaced from the bell-and-spigot joint, leaving nothing for the sealant to bond to. In addition, low-pressure cast-iron mains often have significant amounts of debris. As the tethered robot is pushed through the main, this debris can accumulate in front of the tool. This can reduce the operator's ability to correctly position the robot at the bell-and-spigot interface due to obstruction of the video camera lens, or prevent further forward movement due to build-up of a debris wall. It has also been reported that debris can cut and damage the robot umbilical and that the anaerobic material can prematurely solidify due to its contact with metal ions in the debris.

\section{Cured-In-Place Pipe}

Several manufacturers provide cured-in-place pipe (CIPP) liners for rehabilitating sections of damaged piping. These systems consist of a flexible liner, usually made from polyester that has been inverted (turned inside out) prior to installation. The liner is saturated with a liquid thermosetting resin that is caused to harden by pumping either hot water or steam inside the liner once it has been placed across the pipe section to be rehabilitated. This process 
results in a continuous, tight-fitting pipe liner within the existing host pipe. Products are available for both non-pressurized and pressurized piping systems operating at pressures up to 200 psig. Once cured, the liner has sufficient mechanical strength to bridge small holes and joints in pressurized pipes but still requires the overall host pipe to be mechanically sound. The pipe ID is typically cleaned prior to the installation using high-pressure water jetting systems.

As practiced, conventional CIPP liners are not suitable for use in live gas mains. The CIPP process blocks the entire pipe flow area during installation and curing, which prevents gas delivery to attached customers. In addition, a camera and cutter head robot are required to cut through the cured liner at each service tap location to re-establish flow communication between the line main and the service lines.

CIPP is used to rehabilitate continuous sections of pipe, whereas the proposed research focuses on making spot repairs to only to joints and other areas of pipe that have experienced localized corrosion or mechanical damage.

\section{Internal Repair Sleeves}

Link-Pipe's repair system comprises a cylindrical stainless-steel sleeve surrounded by an outer sleeve constructed of a combination felt/foam liner that is saturated with a liquid resin such as urethane immediately prior to installation. Sizes are available for repairing pipes from 4 to 54 inches in diameter.

The stainless-steel sleeve has a series of locking barbs along the longitudinal cut line that lock the sleeve against the host pipe wall once the sleeve has been mechanically expanded outward against the host pipe wall using an inflatable air bladder. The sleeve is carried to the repair point by slightly inflating the air bladder to hold the sleeve in place and then moving the wheeled sleeve carrier/inflation bladder through the pipe using push rods or by pulling it into place using cables. A CCD camera is used to observe each step of the installation.

At present, Link-Pipe installations require the host pipe to be taken out of service. As importantly, the Link-Pipe product is not capable of sealing active leaks since there is no pressure seal across the split sleeve. The operational procedure is to clean the pipe wall at each patch location in order to allow the resin to intimately bond to the pipe wall. This is necessary because the resin is relied on to create the pressure seal. Any voids or channels caused by lack of adhesion represent potential leak paths. Fortunately, the resins used by LinkPipe swell several-fold. This makes the design quite forgiving with regard to the cleanliness of the pipe, especially when combined with the mechanical compression provided by the sleeve once it is set. In practice, this has meant that use of high-pressure water jets to clean sewer lines and wire brushing of steel lines have been sufficient to effect pressure-tight bonds. The sleeve is then moved into place and the bladder inflated to 20-30 psig to lock the sleeve into place. The resin normally cures in 30 minutes with full cure strength achieved in one hour. A simple visual inspection of the stainless steel sleeve using the CCD camera indicates proper installation. Link-Pipe has reported that they are now developing products for the gas industry. 


\section{Technology Comparison}

Advantages and disadvantages of various joint-repair technologies are compared in Table 3. The comparison shows that the proposed technology based on robotics offers significant advantages over competing systems.

Table 3. Comparison of Cast-Iron Pipe Joint Repair Methods

\begin{tabular}{|c|c|c|c|}
\hline Joint Repair Method & Main Condition & $\begin{array}{l}\text { Repairs per } \\
\text { Excavation }\end{array}$ & Comments \\
\hline $\begin{array}{l}\text { External Bolt-on Repair } \\
\text { Sleeve }\end{array}$ & $\begin{array}{l}\text { in service (no impact on } \\
\text { gas delivery) }\end{array}$ & 1 & $\begin{array}{l}\text { conventional technique, most } \\
\text { common for steel pipes }\end{array}$ \\
\hline External Encapsulation & $\begin{array}{l}\text { in service (no impact on } \\
\text { gas delivery) }\end{array}$ & 1 & $\begin{array}{l}\text { most common repair technique for } \mathrm{Cl} \\
\text { joints }\end{array}$ \\
\hline Internal Encapsulation & $\begin{array}{l}\text { in service (no impact on } \\
\text { gas delivery) }\end{array}$ & $\begin{array}{l}\text { 10-12 repairs each } \\
\text { direction }\end{array}$ & $\begin{array}{l}\text { dependent on condition of jute } \\
\text { sealant }\end{array}$ \\
\hline Cured-in-Place Pipe & $\begin{array}{l}\text { out of service } \\
\text { (interrupts gas delivery) }\end{array}$ & $\begin{array}{l}\text { entire pipe segment } \\
\text { up to } 40 \text { joint repairs }\end{array}$ & $\begin{array}{l}\text { rarely used due to length of time } \\
\text { main must be taken out of service }\end{array}$ \\
\hline $\begin{array}{l}\text { Internal Repair Sleeve } \\
\text { (Conventional) }\end{array}$ & $\begin{array}{l}\text { out of service } \\
\text { (interrupts gas delivery) }\end{array}$ & Up to 40 joint repairs & $\begin{array}{l}\text { rarely used due to length of time } \\
\text { main must be taken out of service }\end{array}$ \\
\hline $\begin{array}{l}\text { Internal Repair Sleeve } \\
\text { (Robotic) }\end{array}$ & $\begin{array}{l}\text { in service (no impact on } \\
\text { gas delivery) }\end{array}$ & $\begin{array}{l}40-80 \text { repairs each } \\
\text { direction }\end{array}$ & $\begin{array}{l}\text { independent of condition of jute; } \\
\text { significant savings possible versus } \\
\text { other techniques }\end{array}$ \\
\hline
\end{tabular}

Advantage; Disadvantage

Of the potential repair technologies listed in Table 3, only one is suited for detailed comparison with the proposed robotic system, namely, external encapsulation. External bolt-on sleeves are very similar in cost to external encapsulation. Of these two, external encapsulation is greatly preferred because it provides superior sealing performance.

Internal encapsulation is under development, but is currently not commercially available on a wide scale. The primary deficiency of these methods is the requirement that the original jute material is sufficiently intact to allow injected sealant to wick around the entire circumference, which is often not the situation in old mains. In addition, these systems have limited push distances since they use a fiberglass push rod rather than steel coiled tubing.

Cured-in-place liners would be a very expensive approach for repairing joints. Industry team member PSE\&G has reported that they would not consider using a liner for joint repair. Consequently, costs were not evaluated in detail.

Internal repair sleeves are not favored as an option because the gas main must be taken out of service. These were not included in the cost analysis.

\section{Cost Comparison}

The base-case for comparison was derived based on a conservative estimate that the robotic system will be capable of repairing at least $500 \mathrm{ft}$ of pipeline containing 25 joints through one excavation and access fitting. Costs of the proposed robotic system are compared to those of external encapsulation in Table 4. 
Table 4. Costs of Cast-Iron Pipe Joint Repair Methods

\begin{tabular}{|l|c|c|c|}
\multicolumn{1}{|c|}{ Item } & $\begin{array}{c}\text { External } \\
\text { Encapsulation }\end{array}$ & $\begin{array}{c}\text { Internal Repair } \\
\text { Sleeve (Robotic) }\end{array}$ & Comments \\
\hline Excavation/Remediation & $\$ 800-\$ 1000$ & $\$ 2400-\$ 3000$ & $\sim 3$ times larger area for robotic \\
\hline Access Fitting & - & $\$ 8000$ & \\
\hline Repair Hardware per Joint & $\$ 380$ & $\$ 523$ & \\
\hline Labor per Joint & $\$ 420$ & $\$ 75$ & \\
\hline Repairs per Excavation & 1 & 25 & \\
\hline Repairs per Day & 3 & 10 & \\
\hline Total Time for 25 Joints & 8.33 days & 2.5 days & Robotic system is 42\% less \\
\hline Total Cost for 25 Joints & $\$ 45,000$ & $\$ 25,950$ & \\
\hline Prorated Cost for 1 Joint & $\$ 1,800$ & $\$ 1,038$ & \\
\hline
\end{tabular}

For the base case repair consisting of 25 bell and spigot joints, the internal robotic sleeve repair is estimated to cost $42 \%$ less than the conventional approach of excavation and encapsulation of each joint. Perhaps as importantly, the robotic system is expected to be considerably more rapid at ten joints/day, compared to an estimated three joints/day for encapsulation.

The break-even cost for the robotic system is achieved after about 10 joints are repaired (Figure 65). The higher cost of robotic repairs for fewer than 10 joints is due to the high cost of the access fitting (which cannot be reused). Capital costs for the surface equipment are quite low-on the order of $\$ 40,000$ for the coiled-tubing delivery system and the related control and display electronics. As importantly, these elements are quite robust and will provide a long service life in excess of seven years with minimal service requirements.

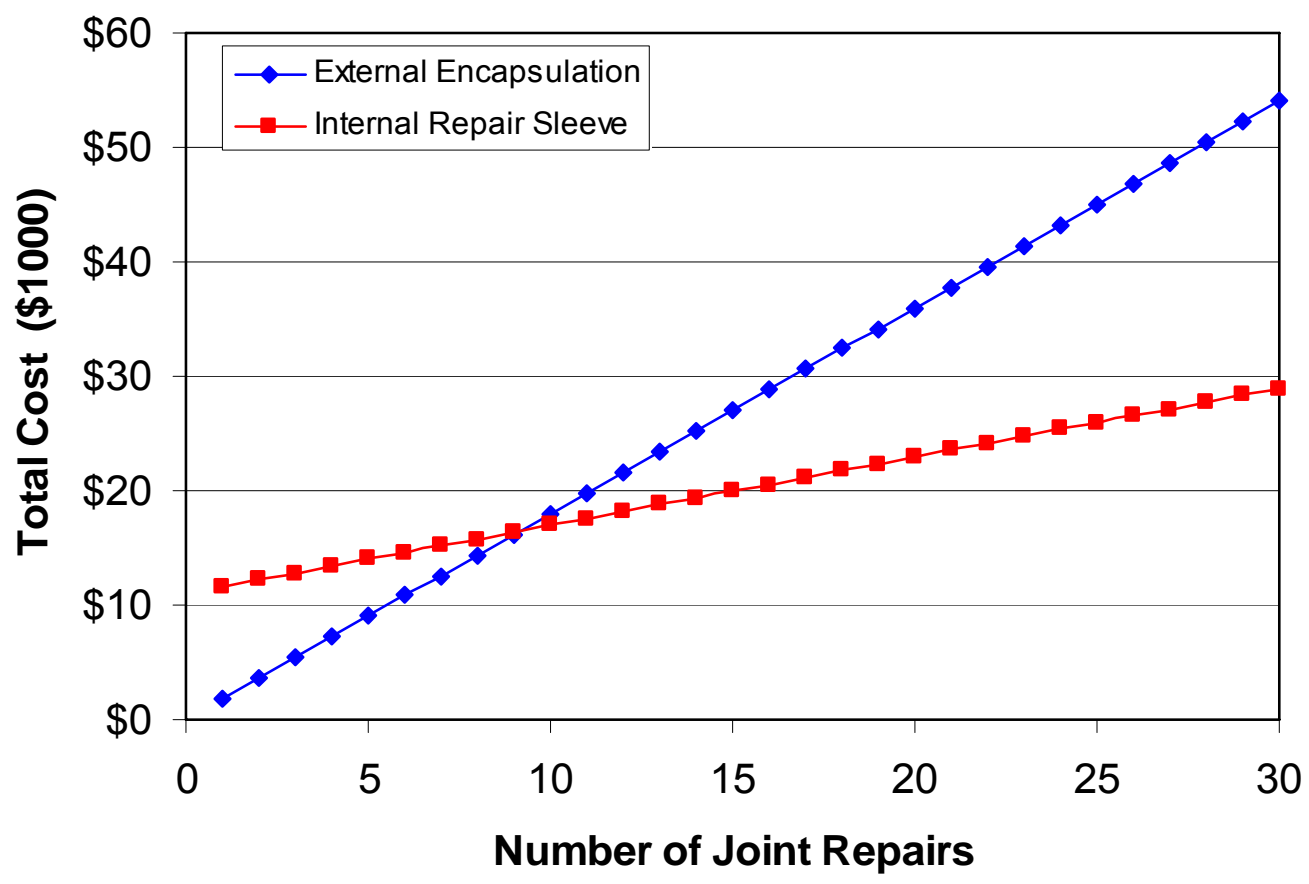

Figure 65. Break-Even Cost for Robotic Joint Repair 
In summary, a conservative cost comparison between the robotic joint repair system and external encapsulation shows that the robotic system will be considerably more economic. Cost savings would be expected to increase even further as the field crew becomes more experienced in system deployment and application.

\section{Task 11 - Final Report}

A project Final Report was to be compiled to document all aspects of design and operation of the system. The report was completed during the final quarter of the effort.

\section{Next Steps in System Development}

Development of the large-diameter cast-iron pipe joint repair system will continue after this project is concluded. Industry interest for this economical repair system remains very high. Among the next steps to be pursued in the near future are:

1. Continue full-scale testing of the pipe wall cleaning module in conjunction with the PZT camera under increasingly more difficult and realistic conditions. These tests will be conducted in the laboratory with larger in-pipe travel distances, introduction of more debris, and full exercise of the control electronics and software.

2. Continue full-scale testing of the patch-setting module and its use in setting the latest generation of 12 -inch repair sleeves. Test results will be used to optimize design of the patch assembly and the patch-setting robot train.

3. Collect additional information and data to conduct benefit analysis as part of the planning and execution of field tests in 2006.

4. Conduct field test demonstration of large-diameter system with Public Service Electric and Gas Company currently scheduled in second quarter 2006.

5. Conduct additional field tests with a second Northeast utility after applying lessons learned from the first field tests.

6. Evaluate utility comments and system performance/reliability versus competing jointrepair technologies to determine if the technology will be commercially viable.

7. Work with industry and select service contractors to commercialize the technology if item 7 is confirmed. 


\section{Conclusions}

The DOE-sponsored phase of development of a robotic system for patching bell-andspigot joints in 12-in. cast-iron gas mains is complete. Many important accomplishments were achieved during this project and are described in Section 3 of this report.

The complete robotic repair system was successfully tested in full-scale joint patching tests in 12-in. cast-iron joints in the laboratory. The drilling assembly for cutting an access hole through the wall of a gas main was successfully tested. All components and systems functioned as required and field application of the robotic system is very promising.

Development of the system will continue in the coming months. Full-scale field tests of the large-diameter patching system are currently being planned and will be conducted in the second quarter of 2006 in gas mains operated by Public Service Electric and Gas Company. 


\section{References}

(No references are cited in this report.) 


\section{Appendix A - Technology Assessment}

\section{Background}

Several older urban areas of the United States have a large number of cast-iron gas distribution mains. Some 47,000 miles of cast-iron mains remain in service. Individual segments of these mains average between 12 and $20 \mathrm{ft}$ in length and are connected together by a belland-spigot joint as shown in the figure. The annular space between the bell and spigot was filled with a jute packing to provide a fluid seal and finished with a lead or cement plug.

In the days of manufactured gas, the jute material was kept moist and compliant by the humidity and higher molecular-weight hydrocarbons present in this gas. As a result, the joints were usually leak-free. However, in more recent years natural gas in these mains has been characterized by low humidity and high methane purity. This has resulted in the jute drying out and subsequently shrinking

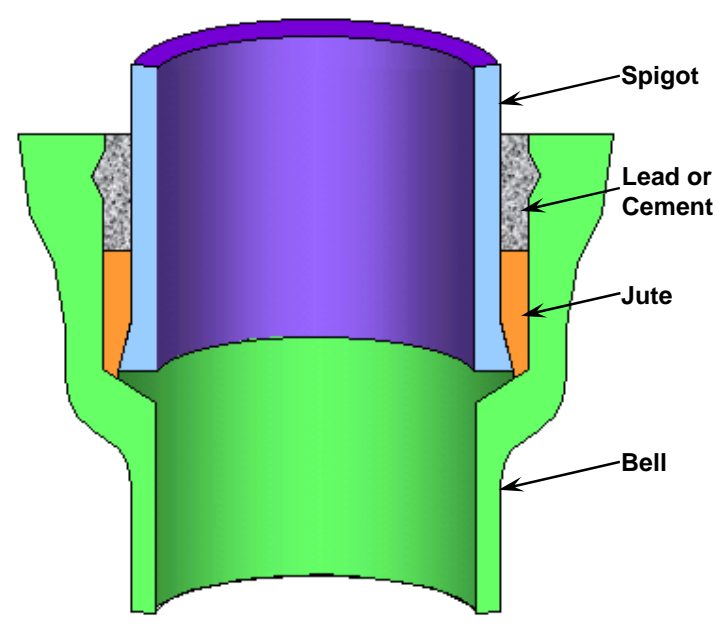
and/or cracking which, in turn, produces numerous leaks. Costs to replace significant lengths of cast-iron mains on a yearly basis are prohibitive due to their large size and location in highly urbanized environments. Instead, gas distribution companies must extend the useful service life of their cast-iron mains by finding ways to repair leaking joints inexpensively.

\section{Technology Being Developed}

The industry has responded to this challenge by the development and use of several different means for repairing cast-iron joints both externally and internally. The objective of this project is to develop and commercialize a robotic repair system capable of sealing multiple belland-spigot joints from a single pipe entry point. The proposed system will repair joints while the pipe remains in service by traveling through the pipe, cleaning each joint surface and attaching a steel sleeve lined with an epoxy-impregnated felt across each joint. Sufficient bypass of natural gas around the robot will be maintained during in-pipe operations so gas delivery to attached customers is unaffected. The approach will save costs over external encapsulation by greatly reducing the number of excavations required to access the cast-iron pipe, and over competitive internal repair technologies which either require the line to be taken out of service during the repair cycle or rely on rejuvenating the original jute material that exists in various (and unknown) stages of deterioration.

The joint-sealing robot will be comprised of four main subsystems: (1) two sequentiallyrun robot trains; (2) pipe access hardware for safely admitting into and removing the robot trains from the live gas-main environment; (3) a coiled-tubing delivery system for providing primary 
locomotion and transmission of command/control signals to the robot; and (4) surface control and display electronics.

The first robot train will have a front mounted pan/zoom/tilt camera which will be used to locate each bell-and-spigot joint. Directly behind the camera is a brushing module whose function is to remove debris from the wall of the cast-iron bell-and-spigot joint. Immediately behind the brushing module is a base module that provides power and control to the two other modules and a supplemental locomotive (tractor).

In operation, coiled tubing is used to deliver the pipe-wall preparation module to the farthest cast-iron bell-and-spigot joint to be repaired from a launch location (i.e., 500-1000 ft from the single pipe entry point). The brushing module is then activated to clean the joint by translating the abrasive brushes back and forth across the patch site. Proper cleaning of the joint is visually confirmed using the on-board camera. The coiled tubing is then used to withdraw the train back to the next joint where the cleaning process is continued. This sequence is repeated until all of the joints have been prepared (cleaned) for patching.

The brush module is then removed from the train and replaced with the repair sleeve carrier/patch setting module. A steel sleeve is slid over the carrier along with its polymer gasket and epoxy-saturated felt. The coiled tubing unit is then used to deliver the patch-setting train to the most distant bell-and-spigot joint. This location is confirmed with both the quadrature encoder footage counter and the in-pipe camera. Once the camera is located exactly at the belland-spigot-joint gap, the fine resolution odometer on the camera is set to zero. The coiledtubing unit is then used with the camera's odometer to move the patch setting train forward by a known, fixed distance to ensure that the patch is properly aligned with the bell-and-spigot joint. A control command is then issued from the surface unit to the base unit to release nitrogen from a stainless-steel pressure vessel on-board the patch setting module into its expandable rubber bladder. This causes the bladder to inflate and locks the stainless-steel sleeve into position via its interlocking, ratcheting barbs. The epoxy is allowed to cure and reaches full strength within 12 hours. During the interim, a gas-tight seal is assured by a polymer sleeve which has been energized against the joint by the hoop stress of the stainless-steel sleeve. (Note: The volume and rate at which the nitrogen is bled from the inflation bladder results in no appreciable dilution of the BTU-quality of the natural gas.)

The patch-setting module is then pulled back into the access fitting/launch chamber and loaded with a new patch. It is then moved to the bell joint immediately prior to the one previously repaired and the next patch installed. This process is repeated until all joints in the segment have been repaired.

\section{Competing Technologies}

\section{Bolt-On Repair Sleeves}

The simplest repair option is to install a full-circle leak clamp externally over the bell-andspigot joint. Each joint location is excavated, the pipe exterior cleaned and the rubber lined, stainless steel sleeve bolted into place. This option is routinely used to spot repair welded steel 
lines and variations of it have been used to bridge cast-iron joints in the past. However, this repair method is generally not used for cast-iron pipes because external encapsulation is considered to provide superior sealing characteristics.

\section{External Encapsulation}

The most common cast-iron joint repairs involve external encapsulation. Several utilities making use of keyhole tools and vacuum excavation to minimize the size (and therefore costs) associated with excavation and follow-on surface restoration. Once the bell joint is fully exposed and its entire circumference cleaned with pneumatic chippers and grit blasters, an encapsulation mold is placed around the joint. The mold is then filled with a synthetic rubber in its liquid state that cures to a flexible material that permanently adheres to the pipe yet allows the joint to move under thermal expansion/contraction cycles without leaking. These systems are suitable for low-pressure lines.

The primary benefits of external encapsulation are its relatively low costs and the ability to test that leaks have been stopped using a simple soap test before closing the excavation. The main drawbacks are the large (and expensive) excavation for larger pipes (12 inch and up) and the necessity to completely expose and clean the entire joint circumference.

\section{Internal Encapsulation}

Several groups are developing internally-applied anaerobic sealant for repairing leaking cast-iron joints. Products include the PLCS Mainspray and the EmBridge Energy/Con Edison Cis-Bot joint sealing robot. To date, these systems have demonstrated limited success and limited usage for a variety of reasons not related to the anaerobic sealant used.

For example, those systems which simply spray sealant at each joint location and depend on diffusion to wet the jute often do not completely eliminate leaks since full wetting of the packing material cannot be guaranteed. In fact, in some situations large amounts of jute material may have actually broken out and have become displaced from the bell-and-spigot joint, leaving nothing for the sealant to bond to. In addition, low-pressure cast-iron mains often have significant amounts of debris. As the tethered robot is pushed through the main, this debris can accumulate in front of the tool. This can reduce the operator's ability to correctly position the robot at the bell-and-spigot interface due to obstruction of the video camera lens, or prevent further forward movement due to build-up of a debris wall. It has also been reported that debris can cut and damage the robot umbilical and that the anaerobic material can prematurely solidify due to its contact with metal ions in the debris.

\section{Cured-In-Place Pipe}

Several manufacturers provide cured-in-place pipe (CIPP) liners for rehabilitating sections of damaged piping. These systems consist of a flexible liner, usually made from polyester that has been inverted (turned inside out) prior to installation. The liner is saturated with a liquid thermosetting resin that is caused to harden by pumping either hot water or steam inside the liner once it has been placed across the pipe section to be rehabilitated. This process 
results in a continuous, tight-fitting pipe liner within the existing host pipe. Products are available for both non-pressurized and pressurized piping systems operating at pressures up to 200 psig. Once cured, the liner has sufficient mechanical strength to bridge small holes and joints in pressurized pipes but still requires the overall host pipe to be mechanically sound. The pipe ID is typically cleaned prior to the installation using high-pressure water jetting systems.

As practiced, conventional CIPP liners are not suitable for use in live gas mains. The CIPP process blocks the entire pipe flow area during installation and curing, which prevents gas delivery to attached customers. In addition, a camera and cutter head robot are required to cut through the cured liner at each service tap location to re-establish flow communication between the line main and the service lines.

CIPP is used to rehabilitate continuous sections of pipe, whereas the proposed research focuses on making spot repairs to only to joints and other areas of pipe that have experienced localized corrosion or mechanical damage.

\section{Internal Repair Sleeves}

Link-Pipe's repair system comprises a cylindrical stainless-steel sleeve surrounded by an outer sleeve constructed of a combination felt/foam liner that is saturated with a liquid resin such as urethane immediately prior to installation. Sizes are available for repairing pipes from 4 to 54 inches in diameter.

The stainless-steel sleeve has a series of locking barbs along the longitudinal cut line that lock the sleeve against the host pipe wall once the sleeve has been mechanically expanded outward against the host pipe wall using an inflatable air bladder. The sleeve is carried to the repair point by slightly inflating the air bladder to hold the sleeve in place and then moving the wheeled sleeve carrier/inflation bladder through the pipe using push rods or by pulling it into place using cables. A CCD camera is used to observe each step of the installation.

At present, Link-Pipe installations require the host pipe to be taken out of service. As importantly, the Link-Pipe product is not capable of sealing active leaks since there is no pressure seal across the split sleeve. The operational procedure is to clean the pipe wall at each patch location in order to allow the resin to intimately bond to the pipe wall. This is necessary because the resin is relied on to create the pressure seal. Any voids or channels caused by lack of adhesion represent potential leak paths. Fortunately, the resins used by LinkPipe swell several-fold. This makes the design quite forgiving with regard to the cleanliness of the pipe, especially when combined with the mechanical compression provided by the sleeve once it is set. In practice, this has meant that use of high-pressure water jets to clean sewer lines and wire brushing of steel lines have been sufficient to effect pressure-tight bonds. The sleeve is then moved into place and the bladder inflated to 20-30 psig to lock the sleeve into place. The resin normally cures in 30 minutes with full cure strength achieved in one hour. A simple visual inspection of the stainless steel sleeve using the CCD camera indicates proper installation. Link-Pipe has reported that they are now developing products for the gas industry. 


\section{Technology Comparison}

Advantages and disadvantages of various joint-repair technologies are compared in the table below. The initial comparison shows that the proposed technology based on robotics will save significant costs to repair cast-iron joints.

\section{Comparison of Cast-Iron Pipe Joint Repair Methods}

\begin{tabular}{|c|c|c|c|}
\hline Joint Repair Method & Main Condition & $\begin{array}{l}\text { Repairs per } \\
\text { Excavation }\end{array}$ & Comments \\
\hline $\begin{array}{l}\text { External Bolt-on Repair } \\
\text { Sleeve }\end{array}$ & $\begin{array}{l}\text { in service (no impact on } \\
\text { gas delivery) }\end{array}$ & 1 & $\begin{array}{l}\text { conventional technique, most } \\
\text { common for steel pipes }\end{array}$ \\
\hline External Encapsulation & $\begin{array}{l}\text { in service (no impact on } \\
\text { gas delivery) }\end{array}$ & 1 & $\begin{array}{l}\text { most common repair technique for } \mathrm{Cl} \\
\text { joints }\end{array}$ \\
\hline Internal Encapsulation & $\begin{array}{l}\text { in service (no impact on } \\
\text { gas delivery) }\end{array}$ & $\begin{array}{l}\text { 10-12 repairs each } \\
\text { direction }\end{array}$ & $\begin{array}{l}\text { dependent on condition of jute } \\
\text { sealant }\end{array}$ \\
\hline Cured-in-Place Pipe & $\begin{array}{l}\text { out of service } \\
\text { (interrupts gas delivery) }\end{array}$ & $\begin{array}{l}\text { entire pipe segment } \\
\text { up to } 40 \text { joint repairs }\end{array}$ & $\begin{array}{l}\text { rarely used due to length of time } \\
\text { main must be taken out of service }\end{array}$ \\
\hline $\begin{array}{l}\text { Internal Repair Sleeve } \\
\text { (Conventional) }\end{array}$ & $\begin{array}{l}\text { out of service } \\
\text { (interrupts gas delivery) }\end{array}$ & up to 40 joint repairs & $\begin{array}{l}\text { rarely used due to length of time } \\
\text { main must be taken out of service }\end{array}$ \\
\hline $\begin{array}{l}\text { Internal Repair Sleeve } \\
\text { (Robotic) }\end{array}$ & $\begin{array}{l}\text { in service (no impact on } \\
\text { gas delivery) }\end{array}$ & $\begin{array}{l}\text { 40-80 repairs each } \\
\text { direction }\end{array}$ & $\begin{array}{l}\text { independent of condition of jute; } \\
\text { significant savings possible versus } \\
\text { other techniques }\end{array}$ \\
\hline
\end{tabular}

Advantage; Disadvantage 


\section{Appendix B - CT Pushing/Buckling Analysis}

\section{CT Technology}

Coiled tubing (CT) is a long string of tubing without joints that is bent onto and off of a spool as it is deployed. It was first introduced to the oilfield in 1963 as a cost-saving technique for performing workovers in wells. Early applications were limited to lighter duties due to small CT diameter and relatively poor reliability. Development of CT remained relatively static until an oil price shock in the 1980s spurred the development of CT equipment and techniques. Dramatic improvements in materials and performance then ushered CT technology into the mainstream of oilfield operations throughout the 1990s and continuing to the present.

CT systems have found widespread use for drilling, completion and workover operations in the oil and gas industry. Primary advantages with CT include easier and less expensive transportation and mobilization; faster trip times in and out of the well (no threaded joints to make and break); and the ability to perform operations in live wells. Reduced rig costs and trip times have provided cost reductions by as much as $50-70 \%$ when compared to conventional workovers in oil and gas wells. Cost savings and increased efficiencies are particularly dramatic in more remote locations (such as Arctic fields) where infrastructures are less developed.

GTI and MTI have successfully used CT systems for a variety of utility pipe inspection and repair operations (Porter and Pittard, 1999). In this project, the CT and its surface unit (Figure B-1) will provide primary locomotion of the cast-iron joint sealing robot trains.

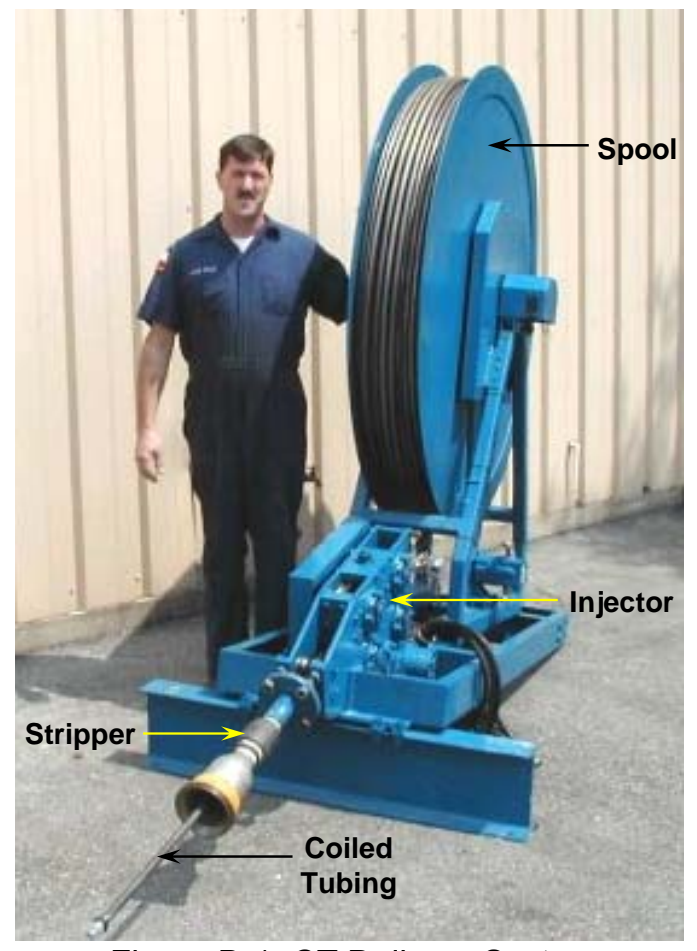

Figure B-1. CT Delivery System

\section{Buckling Theory}

Buckling is almost always a serious concern in CT operations (especially true inside a horizontal section of gas main) because CT is relatively thin and flexible. A buckled CT string does not effectively transmit axial push force along the sting, and requires greater push force simply to overcome friction and move the string forward. To best design the surface CT unit, understanding and minimizing the impacts of CT buckling inside the gas main are especially critical, since it is desired to reach far into very long and shallow horizontal gas mains.

As a compressive force is increased on a length of CT lying along the bottom of a nonvertical gas main, a critical point is reached where the tubing just begins to buckle. At this point, 
the CT will assume a sinusoidal configuration (basically a two-dimensional undulation) across the bottom of the gas main (Figure B-2). The critical force required to initiate sinusoidal buckling can be estimated using the following equation (Dawson and Paslay, 1984).

$$
\mathrm{F}_{\mathrm{sin}}=2 \sqrt{\frac{\mathrm{EIW} \sin \theta}{\mathrm{r}}}
$$

where

$$
\begin{aligned}
& \mathrm{F}_{\text {sin }}=\text { critical axial load to begin sinusoidal buckling } \\
& \mathrm{E} \quad=\text { elastic modulus } \\
& \mathrm{I}=\text { moment of inertia of tubing cross section } \\
& \mathrm{W}=\text { tubing weight per unit length in mud } \\
& \theta \quad=\text { inclination angle of gas main }\left(90^{\circ}\right. \text { for a horizontal gas main) } \\
& \mathrm{r}=\text { radial clearance between tubing and gas main }
\end{aligned}
$$

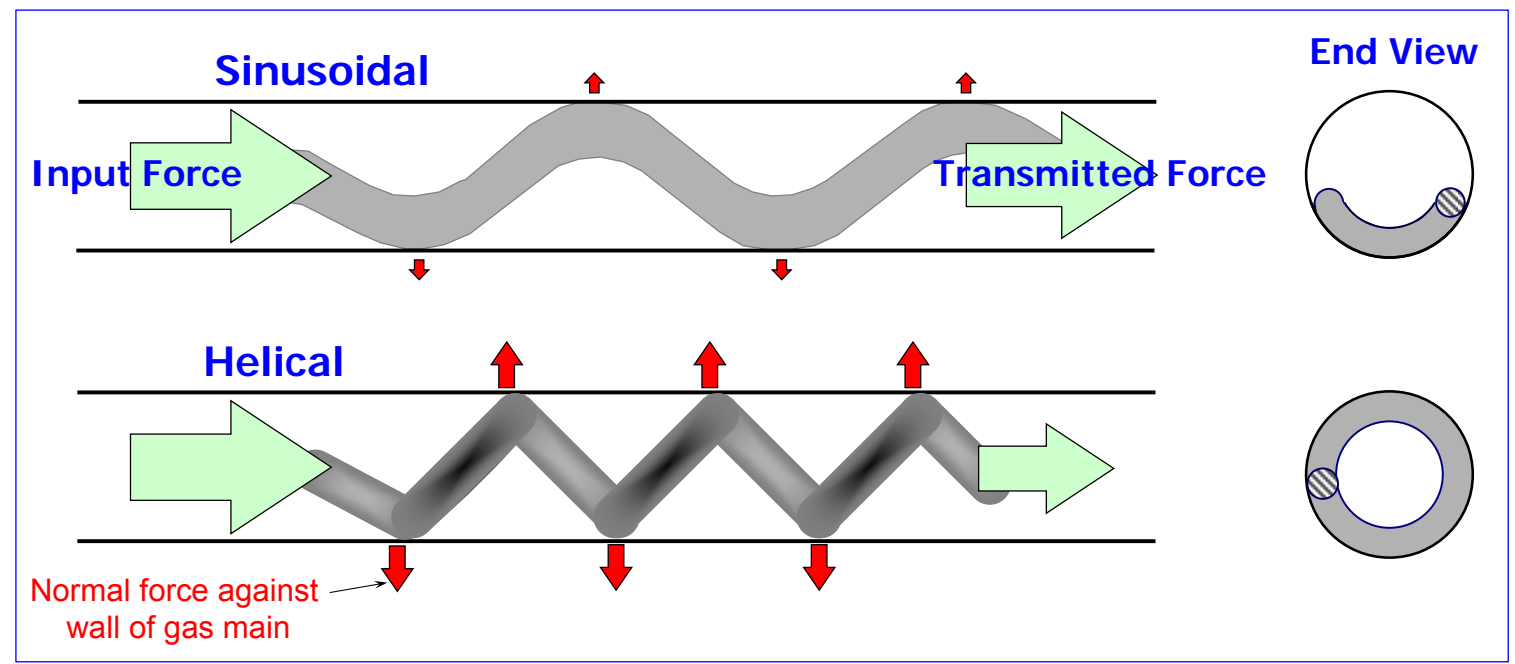

Figure B-2. CT Buckling Modes

If the compressive load pushing the CT farther down the gas main is increased beyond the point where sinusoidal buckling occurs, a second general mode of buckling-helical buckling - will eventually set up. In helical buckling, the tubing forms a helix (spiral) against the wall of the gas main (a three-dimensional shape like a stretched spring). The critical axial load required to achieve helical buckling is estimated using (Chen, Lin, and Cheatham, 1989):

$$
F_{\text {hel }}=2 \sqrt{2} \sqrt{\frac{\text { EIW } \sin \theta}{r}}
$$

where

$$
F_{\text {hel }}=\text { critical axial load for helical buckling }
$$

By comparing Equations B-1 and B-2, it is seen that helical buckling begins when the axial compressive force is about 1.4 times the sinusoidal critical buckling load. 
As described, the smallest critical force for pushing CT in a horizontal gas main is the compressive load that initiates sinusoidal buckling. Next is the critical compressive force that shifts the tubing from sinusoidal to helical buckling. Finally, if the axial load is increased above the helical buckling load, eventually the tubing begins to yield, which is closely associated with a lock-up condition (no forward advance regardless of the force applied).

Numerous operations in oil and gas wells have demonstrated that CT can safely be pushed into a hole using axial loads considerably in excess of the sinusoidal buckling limit. Field operations have also verified that axial forces larger than the helical buckling limit can safely be used to push CT into deviated holes. For designing the expected limits of the cast-iron joint sealing robot system, it was assumed that the maximum practical load that could be applied to push the CT down the gas main was dictated by the onset of helical buckling.

\section{Maximum Reach of CT}

The maximum length of CT that can be pushed into a horizontal gas main can be estimated as occurring when any axial load along the tubing reaches the helical buckling load. This maximum reach of tubing, L, can be calculated by the following:

$$
L=\frac{F-B}{f W}
$$

where

$\mathrm{F}=$ critical buckling load, using $\mathrm{F}_{\text {hel }}$ (Eq. B-2)

$\mathrm{B}=$ load or tractor pulling force at the CT end

$\mathrm{f} \quad=$ friction factor between gas main and CT string (typical values from 0.2 to 0.4 )

$\mathrm{W}=$ tubing weight per unit length

Equation B-3 is only applicable for a uniform tubing with constant OD and wall thickness.

As stated, a primary concern for the joint sealing robot system is to determine the length of CT that can be pushed into a gas main with the repair train elements before helical buckling occurs. An analysis was performed to determine what choices of CT (CT size and wall thickness, gas main size, and friction factor) would allow the maximum travel in the gas main.

By applying Equations B-2 and B-3, maximum lengths of CT in the gas main were calculated for a range of CT diameters $\left(1 \frac{1}{4}, 1\right.$ and $7 / 8$ in) and wall thicknesses, gas main sizes, and friction factors between CT string and gas main. In the analysis, an elastic material modulus of $30,000,000 \mathrm{psi}$ and density of $490 \mathrm{lb} / \mathrm{ft}^{3}$ were used for standard steel CT material.

Table B-1 shows maximum reach for CT in a 12-in. gas main with 0.25 friction factor; Table B-2 maximum reach for CT in an 18-in. gas main with 0.25 friction factor; and Table B-3 maximum reach for $\mathrm{CT}$ in a 24 -in. gas main with 0.25 friction factor.

These cases were then run with a more conservative friction factor of 0.35 . Table B-4 shows maximum reach for $\mathrm{CT}$ in a 12-in. gas main with 0.35 friction factor; Table B-5 maximum 
reach for $\mathrm{CT}$ in an 18-in. gas main with 0.35 friction factor; and Table B-6 maximum reach for $\mathrm{CT}$ in a 24-in. gas main with 0.35 friction factor.

Five base cases of CT downhole loading conditions are shown in each table. In the first case (L1), there is no load acting on the CT leading end, which simulates the condition when tripping CT only into the gas main. In the second and third cases (L2 and L3), there are 25-Ib and $50-\mathrm{lb}$ forces acting at the CT leading end, which is to simulate pushing with moderate drag loads present due to the weight of the robot train. In the fourth and fifth cases (L4 and L5), there are $100 \mathrm{lb}$ and $200 \mathrm{lb}$ forces pulling the CT string forward, which simulates the case of a special tractor incorporated as part of the bottomhole assembly.

If 1 -in. OD CT is used for the cast-iron pipe joint sealing operation, the maximum reach is just above $1200 \mathrm{ft}$ in 12-in. diameter gas mains with a 25-lb drag load and a friction factor of 0.25 (Table B-1). This distance is reduced to approximately $1000 \mathrm{ft}$ for $7 / 8$-in. CT for the same end load.

Table B-1. Maximum Reach of CT String

(Gas Main ID $=12$ in, Friction Factor $=0.25$ )

\begin{tabular}{|c|c|c|c|c|c|c|c|c|c|}
\hline $\begin{array}{l}\text { OD } \\
\text { (in) }\end{array}$ & $\begin{array}{l}\text { Wall } \\
\text { (in) }\end{array}$ & $\begin{array}{l}\text { ID } \\
\text { (in) }\end{array}$ & $\begin{array}{c}\text { Weight } \\
\text { (lb/ft) }\end{array}$ & $\begin{array}{l}F_{\text {hel }} \\
\left(\mathbf{l b}_{\mathrm{f}}\right)\end{array}$ & $\begin{array}{c}\text { L1 }\left(0 \mathrm{Ib}_{\mathrm{f}}\right) \\
(\mathrm{ft})\end{array}$ & $\begin{array}{c}\left.\text { L2 (25 ll } b_{f}\right) \\
(f t)\end{array}$ & $\begin{array}{c}\text { L3 }\left(50 \mathrm{lb}_{\mathrm{f}}\right) \\
(\mathrm{ft})\end{array}$ & $\begin{array}{c}\left.\text { L4 (-100 lb } b_{f}\right) \\
(f t)\end{array}$ & $\begin{array}{c}\left.\text { L5 (-200 lb } b_{f}\right) \\
(f t)\end{array}$ \\
\hline 1.250 & 0.087 & 1.076 & 1.082 & 466 & 1724 & 1632 & 1539 & 2094 & 2464 \\
\hline 1.250 & 0.095 & 1.060 & 1.173 & 503 & 1714 & 1628 & 1543 & 2055 & 2396 \\
\hline 1.250 & 0.102 & 1.046 & 1.252 & 533 & 1704 & 1624 & 1544 & 2023 & 2343 \\
\hline 1.250 & 0.109 & 1.032 & 1.330 & 563 & 1694 & 1619 & 1544 & 1995 & 2296 \\
\hline 1.250 & 0.118 & 1.014 & 1.428 & 601 & 1683 & 1613 & 1543 & 1963 & 2243 \\
\hline 1.250 & 0.125 & 1.000 & 1.503 & 629 & 1674 & 1607 & 1541 & 1940 & 2206 \\
\hline 1.250 & 0.134 & 0.982 & 1.599 & 664 & 1662 & 1599 & 1537 & 1912 & 2162 \\
\hline 1.250 & 0.145 & 0.960 & 1.713 & 706 & 1648 & 1589 & 1531 & 1881 & 2115 \\
\hline 1.250 & 0.156 & 0.938 & 1.824 & 745 & 1634 & 1579 & 1525 & 1853 & 2073 \\
\hline 1.250 & 0.175 & 0.900 & 2.011 & 810 & 1610 & 1561 & 1511 & 1809 & 2008 \\
\hline 1.000 & 0.087 & 0.826 & 0.849 & 285 & 1341 & 1223 & 1105 & 1812 & 2283 \\
\hline 1.000 & 0.095 & 0.810 & 0.919 & 306 & 1330 & 1221 & 1113 & 1765 & 2201 \\
\hline 1.000 & 0.102 & 0.796 & 0.979 & 323 & 1321 & 1219 & 1117 & 1730 & 2138 \\
\hline 1.000 & 0.109 & 0.782 & 1.038 & 341 & 1312 & 1216 & 1120 & 1698 & 2083 \\
\hline 1.000 & 0.118 & 0.764 & 1.113 & 362 & 1300 & 1211 & 1121 & 1660 & 2019 \\
\hline 1.000 & 0.125 & 0.750 & 1.169 & 378 & 1292 & 1207 & 1121 & 1634 & 1976 \\
\hline 0.875 & 0.080 & 0.715 & 0.680 & 197 & 1161 & 1014 & 867 & 1750 & 2338 \\
\hline 0.875 & 0.087 & 0.701 & 0.733 & 211 & 1152 & 1016 & 879 & 1698 & 2244 \\
\hline 0.875 & 0.095 & 0.685 & 0.792 & 226 & 1142 & 1016 & 890 & 1647 & 2152 \\
\hline 0.875 & 0.102 & 0.671 & 0.843 & 239 & 1133 & 1015 & 896 & 1608 & 2082 \\
\hline 0.875 & 0.109 & 0.657 & 0.893 & 251 & 1124 & 1012 & 900 & 1572 & 2020 \\
\hline 0.875 & 0.118 & 0.639 & 0.955 & 266 & 1114 & 1009 & 904 & 1532 & 1951 \\
\hline
\end{tabular}


Table B-2. Maximum Reach of CT String

(Gas Main ID = 18 in, Friction Factor $=0.25$ )

\begin{tabular}{|c|c|c|c|c|c|c|c|c|c|}
\hline $\begin{array}{l}\text { OD } \\
\text { (in) }\end{array}$ & $\begin{array}{l}\text { Wall } \\
\text { (in) }\end{array}$ & $\begin{array}{l}\text { ID } \\
\text { (in) }\end{array}$ & $\begin{array}{l}\text { Weight } \\
\text { (Ib/ft) }\end{array}$ & $\begin{array}{l}F_{\text {hel }} \\
\left(I b_{f}\right)\end{array}$ & $\begin{array}{l}\text { L1 }\left(0 \mathrm{Ib}_{\mathrm{f}}\right) \\
\text { (ft) }\end{array}$ & $\begin{array}{l}\text { L2 }\left(25 \mathrm{Ib}_{\mathrm{f}}\right) \\
\text { (ft) }\end{array}$ & $\begin{array}{c}\text { L3 }\left(50 \mathrm{Ib}_{\mathrm{f}}\right) \\
(\mathrm{ft})\end{array}$ & $\begin{array}{c}\left.\text { L4 (-100 l lb } b_{f}\right) \\
\text { (ft) }\end{array}$ & $\begin{array}{c}\operatorname{L5}\left(-200 \quad l b_{f}\right) \\
\text { (ft) }\end{array}$ \\
\hline 1.250 & 0.087 & 1.076 & 1.082 & 374 & 1381 & 1289 & 1196 & 1751 & 2121 \\
\hline 1.250 & 0.095 & 1.060 & 1.173 & 403 & 1373 & 1288 & 1202 & 1714 & 2055 \\
\hline 1.250 & 0.102 & 1.046 & 1.252 & 427 & 1365 & 1285 & 1205 & 1685 & 2004 \\
\hline 1.250 & 0.109 & 1.032 & 1.330 & 451 & 1357 & 1282 & 1207 & 1658 & 1959 \\
\hline 1.250 & 0.118 & 1.014 & 1.428 & 481 & 1348 & 1278 & 1208 & 1628 & 1908 \\
\hline 1.250 & 0.125 & 1.000 & 1.503 & 504 & 1341 & 1274 & 1208 & 1607 & 1873 \\
\hline 1.250 & 0.134 & 0.982 & 1.599 & 532 & 1331 & 1269 & 1206 & 1581 & 1832 \\
\hline 1.250 & 0.145 & 0.960 & 1.713 & 565 & 1320 & 1262 & 1203 & 1554 & 1787 \\
\hline 1.250 & 0.156 & 0.938 & 1.824 & 597 & 1309 & 1254 & 1200 & 1528 & 1748 \\
\hline 1.250 & 0.175 & 0.900 & 2.011 & 649 & 1290 & 1240 & 1191 & 1489 & 1688 \\
\hline 1.000 & 0.087 & 0.826 & 0.849 & 229 & 1078 & 961 & 843 & 1550 & 2021 \\
\hline 1.000 & 0.095 & 0.810 & 0.919 & 246 & 1070 & 961 & 852 & 1505 & 1941 \\
\hline 1.000 & 0.102 & 0.796 & 0.979 & 260 & 1063 & 961 & 858 & 1471 & 1880 \\
\hline 1.000 & 0.109 & 0.782 & 1.038 & 274 & 1056 & 959 & 863 & 1441 & 1826 \\
\hline 1.000 & 0.118 & 0.764 & 1.113 & 291 & 1046 & 956 & 866 & 1406 & 1765 \\
\hline 1.000 & 0.125 & 0.750 & 1.169 & 304 & 1039 & 954 & 868 & 1382 & 1724 \\
\hline 0.875 & 0.080 & 0.715 & 0.680 & 159 & 936 & 789 & 642 & 1524 & 2112 \\
\hline 0.875 & 0.087 & 0.701 & 0.733 & 170 & 929 & 792 & 656 & 1474 & 2020 \\
\hline 0.875 & 0.095 & 0.685 & 0.792 & 182 & 921 & 794 & 668 & 1426 & 1931 \\
\hline 0.875 & 0.102 & 0.671 & 0.843 & 192 & 913 & 795 & 676 & 1388 & 1862 \\
\hline 0.875 & 0.109 & 0.657 & 0.893 & 202 & 906 & 794 & 682 & 1354 & 1802 \\
\hline 0.875 & 0.118 & 0.639 & 0.955 & 214 & 898 & 793 & 688 & 1316 & 1735 \\
\hline
\end{tabular}

Table B-3. Maximum Reach of CT String

(Gas Main ID = 24 in, Friction Factor $=0.25$ )

\begin{tabular}{|c|c|c|c|c|c|c|c|c|c|}
\hline $\begin{array}{l}\text { OD } \\
\text { (in) }\end{array}$ & $\begin{array}{l}\text { Wall } \\
\text { (in) }\end{array}$ & $\begin{array}{l}\text { ID } \\
\text { (in) }\end{array}$ & $\begin{array}{l}\text { Weight } \\
\text { (lb/ft) }\end{array}$ & $\begin{array}{l}F_{\text {hel }} \\
\left(I b_{f}\right)\end{array}$ & $\begin{array}{l}\text { L1 }\left(0 \mathrm{Ib}_{\mathrm{f}}\right) \\
\text { (ft) }\end{array}$ & $\begin{array}{l}\text { L2 }\left(25 \mathrm{Ib}_{\mathrm{f}}\right) \\
\text { (ft) }\end{array}$ & $\begin{array}{c}\text { L3 }\left(50 \mathrm{Ib}_{\mathrm{f}}\right) \\
\text { (ft) }\end{array}$ & $\begin{array}{c}\left.\text { L4 (-100 lb } b_{f}\right) \\
\text { (ft) }\end{array}$ & $\begin{array}{c}\operatorname{L5}\left(-200 \quad l b_{f}\right) \\
(f t)\end{array}$ \\
\hline 1.250 & 0.087 & 1.076 & 1.082 & 321 & 1185 & 1093 & 1000 & 1555 & 1925 \\
\hline 1.250 & 0.095 & 1.060 & 1.173 & 345 & 1178 & 1093 & 1007 & 1519 & 1860 \\
\hline 1.250 & 0.102 & 1.046 & 1.252 & 367 & 1171 & 1091 & 1012 & 1491 & 1810 \\
\hline 1.250 & 0.109 & 1.032 & 1.330 & 387 & 1165 & 1090 & 1014 & 1466 & 1766 \\
\hline 1.250 & 0.118 & 1.014 & 1.428 & 413 & 1157 & 1087 & 1017 & 1437 & 1717 \\
\hline 1.250 & 0.125 & 1.000 & 1.503 & 432 & 1151 & 1084 & 1018 & 1417 & 1683 \\
\hline 1.250 & 0.134 & 0.982 & 1.599 & 457 & 1142 & 1080 & 1017 & 1392 & 1643 \\
\hline 1.250 & 0.145 & 0.960 & 1.713 & 485 & 1133 & 1074 & 1016 & 1366 & 1600 \\
\hline 1.250 & 0.156 & 0.938 & 1.824 & 512 & 1123 & 1069 & 1014 & 1343 & 1562 \\
\hline 1.250 & 0.175 & 0.900 & 2.011 & 557 & 1107 & 1057 & 1008 & 1306 & 1505 \\
\hline 1.000 & 0.087 & 0.826 & 0.849 & 197 & 927 & 809 & 692 & 1398 & 1869 \\
\hline 1.000 & 0.095 & 0.810 & 0.919 & 211 & 920 & 811 & 702 & 1355 & 1790 \\
\hline 1.000 & 0.102 & 0.796 & 0.979 & 224 & 914 & 812 & 709 & 1322 & 1731 \\
\hline 1.000 & 0.109 & 0.782 & 1.038 & 235 & 908 & 811 & 715 & 1293 & 1678 \\
\hline 1.000 & 0.118 & 0.764 & 1.113 & 250 & 899 & 810 & 720 & 1259 & 1618 \\
\hline 1.000 & 0.125 & 0.750 & 1.169 & 261 & 894 & 808 & 723 & 1236 & 1578 \\
\hline 0.875 & 0.080 & 0.715 & 0.680 & 137 & 805 & 658 & 511 & 1394 & 1982 \\
\hline 0.875 & 0.087 & 0.701 & 0.733 & 146 & 799 & 663 & 526 & 1345 & 1891 \\
\hline 0.875 & 0.095 & 0.685 & 0.792 & 157 & 792 & 666 & 540 & 1297 & 1802 \\
\hline 0.875 & 0.102 & 0.671 & 0.843 & 166 & 786 & 667 & 549 & 1260 & 1735 \\
\hline 0.875 & 0.109 & 0.657 & 0.893 & 174 & 780 & 668 & 556 & 1228 & 1676 \\
\hline 0.875 & 0.118 & 0.639 & 0.955 & 184 & 772 & 668 & 563 & 1191 & 1610 \\
\hline
\end{tabular}


Table B-4. Maximum Reach of CT String

(Gas Main ID $=12$ in, Friction Factor $=0.35$ )

\begin{tabular}{|c|c|c|c|c|c|c|c|c|c|}
\hline $\begin{array}{l}\text { OD } \\
\text { (in) }\end{array}$ & $\begin{array}{l}\text { Wall } \\
\text { (in) }\end{array}$ & $\begin{array}{l}\text { ID } \\
\text { (in) }\end{array}$ & $\begin{array}{l}\text { Weight } \\
\text { (Ib/ft) }\end{array}$ & $\begin{array}{l}F_{\text {hel }} \\
\left(I b_{f}\right)\end{array}$ & $\begin{array}{l}\text { L1 }\left(0 \mathrm{Ib}_{\mathrm{f}}\right) \\
\text { (ft) }\end{array}$ & $\begin{array}{l}\text { L2 }\left(25 \mathrm{Ib}_{\mathrm{f}}\right) \\
\text { (ft) }\end{array}$ & $\begin{array}{c}\text { L3 }\left(50 \mathrm{Ib}_{\mathrm{f}}\right) \\
(\mathrm{ft})\end{array}$ & $\begin{array}{c}\left.\text { L4 (-100 l lb } b_{f}\right) \\
\text { (ft) }\end{array}$ & $\begin{array}{c}\left.\text { L5 (-200 l lb } b_{f}\right) \\
\text { (ft) }\end{array}$ \\
\hline 1.250 & 0.087 & 1.076 & 1.082 & 466 & 1232 & 1166 & 1100 & 1496 & 1760 \\
\hline 1.250 & 0.095 & 1.060 & 1.173 & 503 & 1224 & 1163 & 1102 & 1468 & 1711 \\
\hline 1.250 & 0.102 & 1.046 & 1.252 & 533 & 1217 & 1160 & 1103 & 1445 & 1674 \\
\hline 1.250 & 0.109 & 1.032 & 1.330 & 563 & 1210 & 1157 & 1103 & 1425 & 1640 \\
\hline 1.250 & 0.118 & 1.014 & 1.428 & 601 & 1202 & 1152 & 1102 & 1402 & 1602 \\
\hline 1.250 & 0.125 & 1.000 & 1.503 & 629 & 1196 & 1148 & 1101 & 1386 & 1576 \\
\hline 1.250 & 0.134 & 0.982 & 1.599 & 664 & 1187 & 1142 & 1098 & 1366 & 1544 \\
\hline 1.250 & 0.145 & 0.960 & 1.713 & 706 & 1177 & 1135 & 1094 & 1344 & 1511 \\
\hline 1.250 & 0.156 & 0.938 & 1.824 & 745 & 1167 & 1128 & 1089 & 1324 & 1481 \\
\hline 1.250 & 0.175 & 0.900 & 2.011 & 810 & 1150 & 1115 & 1079 & 1292 & 1434 \\
\hline 1.000 & 0.087 & 0.826 & 0.849 & 285 & 958 & 874 & 789 & 1294 & 1631 \\
\hline 1.000 & 0.095 & 0.810 & 0.919 & 306 & 950 & 872 & 795 & 1261 & 1572 \\
\hline 1.000 & 0.102 & 0.796 & 0.979 & 323 & 944 & 871 & 798 & 1236 & 1527 \\
\hline 1.000 & 0.109 & 0.782 & 1.038 & 341 & 937 & 869 & 800 & 1213 & 1488 \\
\hline 1.000 & 0.118 & 0.764 & 1.113 & 362 & 929 & 865 & 801 & 1186 & 1442 \\
\hline 1.000 & 0.125 & 0.750 & 1.169 & 378 & 923 & 862 & 801 & 1167 & 1412 \\
\hline 0.875 & 0.080 & 0.715 & 0.680 & 197 & 829 & 724 & 619 & 1250 & 1670 \\
\hline 0.875 & 0.087 & 0.701 & 0.733 & 211 & 823 & 726 & 628 & 1213 & 1603 \\
\hline 0.875 & 0.095 & 0.685 & 0.792 & 226 & 816 & 726 & 635 & 1177 & 1537 \\
\hline 0.875 & 0.102 & 0.671 & 0.843 & 239 & 809 & 725 & 640 & 1148 & 1487 \\
\hline 0.875 & 0.109 & 0.657 & 0.893 & 251 & 803 & 723 & 643 & 1123 & 1443 \\
\hline 0.875 & 0.118 & 0.639 & 0.955 & 266 & 795 & 721 & 646 & 1095 & 1394 \\
\hline
\end{tabular}

Table B-5. Maximum Reach of CT String

(Gas Main ID = 18 in, Friction Factor $=0.35$ )

\begin{tabular}{|c|c|c|c|c|c|c|c|c|c|}
\hline $\begin{array}{l}\text { OD } \\
\text { (in) }\end{array}$ & $\begin{array}{l}\text { Wall } \\
\text { (in) }\end{array}$ & $\begin{array}{l}\text { ID } \\
\text { (in) }\end{array}$ & $\begin{array}{l}\text { Weight } \\
\text { (lb/ft) }\end{array}$ & $\begin{array}{l}F_{\text {hel }} \\
\left(I b_{f}\right)\end{array}$ & $\begin{array}{c}\text { L1 }\left(0 \mathrm{Ib}_{\mathrm{f}}\right) \\
\text { (ft) }\end{array}$ & $\begin{array}{l}\text { L2 }\left(25 \mathrm{Ib}_{\mathrm{f}}\right) \\
\text { (ft) }\end{array}$ & $\begin{array}{c}\text { L3 }\left(50 \mathrm{Ib}_{\mathrm{f}}\right) \\
\text { (ft) }\end{array}$ & $\begin{array}{c}\left.\text { L4 (-100 lb } b_{f}\right) \\
\text { (ft) }\end{array}$ & $\begin{array}{c}\left.\text { L5 (-200 lb } \mathrm{Ib}_{\mathrm{f}}\right) \\
(\mathrm{ft})\end{array}$ \\
\hline 1.250 & 0.087 & 1.076 & 1.082 & 374 & 987 & 921 & 855 & 1251 & 1515 \\
\hline 1.250 & 0.095 & 1.060 & 1.173 & 403 & 981 & 920 & 859 & 1224 & 1468 \\
\hline 1.250 & 0.102 & 1.046 & 1.252 & 427 & 975 & 918 & 861 & 1203 & 1431 \\
\hline 1.250 & 0.109 & 1.032 & 1.330 & 451 & 970 & 916 & 862 & 1184 & 1399 \\
\hline 1.250 & 0.118 & 1.014 & 1.428 & 481 & 963 & 913 & 863 & 1163 & 1363 \\
\hline 1.250 & 0.125 & 1.000 & 1.503 & 504 & 958 & 910 & 863 & 1148 & 1338 \\
\hline 1.250 & 0.134 & 0.982 & 1.599 & 532 & 951 & 906 & 862 & 1130 & 1308 \\
\hline 1.250 & 0.145 & 0.960 & 1.713 & 565 & 943 & 901 & 860 & 1110 & 1277 \\
\hline 1.250 & 0.156 & 0.938 & 1.824 & 597 & 935 & 896 & 857 & 1092 & 1248 \\
\hline 1.250 & 0.175 & 0.900 & 2.011 & 649 & 922 & 886 & 851 & 1064 & 1206 \\
\hline 1.000 & 0.087 & 0.826 & 0.849 & 229 & 770 & 686 & 602 & 1107 & 1443 \\
\hline 1.000 & 0.095 & 0.810 & 0.919 & 246 & 764 & 687 & 609 & 1075 & 1386 \\
\hline 1.000 & 0.102 & 0.796 & 0.979 & 260 & 759 & 686 & 613 & 1051 & 1343 \\
\hline 1.000 & 0.109 & 0.782 & 1.038 & 274 & 754 & 685 & 616 & 1029 & 1304 \\
\hline 1.000 & 0.118 & 0.764 & 1.113 & 291 & 747 & 683 & 619 & 1004 & 1261 \\
\hline 1.000 & 0.125 & 0.750 & 1.169 & 304 & 742 & 681 & 620 & 987 & 1231 \\
\hline 0.875 & 0.080 & 0.715 & 0.680 & 159 & 669 & 564 & 458 & 1089 & 1509 \\
\hline 0.875 & 0.087 & 0.701 & 0.733 & 170 & 663 & 566 & 468 & 1053 & 1443 \\
\hline 0.875 & 0.095 & 0.685 & 0.792 & 182 & 658 & 567 & 477 & 1018 & 1379 \\
\hline 0.875 & 0.102 & 0.671 & 0.843 & 192 & 652 & 568 & 483 & 991 & 1330 \\
\hline 0.875 & 0.109 & 0.657 & 0.893 & 202 & 647 & 567 & 487 & 967 & 1287 \\
\hline 0.875 & 0.118 & 0.639 & 0.955 & 214 & 641 & 566 & 491 & 940 & 1239 \\
\hline
\end{tabular}


Table B-6. Maximum Reach of CT String

(Gas Main ID = 24 in, Friction Factor $=0.35$ )

\begin{tabular}{|c|c|c|c|c|c|c|c|c|c|}
\hline $\begin{array}{l}\text { OD } \\
\text { (in) }\end{array}$ & $\begin{array}{l}\text { Wall } \\
\text { (in) }\end{array}$ & $\begin{array}{l}\text { ID } \\
\text { (in) }\end{array}$ & $\begin{array}{c}\text { Weight } \\
\text { (lb/ft) }\end{array}$ & $\begin{array}{l}F_{\text {hel }} \\
\left(\mathbf{l b}_{\mathrm{f}}\right)\end{array}$ & $\begin{array}{c}\text { L1 }\left(0 \mathrm{Ib}_{\mathrm{f}}\right) \\
\text { (ft) }\end{array}$ & $\begin{array}{c}\left.\text { L2 (25 I l } b_{f}\right) \\
\text { (ft) }\end{array}$ & $\begin{array}{c}\text { L3 }\left(50 \mathrm{Ib}_{\mathrm{f}}\right) \\
\text { (ft) }\end{array}$ & $\begin{array}{c}\left.\text { L4 (-100 lb } b_{f}\right) \\
\text { (ft) }\end{array}$ & $\begin{array}{c}\left.\text { L5 (-200 lb } b_{f}\right) \\
\text { (ft) }\end{array}$ \\
\hline 1.250 & 0.087 & 1.076 & 1.082 & 321 & 847 & 781 & 715 & 1111 & 1375 \\
\hline 1.250 & 0.095 & 1.060 & 1.173 & 345 & 841 & 780 & 720 & 1085 & 1329 \\
\hline 1.250 & 0.102 & 1.046 & 1.252 & 367 & 837 & 780 & 723 & 1065 & 1293 \\
\hline 1.250 & 0.109 & 1.032 & 1.330 & 387 & 832 & 778 & 725 & 1047 & 1262 \\
\hline 1.250 & 0.118 & 1.014 & 1.428 & 413 & 826 & 776 & 726 & 1026 & 1226 \\
\hline 1.250 & 0.125 & 1.000 & 1.503 & 432 & 822 & 774 & 727 & 1012 & 1202 \\
\hline 1.250 & 0.134 & 0.982 & 1.599 & 457 & 816 & 771 & 727 & 995 & 1173 \\
\hline 1.250 & 0.145 & 0.960 & 1.713 & 485 & 809 & 767 & 726 & 976 & 1143 \\
\hline 1.250 & 0.156 & 0.938 & 1.824 & 512 & 802 & 763 & 724 & 959 & 1116 \\
\hline 1.250 & 0.175 & 0.900 & 2.011 & 557 & 791 & 755 & 720 & 933 & 1075 \\
\hline 1.000 & 0.087 & 0.826 & 0.849 & 197 & 662 & 578 & 494 & 999 & 1335 \\
\hline 1.000 & 0.095 & 0.810 & 0.919 & 211 & 657 & 579 & 502 & 968 & 1279 \\
\hline 1.000 & 0.102 & 0.796 & 0.979 & 224 & 653 & 580 & 507 & 944 & 1236 \\
\hline 1.000 & 0.109 & 0.782 & 1.038 & 235 & 648 & 579 & 511 & 923 & 1199 \\
\hline 1.000 & 0.118 & 0.764 & 1.113 & 250 & 642 & 578 & 514 & 899 & 1156 \\
\hline 1.000 & 0.125 & 0.750 & 1.169 & 261 & 638 & 577 & 516 & 883 & 1127 \\
\hline 0.875 & 0.080 & 0.715 & 0.680 & 137 & 575 & 470 & 365 & 995 & 1416 \\
\hline 0.875 & 0.087 & 0.701 & 0.733 & 146 & 571 & 473 & 376 & 961 & 1350 \\
\hline 0.875 & 0.095 & 0.685 & 0.792 & 157 & 566 & 476 & 386 & 927 & 1287 \\
\hline 0.875 & 0.102 & 0.671 & 0.843 & 166 & 561 & 477 & 392 & 900 & 1239 \\
\hline 0.875 & 0.109 & 0.657 & 0.893 & 174 & 557 & 477 & 397 & 877 & 1197 \\
\hline 0.875 & 0.118 & 0.639 & 0.955 & 184 & 552 & 477 & 402 & 851 & 1150 \\
\hline
\end{tabular}

As gas main OD is increased, maximum distance the repair robot can be pushed into the main decreases. For example, the maximum distance for 1-in. CT (which was shown to be near $1200 \mathrm{ft}$ for a $25 \mathrm{lb}$ robot drag load when pushed inside $12 \mathrm{in}$. mains) is reduced to $961 \mathrm{ft}$ in $18 \mathrm{in}$. mains and to $800 \mathrm{ft}$ in $24 \mathrm{in}$. mains for a friction factor of 0.25 . Additional push length can be achieved by employing a tapered CT string, use of a downhole tractor or a combination of these two approaches.

\section{References}

Porter, P.C., and Pittard, G.T., 1999: "Magnetic Flux Leakage Technology for Inspecting Live Gas Distribution Mains," GRI-99/0199, Gas Research Institute, October 1999.

Chen, Y.C., Lin, Y.H. and Cheatham, J.B., 1989: "An Analysis of Tubing and Casing Buckling in Horizontal Wells," OTC 6037, $21^{\text {st }}$ Annual OTC, Houston, Texas, May 1-4.

Dawson, P., and Paslay, P.R., 1984: "Drillpipe Buckling in Inclined Holes," Journal of Petroleum Technology, October.

Newman, K.R., Corrigan, M. and Cheatham, J.B., Jr., 1989: "Safely Exceeding the 'Critical Buckling Load' in Highly Deviated Holes," SPE 19229, Offshore Europe '89, Aberdeen, September 5-8. 